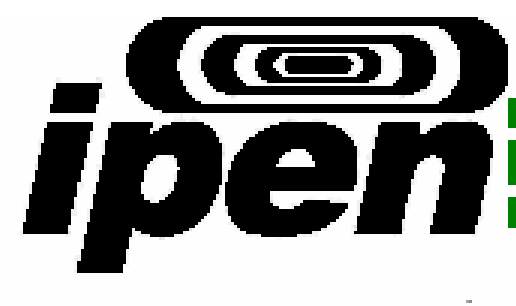

AUTARQUIA ASSOCIAD A A

UIIVERSIDADE DE SÄO PAULO

\title{
DESENVOLVIMENTO E IMPLANTAÇÃO DE UM PROGRAMA DE CONTROLE E AQUISIÇÃO DE DADOS NA CALIBRAÇÃO DE INSTRUMENTOS EM RADIODIAGNÓSTICO
}

\author{
FLÁVIO BETTI
}

Dissertação apresentada como parte dos requisitos para obtenção do Grau de Mestre em Ciências na Área de Tecnologia Nuclear - Aplicações.

Orientadora:

Dra. Maria da Penha Albuquerque Potiens 
INSTITUTO DE PESQUISAS ENERGÉTICAS E NUCLEARES

Autarquia associada à Universidade de São Paulo

\title{
DESENVOLVIMENTO E IMPLANTAÇÃO DE UM PROGRAMA DE CONTROLE E AQUISIÇÃO DE DADOS NA CALIBRAÇÃO DE INSTRUMENTOS EM RADIODIAGNÓSTICO
}

\author{
Flávio Betti
}

\begin{abstract}
Dissertação apresentada como parte dos requisitos para obtenção do Grau de Mestre em Ciências na Área de Tecnologia Nuclear - Aplicações.
\end{abstract}

Orientadora:

Dra. Maria da Penha Albuquerque Potiens 


\section{Dedicatória}

Neste momento imagino se a marcante sensação de apresentar este trabalho pode ser comparada à emoção de alguém que ganha um filho aos 47 anos... Em que pese meu sentimento de profunda gratidão a todos que me incentivaram a trilhar por este caminho, é impossível deixar de dedicar este trabalho exclusivamente a Maria, minha querida esposa, e mãe do meu casal de filhos já criados... 


\section{AGRADECIMENTOS}

À Dra. Maria da Penha A. Potiens, minha orientadora, pela iniciativa e espírito de inovação ao dar suporte ao desenvolvimento do sistema automatizado de medição baseado na câmara monitora, e particularmente pela confiança depositada ao delegar a mim tal missão.

À Dra. Letícia L. de Campos Rodrigues e à Dra. Linda V. E. Caldas, que me acolheram no âmbito do Centro de Metrologia das Radiações do IPEN, permitindo assim reduzir minha distância profissional em relação aos assuntos ligados ao universo da Física Médica.

Aos órgãos de fomento - FINEP, CNPq, FAPESP e AIEA - cujo suporte financeiro tem servido de alavanca ao aprimoramento tecnológico do LCI (Laboratório de Calibração de Instrumentos) do IPEN.

Ao Dr. Orlando Rodrigues Jr. e ao Dr. Alberto S. Todo, que ao longo do convívio diário sempre se mostraram dispostos a me amparar revelando os mistérios da produção acadêmica.

Aos colegas Vitor Vivolo, Gelson P. dos Santos e Claudinei T. Cescon, pela incessante disposição em auxiliar e trocar idéias a respeito dos mais variados aspectos deste trabalho.

A todos os demais colegas de Centro e alunos da Pós-Graduação que me ajudaram, cujos nomes evitarei tentar enumerar, em face do risco de imperdoavelmente deixar alguém de fora.

Um agradecimento especial à Dra. Felícia D. G. Rocha, sem cuja voluntariedade perante o Laboratório de Dosimetria TL não teria sido possível dispor do tempo necessário para elaborar este trabalho; e ao Eduardo Heredia, hoje aluno do Dr. Orlando, na realidade um grande professor com quem aprendi mais do que com muitos que passaram, inclusive pelo veloz desenvolvimento do programa em Java que permitiu a leitura remota do barômetro pela rede.

À minha esposa, bem como à minha irmã, ambas Marias, assim como minha orientadora, minha sincera gratidão por acreditarem em meu potencial, e principalmente por nunca terem deixado de me incentivar a seguir por este árduo, mas gratificante caminho. 


\title{
DESENVOLVIMENTO E IMPLANTAÇÃO DE UM PROGRAMA DE CONTROLE E AQUISIÇÃO DE DADOS NA CALIBRAÇÃO DE INSTRUMENTOS EM RADIODIAGNÓSTICO
}

\section{Flávio Betti}

\begin{abstract}
Resumo
Neste trabalho foram desenvolvidas as técnicas para projetar e implantar um sistema automatizado de controle e aquisição de dados para o arranjo de calibração em radiação $X$ níveis diagnóstico e radioproteção do Laboratório de Calibração de Instrumentos (LCI) do IPEN. Os programas desenvolvidos fornecem diretamente os valores de kerma corrigidos para as condições ambientais. A automatização do obturador viabilizou a temporização precisa de exposições de curta duração. A utilização da câmara monitora como padrão de calibração beneficiou-se de um programa para a determinação de seus fatores de calibração a partir de uma câmara de referência para as diferentes qualidades de feixe.

Foram utilizados como instrumentos de referência, dois eletrômetros, um para a câmara monitora, e outro para a câmara padrão; um termômetro de dois canais, e um barômetro absoluto, todos comunicando-se com 0 microcomputador através de interface padrão RS-232. São descritos os métodos computacionais utilizados nos programas de controle do kerma pela câmara monitora, bem como no de obtenção de seus fatores de calibração. A linguagem de programação adotada (LabVIEW ${ }^{M R}$ ) permitiu a obtenção de resultados rápidos e adequados. Os resultados obtidos demonstraram que o novo sistema proposto está apto a substituir as técnicas anteriormente adotadas no $\mathrm{LCl}$, com vantagens no que diz respeito à rapidez e precisão na execução das calibrações, notadamente sob situações adversas, como as observadas em exposições muito curtas, ou então longas o suficiente para que sejam substancialmente afetadas pela flutuação de parâmetros tais como a taxa de kerma do gerador de raios $X$, ou então pelas condições ambientais de temperatura e pressão.
\end{abstract}




\title{
DEVELOPMENT AND IMPLANTATION OF A CONTROL AND DATA ACQUISITION PROGRAM FOR THE CALIBRATION OF INSTRUMENTS FOR DIAGNOSTIC RADIOLOGY
}

\section{Flavio Betti}

\begin{abstract}
Design techniques of an automatic control system implementing corrected kerma determination and shutter command in the calibration laboratory at IPEN are shown, as well as the periodic calibration program developed for a monitor chamber for several X-ray beam qualities used for diagnostic radiology and radiation protection instruments. Two reference electrometers, a multichannel secondary standard thermometer, and an absolute pressure barometer were connected to the RS-232 interface from a PC computer equipped with a National Instruments multifunction analog and digital I/O card. LabVIEW ${ }^{\mathrm{MR}}$ was chosen as programming tool, which allowed for the development of a suite of programs for both controlling the shutter timing cycles and the calibration of the monitor chamber against a reference standard. A detailed description of the methods used for troubleshooting, fine tuning of parameters and evaluation of program results is followed by an analysis showing that considerable advantages regarding reduction of time and precision improvements during the calibrations could be achieved by the use of the developed programs, particularly under adverse conditions like those found during short expositions, or instead during long irradiation intervals where fluctuation of parameters like kerma rate or room conditions (temperature or pressure) can be found.
\end{abstract}




\section{SUMÁRIO}

1

1.1

INTRODUÇÃO.

1.1 .1

JUSTIFICATIVA.

1.1 .2

CRITÉRIOS DE ESCOLHA DE UMA FERRAMENTA DE AUTOMAÇÃO..

GRANDEZAS E UNIDADES.

RECURSOS COMPUTACIONAIS................................................ 37

4.2.2 CONTROLE PELA CARGa NA CÂMARA MONITORA .................................. 51

4.2.3 CONTROLE PELO KERMA NA CÂMARA MONITORA............................. 54

4.3 Programa de CALIBRAÇÃo dA CÂMARA Monitora.......................... 56

$4.4 \quad$ DISCUSSÕES DOS RESULTADOS................................................ 65

$4.5 \quad$ PERSPECTIVAS FUTURAS...................................................... 67 


\section{$1.1 \quad$ Justificativa}

Com o advento em 1998 da Portaria $453^{[1]}$ do Ministério da Saúde, foram estabelecidas diretrizes básicas de proteção radiológica em radiodiagnóstico médico e odontológico em todo o território nacional, tornando obrigatória a implantação de controle de qualidade em clínicas e laboratórios, que se vêem obrigados, a cada dois anos, a calibrar em laboratórios credenciados e rastreados à rede nacional de metrologia das radiações ionizantes, os instrumentos utilizados na dosimetria de feixes e em levantamentos radiométricos. No âmbito do ipen, o Laboratório de Calibração de Instrumentos (LCI) desenvolveu por meio de um trabalho de doutorado ${ }^{[2]}$ uma metodologia para a calibração de tais instrumentos, bem como um sistema de referência para a calibração de medidores de tensão de pico $(\mathrm{kVp})^{[3]}$, do qual se beneficiam hospitais, indústrias, clínicas e demais usuários. Mais recentemente, um método específico para calibração de câmaras de ionização utilizadas em tomografia computadorizada foi também implantado no $\mathrm{LCl}^{[4]}$.

Com o conseqüente e previsível aumento da demanda, o $\mathrm{LCl}$ viu crescer rapidamente até o atual limite de sua capacidade (aproximadamente 1800 instrumentos por ano), atingido já em 1999, o número de atendimentos mensais e certificados de calibração emitidos. Como se não bastasse, a carga de trabalho aumentou consideravelmente em função do inevitável, porém necessário aumento da burocracia característica de ambientes regulamentados por normas tais como a NBR ISO/IEC $17025^{[5]}$, obrigatória para a acreditação pelo INMETRO que se pretende em breve obter perante a Rede Brasileira de Calibração (RBC).

Ao longo dos últimos anos, tem-se verificado que muitos laboratórios, e em particular os de metrologia e ensaios, têm implantado sistemas automatizados com o intuito de agilizar e controlar as diversas etapas do processo. Programas especialmente desenvolvidos para a aquisição e análise de dados tem sido cada vez mais comuns na indústria ${ }^{[6,7,8]}$, no ensino ${ }^{[9,10]}$ e em laboratórios ${ }^{[11,12,13]}$, inclusive com capacidade de acesso remoto a instrumentos através da Internet ${ }^{[14]}$.Quando se parte para especificar um projeto de automação para um laboratório de calibração, podem-se descortinar soluções que vão desde as assim chamadas "caseiras" (desenvolvidas pelos próprios funcionários, e baseadas em 
ferramentas computacionais básicas e prontamente disponíveis), até abrangentes (mas dispendiosos) aplicativos comerciais desenvolvidos especificamente com essa finalidade ${ }^{[15]}$, e cuja implantação exige um cuidadoso planejamento para que os melhores resultados possam ser obtidos ${ }^{[16]}$.

A exemplo de muitos outros laboratórios, o $\mathrm{LCl}$ informatizou alguns de seus processos básicos, tais como o banco de dados de clientes e de equipamentos, ou as planilhas para o cálculo das grandezas de referência e das incertezas associadas, utilizando programas de uso geral, tais como o MS-Access ${ }^{M R}$, e o MS-Excel ${ }^{M R}{ }^{(*)}$. Apesar de sua evidente utilidade, algumas limitações inerentes, tais como dificuldades associadas à necessidade de constantes revisões e verificações, falta de um controle confiável de acesso e de integração com outros programas, e principalmente a ausência de facilidades para aquisição automática a partir de placas e dispositivos periféricos acessíveis por interfaces de comunicação, tornaram necessária a busca de soluções mais específicas.

Os requisitos normativos dos sistemas da qualidade ${ }^{[5]}$ estabelecem que sejam adequadamente estimadas as incertezas associadas aos ensaios de calibração, conforme proposto pelo guia ISO GUM ${ }^{[17]}$. Mesmo no contexto da proteção radiológica onde as faixas admissíveis de tolerâncias são bem mais amplas, preconiza-se hoje a busca pela melhor avaliação possível de dose, em contraponto à tendência anterior de dar preferência a superestimá-la em prol da segurança.

Nos casos em que é difícil expressar todas as componentes de incertezas a partir da observação do comportamento estatístico de múltiplas medições sucessivamente repetidas, podem-se agregar contribuições provenientes de modelos matemáticos com distribuição finita. A validação de modelos teóricos para o cálculo de incertezas pode ainda se apoiar em experimentos de simulação pelo método de Monte Carlo $\left[{ }^{18}\right]$.

Delineia-se assim um cenário em que se torna desejável facilitar a ampliação do número de medições consecutivas, reduzindo tanto quanto possível às incertezas de origens distintas do fenômeno básico associado à grandeza que se deseja medir (em nosso caso particular, kerma no ar), sem com isso exigir mão

\footnotetext{
${ }^{*}$ Marcas registradas da Microsoft Corp.
} 
de obra altamente especializada nem penalizar o tempo de execução dos ensaios. Ou seja, um sistema automatizado adequadamente projetado deverá ser capaz de executar um maior número de operações num menor intervalo de tempo, e ainda facilitar o trabalho do técnico operador, desde a preparação do ensaio, até sua execução e o registro dos resultados.

Em vista do exposto, reveste-se da maior importância o cuidado na escolha de uma ferramenta computacional adequada, que seja ao mesmo tempo poderosa, flexível, e que não exija uma grande especialização nas habilidades de programação, encurtando consequentemente o tempo tanto de aprendizado como de desenvolvimento, bem como facilitando a implantação de expansões futuras. A imposição de requisitos tão difíceis de conciliar é também advinda do anseio em não se deslocar o foco para a atividade-meio (programação) em detrimento da atividade-fim do LCl (calibração).

\subsubsection{Critérios de escolha de uma ferramenta de automação}

Um dos principais pontos a favor da aceitação de programas comerciais voltados para a gestão e automação de laboratórios é permitir a rápida incorporação de técnicas e conhecimentos que o fornecedor transfere ao cliente a partir de sua experiência com diferentes usuários que previamente testaram, validaram, e que eventualmente estarão acessíveis para troca de informações. $\mathrm{Na}$ prática, deve-se antes contemplar fatores como:

- $\quad$ Proporcionar boa relação custo-benefício ao longo das etapas de implantação (projeto, implementação, treinamento e validação), sob o pressuposto de causar baixo impacto à rotina do laboratório, e ser de fácil assimilação por parte de seus usuários;

- Facilitar a modernização e aprimoramento dos métodos existentes, particularmente os que já estejam em uso corrente pelo laboratório;

- $\quad$ Permitir introdução de novos recursos (capacidade de expansão futura);

- $\quad$ Oferecer viabilidade de integração com aplicativos pré-existentes, ou que venham a ser adotados no futuro; 
- Possibilitar a incorporação rápida e eficiente dos conhecimentos especializados do laboratório, preferencialmente com baixa ou nenhuma intervenção direta do fornecedor.

Tais requisitos tendem a apontar para soluções modulares de software; entretanto, cuidado deve ser tomado com soluções simplistas que tendem a se tornar insatisfatórias a médio e longo prazo, ainda que supram as necessidades iniciais, e que acarretem um menor impacto de implantação, posto que o impacto de sua substituição posterior tende a ser muito maior.

A eventual tentativa de uma análise objetiva da conveniência da adoção de uma determinada solução em detrimento de outra vê-se prejudicada pelas dificuldades inerentes à determinação dos retornos do investimento, sejam eles diretos ou indiretos ${ }^{[19]}$. É certo, porém, que a passagem de um longo tempo sem o advento de melhorias associadas à infra-estrutura necessária à introdução de inovações certamente irá ampliar os custos futuros de correção da defasagem tecnológica assim originada, com previsível prejuízo ao nível de treinamento do corpo técnico, e de excelência nas atividades de pesquisa (onde houver).

A adoção de soluções altamente customizadas também deve ser evitada, como por exemplo, o emprego de códigos escritos em linguagens de programação normalmente compreensíveis apenas para as próprias pessoas que os escreveram, e frequentemente associados a pouca ou nenhuma documentação, originando uma indesejável dependência entre o laboratório e essas pessoas.

Levando-se em conta os diversos requisitos, alguns dos quais conflitantes, para o estabelecimento de características desejáveis de uma ferramenta de programação que não requeira treinamento altamente especializado e ainda assim seja versátil o suficiente para garantir a rápida obtenção de resultados finais, destacou-se o LabVIEW $^{\mathrm{MR}}$ pela sua ampla conectividade com instrumentos de laboratório e outros periféricos ${ }^{[20]}$.

O LabVIEW ${ }^{M R}$ oferece uma série de características (interface gráfica com o operador, conectividade e capacidade de expansão) que o tornam particularmente adequado ao uso em processos industriais. Por outro lado, são freqüentes os relatos de aplicações em experimentos científicos onde o pesquisador não deseja desviar o foco do objeto de estudo para o 
desenvolvimento de um aplicativo, mas precisa apresentar como resultado final um programa que possa prontamente ser aplicado numa situação prática ${ }^{\text {[21] }}$.

Mesmo em situações em que o hardware especializado torna conveniente ou necessária a integração com rotinas escritas em outra linguagem de programação ( $\mathrm{C}_{++}$, por exemplo), o uso do LabVIEW ${ }^{\mathrm{MR}}$ acelera e simplifica o trabalho, graças a sua estrutura modular ${ }^{[22]}$. Tarefas que até recentemente exigiam o uso dedicado de DSPs ("Digital Signal Processors"), hoje podem ser executadas lançando mão de conversores analógico-digitais e computadores comercialmente disponíveis e de custo mais acessível.

Parte do poder do LabVIEW ${ }^{\mathrm{MR}}$ reside na integração imediata com os módulos de entrada e saída digital e analógica de fabricação da National Instruments (entre outros), que permitem conexão imediata com diferentes variáveis de processo, com pouco ou nenhum desenvolvimento de interfaces específicas. Pelo uso de bibliotecas dedicadas inclusas no pacote, pode-se rapidamente atender necessidades especiais, tais como a necessidade de implementação de um controlador do tipo PID (Proporcional - Integral Derivativo), ou a conexão e transferência de dados via Internet com o protocolo $\mathrm{TCP} / \mathrm{IP}^{[23]}$.

\subsubsection{Considerações sobre o atual cenário em radiodiagnóstico}

Embora as colocações da Portaria 453, e a necessidade de implantação de programas de controle de qualidade ${ }^{[24]}$ pareçam vir em primeiro plano quando se busca explicar o acentuado aumento na demanda dos serviços de calibração de instrumentos para radiodiagnóstico, uma breve busca na literatura técnica recente demonstra aspectos menos evidentes, porém não menos importantes.

A utilização de simuladores, e a análise das imagens obtidas em filmes radiográficos para diferentes condições de energia, dose e taxa de dose, além de alguns outros fatores periféricos, tais como o emprego de colimadores ou de grades anti-espalhamento, são técnicas que tem sido empregadas de longa data em radiodiagnóstico, sempre com o objetivo de garantir a maior sensibilidade sob a forma de maior contraste para os tecidos de densidade semelhante, e melhor resolução espacial, além da preocupação mais recente em tentar conciliar esses 
aspectos com os preceitos da radioproteção (princípio ALARA - As Low As Reasonably Achievable), principalmente numa época em que os exames radiográficos, tanto os convencionais como os especiais (tais como tomografia e fluoroscopia) são mais disponíveis e praticados do que nunca.

A determinação precisa da dose de entrada, e dose de saída na pele, é apenas um exemplo dos objetos de estudo daqueles que se preocupam com a otimização da dose, e dos resultados obtidos em exames utilizando raios $\mathrm{X}$. $\mathrm{O}$ advento de novas técnicas, tais como a mamografia digital, revela em determinados estudos, a possibilidade de se reduzir a dose de entrada na pele em até $264 \%$ em relação à mamografia convencional ${ }^{[25]}$. Tais medidas nessa faixa de energia requerem o emprego de câmaras de ionização meticulosamente calibradas.

O aumento da utilização de exames empregando raios $X$ em pacientes pediátricos foi objeto de um estudo ${ }^{[26]}$ em que três instituições regionais foram comparadas no que diz respeito aos diversos parâmetros de feixe (colimação, alinhamento, tensão e tempo de exposição), sendo que duas foram parcialmente reprovadas, demonstrando a necessidade de implantação de programas de garantia de qualidade visando à redução da dose no paciente sem perda (ou, se possível, com ganho) para a imagem diagnóstica, o que pressupõe a participação dos laboratórios de calibração nesse esforço.

Um outro caso em que a dose é freqüentemente motivo de preocupação por parte dos profissionais da área é a tomografia computadorizada ${ }^{[27]}$. As câmaras de ionização do tipo lápis especialmente talhadas para a medida de feixes estreitos requerem grande atenção em seu posicionamento, tanto no arranjo de calibração, como na utilização em campo; e sua baixa sensibilidade exige o emprego de eletrômetros bastante sensíveis, e que devem ser conjuntamente calibrados.

Outro aspecto menos usual foi abordado em outro trabalho ${ }^{[28]}$ em que se comprova ser possível dilatar a vida útil dos dispendiosos tubos geradores de raios $X$ utilizados em tomógrafos (cuja substituição pode chegar a custar 50 mil dólares) por intermédio da redução de sua temperatura de trabalho. Para tanto, deve-se reduzir a carga expressa em mAs. Ao cabo de um minucioso estudo envolvendo o uso de objetos simuladores e câmaras de ionização devidamente 
calibradas, foi possível reduzir o aquecimento em até $41 \%$, e a dose em até $54 \%$, sem comprometimento significativo da qualidade de imagem (apenas um leve aumento no ruído, sem impedir que o diagnóstico fosse feito), o que é bastante significativo, principalmente quando se consideram os escassos recursos para a substituição de tubos na rede pública em nosso país, e o emprego em pacientes pediátricos de um exame em que a dose máxima aceitável chega a 50 mGy no caso de crânio, ou 25 mGy para abdômen, de acordo com a Portaria 453.

\section{$1.2 \quad$ Objetivos}

O presente trabalho mostra o desenvolvimento e implantação de um sistema baseado em microcomputador com o intuito de automatizar alguns dos procedimentos utilizados na calibração de instrumentos em radiodiagnóstico no sistema de radiação $X$ do $\mathrm{LCl}$. Tal sistema permitirá a elevação dos padrões de qualidade das medidas através da integração online de vários equipamentos associados (obturador, câmara monitora, câmara de referência, termômetros e barômetro de precisão), com a conseqüente redução no tempo de execução dos testes, bem como a minimização de algumas das fontes de incertezas associadas aos métodos manuais anteriormente empregados. 


\section{FUNDAMENTOS}

\subsection{Grandezas e Unidades}

Testes e calibrações de instrumentos utilizados na deteção e medição de radiações ionizantes requerem a quantificação tanto do campo de radiação no ponto de medida (através de grandezas radiométricas), quanto da energia transferida ou depositada na matéria (através de grandezas de interação). Do ponto de vista prático ${ }^{[29]}$, interessa efetuar medições físicas que possam ser diretamente correlacionadas com os efeitos reais ou potenciais da radiação. Para tanto utilizam-se as grandezas dosimétricas, que correspondem a produtos de grandezas radiométricas e coeficientes de interação, quantificando assim a energia convertida (transferida para partículas carregadas secundárias) a partir da radiação primária incidente. Grande parte dos dispositivos desenvolvidos para dosimetria (mensuração de grandezas dosimétricas) depende da deteção direta ou indireta das cargas elétricas originadas num meio.

\subsubsection{Grandezas Radiológicas}

A primeira grandeza física associada a dosimetria da radiação $X$ foi a exposição $(X)$, definida a partir da relação entre a carga elétrica $d Q$ originada pela interação da onda eletromagnética ionizante com uma quantidade de ar de massa $\mathrm{d} m$ :

$$
X=\frac{\mathrm{d} Q}{\mathrm{~d} m}
$$

Sua unidade especial, o röentgen $(\mathrm{R})$, corresponde no SI (Sistema Internacional de Unidades) a 2,58 × 10 $0^{-4}$ coulombs $/$ kilograma $(\mathrm{C} / \mathrm{kg})$.

A taxa de exposição $(X)$ é definida a partir da relação da exposição estabelecida num certo intervalo de tempo:

$$
\dot{X}=\frac{\mathrm{d} X}{\mathrm{~d} t}
$$

Era usualmente expressa em röentgens/hora $(\mathrm{R} / \mathrm{h})$, ou seu submúltiplo, - miliröentgen/hora $(\mathrm{mR} / \mathrm{h})$, que corresponde no $\mathrm{SI}$ a cerca de $7,17 \times 10^{-11} \mathrm{C} . \mathrm{kg}^{-1} \cdot \mathrm{s}^{-1}$. 
Para radiações indiretamente ionizantes (fótons ou partículas não carregadas), define-se o kerma ${ }_{1} K$, como a relação entre a energia cinética $d E_{t r}$ de todas as partículas carregadas liberadas numa massa $\mathrm{d} m$ :

$$
K=\frac{\mathrm{d} E_{t r}}{\mathrm{~d} m}
$$

A unidade correspondente, o joule/kilograma $(\mathrm{J} / \mathrm{kg})$, recebe também o nome especial de gray (Gy).

Assim como para exposição, a taxa de kerma expressa a variação do kerma ao longo de um intervalo de tempo $\mathrm{d} t$ :

$$
\dot{K}=\frac{\mathrm{d} K}{\mathrm{~d} t}
$$

A unidade da taxa de kerma é o gray/segundo (Gy/s), que corresponde a J.kg-1. $\mathrm{s}^{-1}$.

A relação entre a energia média cedida $d \varepsilon$ numa massa $\mathrm{d} m$ constitui a dose absorvida $D$ :

$$
D=\frac{\mathrm{d} \bar{\varepsilon}}{\mathrm{d} m}
$$

Sua unidade também é o gray (Gy), ou seja, o coulomb/kilograma $(\mathrm{C} / \mathrm{kg})$.

A taxa de dose absorvida é a relação entre as variações de dose $(\mathrm{d} D)$ e de tempo $(d t)$ :

$$
\dot{D}=\frac{\mathrm{d} D}{\mathrm{~d} t}
$$

Sua unidade, o gray/segundo (Gy/s), corresponde a $1 \mathrm{~J}^{\mathrm{kg}} \mathrm{gg}^{-1} \cdot \mathrm{s}^{-1}$.

Quando ocorre um balanço entre as partículas carregadas entrando e saindo do volume onde são detetadas, diz-se que há equilíbrio eletrônico. Sob essa e mais algumas condições (em que as energias de ligação e de perdas por radiação podem ser desprezadas), o kerma e a dose absorvida são praticamente iguais.

O kerma no ar é a grandeza física diretamente medida mais utilizada em todos os laboratórios de calibração ${ }^{[30]}$. Ao contrário da dose absorvida, pode ser prontamente determinada, e diretamente aplicada. Pode ainda ser diretamente relacionada com a grandeza exposição, ainda utilizada em muitos instrumentos. 
Valores de exposição expressos em röentgens $(R)$ podem ser prontamente convertidos em grays (Gy).

$$
1 \mathrm{R}=0,876 \times 10^{-2} \mathrm{~Gy}
$$

Essa relação é válida para a grandeza kerma no ${ }^{[31]}$.

Para uso específico em radiodiagnóstico, são propostas mais algumas grandezas: kerma incidente, kerma na superfície de entrada, produto kerma-área, produto kerma-comprimento (em todos os caso, kerma no ar) e, no caso de tomografia computadorizada, os índices CTDI ("Computed Tomography Dose Index") e CTKI (“Computed Tomography Kerma Index") ${ }^{[30]}$. A saída ou rendimento do tubo de raios $X$ é definida como:

$$
Y(d)=\frac{K(d)}{P_{l t}}
$$

Onde $K(d)$ é o kerma no ar medido a uma distância $d$ do ponto focal do tubo (distância focal), e $P_{l t}$ o produto corrente $(I$ tempo de exposição $(t)$.

\subsubsection{Grandezas Elétricas}

É interessante observar que a única grandeza elétrica que aparece na lista das sete grandezas básicas do Sistema Internacional de Unidades é a corrente elétrica, expressa em ampères $(A)$. Todas as demais, inclusive as mais comumente encontradas, entre as quais:

- $\quad$ Diferença de potencial elétrico, em volts (V);

- $\quad$ Carga elétrica, em coulombs (C);

- Resistência elétrica, em ohms $(\Omega)$;

- $\quad$ Capacidade elétrica, em farads $(F)$;

- $\quad$ Indutância, em henries (Hy);

são consideradas grandezas derivadas ${ }^{[32]}$.

No âmbito dos laboratórios de metrologia das radiações, trabalha-se tipicamente com instrumentos (câmaras de ionização e eletrômetros, a serem abordados nas próximas seções) que envolvem o manuseio das seguintes grandezas elétricas:

i. Corrente elétrica ${ }_{1}$ expressa em ampères $(A)$ : dois condutores de comprimento infinito e diâmetro infinitesimal dispostos paralelamente no vácuo a uma distância de um metro estariam submetidos a uma força entre si de $2 \times 10^{-7} \mathrm{~N}$ 
por cada metro de comprimento ${ }^{[33]}$, caso por eles circulasse uma corrente contínua de $1 \mathrm{~A}$, o que corresponde à passagem de aproximadamente $6,2415 \times 10^{18}$ cargas elementares (elétrons) por segundo.

ii. Carga elétrica, em coulombs $(C)$ : a carga elétrica transportada durante um segundo por uma corrente de $1 \mathrm{~A}$ corresponde a um coulomb (1 C), ou seja, o coulomb equivale aproximadamente à carga de $6,2415 \times 10^{18}$ elétrons. Assim:

$$
1 C=1 \text { As }
$$

alternativamente

$$
1 A=1 C s^{-1}
$$

iii. Diferença de potencial elétrico, em volts $(\mathrm{V})$ : uma diferença de potencial (ou, mais simplesmente, tensão) de um volt (1 V) é definida quando a passagem de uma corrente de um ampère (1A) produz uma dissipação de um watt (1 W), o que equivale a dizer que, a cada coulomb de carga transferida, uma energia de um joule $(1 \mathrm{~J})$ é armazenada ou dissipada. Como $1 \mathrm{~W}=1 \mathrm{~J} / \mathrm{s}$, e $1 \mathrm{~A}=1 \mathrm{C} / \mathrm{s}$, então:

$$
1 \mathrm{~V}=\frac{1 \mathrm{~J} \cdot \mathrm{s}^{-1}}{1 \mathrm{C} \cdot \mathrm{S}^{-1}}=1 \frac{\mathrm{J}}{\mathrm{C}}
$$

iv. $\quad$ Capacidade elétrica, em farads $(F)$ : uma capacidade (ou capacitância) de um farad $(1 \mathrm{~F})$ submetida uma diferença de potencial de um volt $(1 \mathrm{~V})$ armazena uma carga de um coulomb (1C), ou seja:

$$
1 F=1 \frac{C}{V}
$$

v. Resistência elétrica, em ohms $(\Omega)$ : obtém-se diretamente a partir das grandezas tensão e corrente elétricas, de acordo com a lei de Ohm:

$$
\mathrm{R}(\Omega)=\frac{\mathrm{V}(\mathrm{V})}{\mathrm{I}(\mathrm{A})}
$$

vi. Impedância elétrica, um termo mais geral, também se expressa em ohms, e pode incorporar componentes adicionais ditos reativos, associados a parcelas indutivas ou capacitivas. Sua representação matemática, usualmente na forma de números complexos ou sua transformada de Laplace, aplica-se ao estudo do comportamento dinâmico (seja no domínio do tempo ou da freqüência) de sistemas elétricos. 


\subsection{Câmaras de lonização}

Instrumentos ou dispositivos desenvolvidos com o intuito de realizar medições de exposição ou dose em campos de radiação são genericamente denominados dosímetros. Apresentam-se sob muitas formas: câmaras de ionização, detectores Geiger-Müller, cintiladores, semicondutores, dosímetros termoluminescentes ou fotográficos, só para enumerar alguns. Possuem em comum no seu interior um volume sensível à radiação, delimitado por paredes de material distinto para proporcionar proteção física bem como condições adequadas de equilíbrio eletrônico, necessário para que se possa avaliar corretamente a dose. A teoria da cavidade ${ }^{[34]}$ estabelece condições que permitem determinar a dose liberada no meio circundante a partir de leitura da dose na cavidade dosimétrica, que pode conter um gás, um líquido ou um sólido.

Pela sua praticidade e precisão, câmaras de ionização estão entre os dosímetros mais utilizados ${ }^{[35]}$. Embora existam câmaras de ionização preenchidas com líquidos para aplicações especiais tais como radioterapia ${ }^{[36]}$, a grande maioria trabalha com o ar ou algum outro gás em seu interior. Como tais podem ser consideradas o tipo mais simples de detetor gasoso. Através da aplicação de uma diferença de potencial entre a parede condutora da câmara e um elemento metálico interno denominado eletrodo coletor, estabelece-se um campo elétrico que promove o deslocamento dos pares de íons (elétrons e partículas positivamente carregadas) originados pela interação da radiação ionizante com o meio. À medida que se eleva a tensão, a coleta da maior parte de íons ocorre antes que possam recombinar-se, e a corrente permanece essencialmente constante, tendendo a um valor limite chamado corrente de saturação.

Em campos de radiação $X$ de baixa a média energia, podem-se utilizar câmaras de ionização de ar livre cujo funcionamento baseia-se na própria definição de exposição (carga originada numa massa conhecida de ar), constituindo-se, assim, num dosímetro absoluto. São utilizadas como padrão primário em laboratórios de referência. Entretanto, para energias maiores do que cerca de $300 \mathrm{keV}$, as dimensões exigidas para equilíbrio eletrônico tornam-se proibitivas, devido ao alcance dos elétrons secundários gerados. Utilizam-se 
nesse caso as câmaras cavitárias ${ }^{[34]}$, amplamente utilizadas como padrão secundário em situações de rotina. Entre suas principais vantagens:

- $\quad$ Podem ser projetadas com os mais diferentes formatos e dimensões, permitindo adaptar-se a situações específicas, tais como feixes de radiação multidirecionais, ou incluindo partículas carregadas, ou mesmo nêutrons. Câmaras do tipo plano, ou de dimensões bem reduzidas, são particularmente adequadas à determinação da dose na superfície de simuladores, ou em vários pontos de um campo de radiação, durante um mapeamento.

- $\quad$ Como o alcance de elétrons secundários é muito menor em sólidos e líquidos do que em meio gasoso, o uso da câmara cavitária dentro de uma capa de equilíbrio eletrônico, ou no interior de um simulador de água ou polimetilmetacrilato (PMMA), permite estender sua aplicação a campos de fótons de alta energia como os provenientes de fontes de ${ }^{60} \mathrm{Co}$ ou aceleradores clínicos (feixes de megavoltagem).

As câmaras cavitárias podem ser do tipo aberto ou fechado. No primeiro caso, o ar em seu interior estará não só na mesma temperatura, como na mesma pressão do ambiente em que se encontra. Considerando-se que a quantidade de cargas geradas está diretamente relacionada à densidade do meio, adota-se como valores de referência para pressão e temperatura:

$$
\begin{aligned}
& T_{\text {ref }}=20^{\circ} \mathrm{C} \\
& P_{\text {ref }}=101,325 \mathrm{kPa}
\end{aligned}
$$

Para as condições ambientais no ponto de medida, que chamaremos de $T_{l a b}$ e de $p_{l a b}$, aplica-se o seguinte fator de correção:

$$
k_{t p}=\frac{T_{l a b}+273,15}{293,15} \times \frac{101,325}{p_{l a b}}
$$

Ou seja, a leitura corrigida ( $\left.L_{c o r}\right)$ para as condições de pressão e temperatura do laboratório obtém-se a partir da leitura $L_{l a b}$ :

$$
L_{c o r}=k_{t p} \cdot L_{l a b}
$$

onde $k_{t p}$ é dado por (14), sendo $T_{\text {lab }}$ expressa em graus Celsius ( $\left.{ }^{\circ} \mathrm{C}\right)$, e $p_{\text {lab }}$ em kilopascal (kPa).

Alguns cuidados devem ser tomados na escolha do tipo, e na forma de utilização da câmara de ionização em cada situação. Embora as câmaras cilíndricas e esféricas sejam de uso amplamente difundido em dosimetria geral e 
em proteção radiológica, as câmaras de placas paralelas são as mais utilizadas em radiodiagnóstico. Sua construção permite o uso de folhas bastante finas como material da janela de entrada, minimizando a atenuação dos raios $X$ de baixa energia.

Ao tipo muito especial de câmara plana, construída para ser virtualmente transparente aos raios $X$, denomina-se câmara transmissão, ou câmara monitora. Pode ser permanentemente interposta entre a posição de irradiação e o gerador do feixe, permitindo a monitoração contínua de sua intensidade. Tal característica revela-se particularmente útil quando se deseja aplicar algum tipo de compensação causado por eventuais flutuações, tendo sido amplamente explorada neste trabalho.

\subsection{Eletrômetros}

Como em situações usuais a quantidade de carga elétrica originada em câmaras de ionização é extremamente reduzida, com correntes na faixa de $10^{-6} \mathrm{~A}$ a $10^{-12} \mathrm{~A}$, exigindo assim resoluções melhores do que $10^{-14} \mathrm{~A}$, torna-se necessário acoplá-las a instrumentos de alta sensibilidade e precisão, genericamente denominados como eletrômetros. Um eletrômetro pode ser definido como um multímetro especializado, capaz de medir baixíssimas correntes, bem como resistências elevadíssimas; ao medir tensões, além de ser capaz de causar uma ínfima perturbação ao circuito, graças a sua elevadíssima impedância de entrada (tipicamente da ordem de $10^{15} \Omega$ ) ${ }^{[37]}$.

Uma funcionalidade adicional dos eletrômetros não normalmente encontrada em multímetros convencionais reside em sua habilidade para medir cargas elétricas muito tênues, não raramente com resolução de alguns femtocoulombs $\left(10^{-15} \mathrm{fC}\right)^{[37]}$. Conceitualmente, tal coulombímetro poderia ser implementado conectando-se um voltímetro de alta impedância a um capacitor de valor precisamente conhecido. Na prática, câmaras de ionização precisam ser polarizadas com uma tensão suficiente elevada para que trabalhem num valor próximo da corrente de saturação. O sinal, ou seja, a polaridade desta tensão irá definir o sentido da corrente que irá se estabelecer através do circuito fechado constituído pela fonte de tensão constante, e pela câmara sob irradiação. 
Normalmente, para que uma corrente tão baixa pudesse ser detetada, seria necessário intercalar uma resistência de valor suficientemente elevado para que fosse possível medir a tensão entre seus terminais com a resolução desejada. Na prática, adotam-se amplificadores de alto ganho de modo a garantir que o potencial do eletrodo conectado à entrada permaneça constante.

Circuitos baseados no princípio da retroalimentação (feedback) são de longa data utilizados na implementação de circuitos eletrométricos ${ }^{[38]}$. No caso de um coulombímetro, o capacitor integrador desloca-se para o elo de realimentação entre a saída e a entrada inversora do amplificador. Na medida em que uma carga positiva é injetada na entrada, surge uma tensão negativa na saída do amplificador, proporcional ao valor dessa carga, e inversamente proporcional ao valor do capacitor, que deve, portanto, ser o menor possível, para máxima sensibilidade. Provendo-se os meios para zerar a tensão no capacitor no instante inicial da medida, tem-se um verdadeiro eletrômetro, capaz de fornecer uma leitura proporcional à carga, que, por sua vez, pode ser diretamente correlacionada ao kerma e à dose. O fundo de escala está diretamente ligado ao máximo valor de tensão com o qual o amplificador é capaz de trabalhar dentro de sua faixa linear, e ao valor do capacitor integrador propriamente dito.

Nota-se que, mesmo com a melhoria nas técnicas de fabricação dos componentes específicos para esse tipo de aplicação (JFETs e MOSFETs), não se pode garantir a total ausência de correntes no nó de entrada do amplificador ${ }^{[39]}$ Para contornar esse inconveniente, e ainda oferecer uma possível compensação para minúsculas correntes externas de fuga que podem aparecer, os fabricantes de eletrômetros disponibilizam um sistema de compensação que deve ser sempre acionado antes de se iniciar a medição propriamente dita. Do contrário, a corrente residual irá subtrair, ou somar-se à corrente proveniente da câmara ${ }^{[37]}$.

A eventual necessidade de se trabalhar com tempos de integração maiores, ou com taxas de dose mais elevadas, leva a princípio ao uso de capacitores integradores de maior valor, o que traz alguns inconvenientes: perda de resolução no início da faixa, influência de correntes de fuga, e até mesmo aumento nos erros de integração causados pela injeção direta de cargas no dielétrico do capacitor a partir de eventos de interação com raios cósmicos ${ }^{[39]}$. 
Felizmente, os fabricantes oferecem uma solução simples e engenhosa para contornar o problema de sobre-escala em seus eletrômetros. Utilizando-se a opção de operar o equipamento como picoamperímetro, e efetuando digitalmente a integração ao longo do tempo, é possível reproduzir com grande fidelidade o comportamento do eletrômetro com integrador capacitivo. A correta compensação de eventuais correntes de fuga permanece essencial para que os melhores resultados possam ser obtidos ${ }^{[40]}$.

\subsection{Testes e Rastreabilidade em Metrologia}

No contexto da Metrologia das Radiações, define-se teste como um procedimento que envolve a determinação do valor indicado por um instrumento (ou suas variações) quando submetido a condições controladas, visando obter dados quantitativos a respeito de suas condições de funcionamento ${ }^{[41]}$. A calibração tem um sentido mais específico, pois requer a determinação da relação entre os valores indicados pelo equipamento e por um sistema constituído por padrões sob condições de referência ${ }^{[42]}$. Ou seja, a calibração, além de certificar que o sistema funciona adequadamente, fornece dados essenciais para a obtenção de leituras com o menor erro possível dentro de suas limitações e condições de uso. A exatidão expressa qualitativamente a capacidade do instrumento em fornecer leituras próximas do valor verdadeiro convencional ${ }^{[42]}$, e deve ser compatível com sua precisão, um conceito quantitativo ligado à resolução do equipamento (sua capacidade em discernir leituras de valor próximo entre si).

Tanto em testes como durante calibrações, é desejável a repetição das medições para ampliar o grau de conhecimento sobre algumas das incertezas associadas. Define-se repetitividade como a aptidão de um instrumento ou sistema de medição em fornecer resultados concordantes durante medições sucessivas sob as mesmas condições. Já a reprodutibilidade expressa a concordância entre os resultados da medição de um mesmo mensurando sob condições distintas de medição ${ }^{[42]}$.

Por definição, a execução de uma calibração requer a utilização de um ou mais padrões de referência. Um padrão pode ser um instrumento, sistema ou material de medição visando reproduzir o valor de uma grandeza que possa servir 
como referência. $O$ estabelecimento de padrões leva naturalmente à constituição de uma cadeia metrológica dentro da qual existirão diversas hierarquias de padrões: primários, secundários, terciários, nacionais, e de trabalho, conforme o contexto e a viabilidade de sua utilização. Ao longo dessa cadeia, define-se rastreabilidade como a propriedade de relação entre o resultado de uma medição e uma série de outras referências de classificação metrológica mais elevada dentro da hierarquia, através de uma cadeia contínua de comparações, cada qual com seu valor de incerteza devidamente estabelecido. No topo dessa cadeia estão os padrões primários, cujo valor é aceito sem referência a outros padrões da mesma grandeza, e servem para calibrar os padrões secundários, que, por sua vez, servirão para propagar a grandeza a um número crescente de laboratórios dentro da rede metrológica, cuidando-se para nunca quebrar a rastreabilidade.

Embora não conste do Vocabulário Internacional de Metrologia, um termo consagrado na metrologia das radiações ionizantes é a intercomparação, que visa proporcionar aos participantes uma verificação independente de seus controles de qualidade na calibração de instrumentos (monitores e dosímetros) ${ }^{[41]}$. Principalmente em países emergentes, surge a necessidade de se apresentar resultados de estudos na impossibilidade de acesso a padrões de classe metrológica mais elevada ${ }^{[43,44]}$. Nesse caso, recorre-se à comparação de instrumentos de mesma classificação, num cenário que de outra forma se assemelharia a uma calibração. Sua utilidade não deve ser menosprezada, pois pode potencialmente fornecer informações valiosas sobre o desempenho de equipamentos em diferentes situações. A realização de intercomparações contempla uma das recomendações da norma NBR ISO/IEC $17025^{[5]}$ referente ao estímulo à participação em comparações interlaboratoriais como ferramenta de garantia da qualidade de ensaios e calibrações.

\subsection{Calibração e controle de qualidade em radiação $X$}

A expansão do uso da radiação levou à necessidade de aperfeiçoamento dos métodos dosimétricos, notadamente no âmbito da radioterapia ${ }^{[45]}$, onde as tolerâncias aceitáveis são consideravelmente menores do que em radioproteção ${ }^{[46]}$. Os protocolos aplicáveis a radiodiagnóstico ${ }^{[30]}$ levam 
em conta o fato de uma fração considerável, cerca de $60 \%$, da radiação recebida pela população ser advinda de exames diagnósticos. Para fins de radioproteção, a dose associada a procedimentos médicos não é considerada como parte dos limites admissíveis, o que dificulta o trabalho de estabelecimento de valores que poderiam ser considerados toleráveis (níveis de referência).

Ainda do ponto de vista da radioproteção, as pessoas potencialmente afetadas por radiações médicas podem ser divididas em três grupos: indivíduos ocupacionalmente expostos (médicos, técnicos e enfermeiros); pacientes propriamente ditos; e pessoas do público em geral. Aceita-se a dose recebida por acompanhantes voluntários como pertencentes ao primeiro grupo ${ }^{[46]}$.

Tendo sido estabelecidas em nosso país diretrizes visando controlar o uso das radiações em radiodiagnóstico ${ }^{[1]}$, cabe aos laboratórios incumbidos da calibração dos instrumentos aplicáveis responder à altura através do aprimoramento de métodos, quantificação e redução das incertezas associadas.

Para instrumentos medidores de radiações $X$ e gama, são internacionalmente aceitos quatro métodos ${ }^{[41]}$ :

- $\quad$ Utilização do instrumento padrão (referência), sem câmara monitora;

- $\quad$ Utilização do instrumento padrão (referência), com câmara monitora;

- $\quad$ Irradiação simultânea dos instrumentos (padrão e sob calibração);

- Irradiação num campo de radiação conhecido.

Aos dois primeiros, costuma-se denominar "método da substituição".

O método por campo conhecido é particularmente aplicável a fontes de grande estabilidade, ou cuja atividade instantânea possa ser prontamente determinada pelo uso de sua constante de decaimento radioativo, como no caso dos irradiadores de ${ }^{137} \mathrm{Cs}$ ou ${ }^{60} \mathrm{Co}$.

A calibração de um instrumento consiste basicamente na determinação de um coeficiente $N_{c a l}$ que, multiplicado pela leitura $M_{c a l}$ do instrumento sendo calibrado, resultará no valor verdadeiro convencional (VVC) da grandeza para a qual a calibração está sendo feita, ou seja:

$$
N_{c a l}=\frac{V V C}{M_{c a l}}
$$

Tanto para o método de campos conhecidos, como para o método da substituição sem câmara monitora, a determinação do valor de $V V C$ requer o uso 
de um instrumento padrão (câmara de referência), cujo coeficiente de calibração $N_{\text {ref }}$ deve ter sido previamente determinado através de sua calibração contra um padrão de classificação metrológica mais elevada, mantendo-se assim os requisitos da cadeia metrológica.

O valor verdadeiro convencional, VVC, para uma medição efetuada com a câmara de referência é dado por:

$$
V V C=N_{\text {ref }} \cdot M_{\text {ref }}
$$

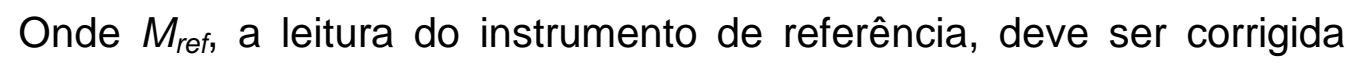
para as condições ambientais de referência, aplicando-se o fator de correção (v. equação 13) segundo a equação 14.

Eventualmente, a unidade (ou mesmo a grandeza) para a qual o sistema de referência foi calibrado não é a mesma encontrada no instrumento sob calibração. Nesse caso, aplica-se um fator adicional $h$ que converte a grandeza padrão para aquela com que o instrumento do cliente trabalha. Feito isso, o fator de calibração $N_{c a l}$ passa a ser dado por:

$$
N_{c a l}=h \times \frac{N_{r e f} \cdot M_{r e f}}{M_{c a l}}
$$

onde a leitura $M_{c a l}$ do instrumento sob calibração também deve ser previamente corrigida para as condições de referência (v. equação 14).

Nas situações práticas em que o irradiador é um gerador de raios $X$, são comuns e previsíveis pequenas variações nas características do campo, decorrentes principalmente de variações na taxa de kerma causadas por flutuações na tensão de alimentação, ou na eficiência do gerador, associadas ao aquecimento ou envelhecimento do tubo. Adicionalmente, conforme será exposto na próxima seção, a caracterização de um feixe para calibração requer o uso de filtros que modificam seu espectro de energia, bem como sua intensidade.

Considerando-se os fatos acima, torna-se sumamente interessante utilizar uma câmara monitora, que consiste numa câmara de ionização de transmissão, ou seja, sua construção permite que ela seja atravessada pelo feixe primário com pouca atenuação. Uma câmara desse tipo posicionada num arranjo fixo permite a monitoração simultânea e contínua da intensidade do feixe durante o ensaio ou calibração. Além disso, no caso de diferentes qualidades de feixe, bons resultados podem ser obtidos a partir de intercomparações ${ }^{[47]}$. 
A técnica de calibração pelo método da substituição com câmara monitora depende da determinação prévia do fator de calibração que chamaremos de $N_{\text {mon: }}$ :

$$
N_{\text {mon }}=\frac{N_{\text {ref }} \cdot M_{\text {ref }}}{m_{\text {ref }}}
$$

onde $m_{\text {ref }}$ é a leitura da câmara monitora na situação de irradiação em que câmara de referência apresenta leitura $M_{\text {ref }}$ na posição de irradiação, sempre lembrando que ambas devem ser corrigidas para as condições de referência de pressão e temperatura.

A partir da leitura $M_{c a l}$ do instrumento sob calibração, seu coeficiente de calibração pode ser obtido por:

$$
N_{c a l}=h \times \frac{N_{\text {mon }} \cdot m_{c a l}}{M_{c a l}}
$$

onde $m_{c a l}$ é a leitura da câmara monitora durante a irradiação do instrumento sendo calibrado, e $h$ o coeficiente de conversão de grandeza previamente explicado.

Além das vantagens já apresentadas, pode-se acrescentar que apenas através do uso de uma câmara monitora torna-se possível uma monitoração "online" no decorrer de todos os ensaios, constituindo-se assim numa poderosa ferramenta de controle de qualidade, bem como de redução de incertezas quando outros parâmetros (temperatura, pressão, taxa de kerma) puderem ser apenas observados, mas não controlados.

\subsubsection{Recomendações para qualidades de feixes}

Os protocolos recentes para 0 controle da qualidade em radiodiagnóstico ressaltam que a completa especificação de um feixe de radiação $X$ só é possível através da determinação de sua distribuição espectral ${ }^{[30]}$. Entretanto, esses mesmos protocolos admitem que a espectrometria da radiação $X$ é uma técnica dispendiosa e difícil de ser implantada.

Há uma série de parâmetros específicos que podem ser utilizados na caracterização de feixes de raios $X^{[48] \text {. }}$

- $\quad$ O valor da alta tensão (kilovoltagem do tubo);

- $\quad$ A espessura da primeira camada semi-redutora; 
- $\quad$ A espessura da segunda camada semi-redutora;

- A razão entre essas duas camadas, conhecida como coeficiente de homogeneidade;

- A energia média, também chamada de energia média efetiva do feixe, expressa em kiloeletronvolts (keV);

- $\quad$ A resolução espectral, expressa em porcentagem.

Através do uso de filtros, é possível modificar o espectro do feixe, no sentido de remover as componentes de menor energia, e, com isso, aumentar seu poder de penetração ("endurecer" o feixe) ${ }^{[34]}$. O resultado pode ser avaliado através da determinação das duas primeiras camadas semi-redutoras ${ }^{[49]}$. Embora pareça insuficiente para uma perfeita caracterização de um feixe, essa técnica é considerada aceitável do ponto de vista do efeito biológico ${ }^{[50]}$.

Normas internacionais estabelecendo conjuntos de qualidades de feixes para diferentes aplicações especificam ainda um segundo parâmetro: a kilovoltagem máxima, uma grandeza que pode ser determinada tanto por métodos invasivos como não-invasivos, entre os quais a própria espectrometria. A energia máxima do feixe está numericamente limitada ao valor da kilovoltagem de pico, o que permite a aplicação do valor do endpoint como um método não invasivo de determinação da energia máxima do feixe ${ }^{[51]}$. Embora esse mesmo conjunto de normas delineie os espectros que devem ser obtidos para cada qualidade recomendada, admite-se que, respeitando-se os valores da kilovoltagem de pico e das camadas semi-redutoras para cada qualidade, estará assegurada a reprodutibilidade das condições para os diversos tipos de dosímetros que vierem a ser irradiados em tais campos ${ }^{[48]}$.

De acordo com a definição internacionalmente aceita ${ }^{[41]}$, cada camada semi-redutora representa a espessura de um determinado material que atenua o feixe incidente de modo a reduzir à metade o valor de sua taxa de kerma, estando exclusos os fótons espalhados. É evidente que sua determinação requer o uso de dosímetros com baixa dependência energética, pois do contrário haverá um erro decorrente da modificação do espectro.

Além disso, devem-se utilizar na composição dos filtros, materiais de alta pureza, principalmente em baixas energias, onde predomina o efeito fotoelétrico, altamente dependente do número atômico efetivo do material. 
Aguarda-se a aprovação da versão final de um protocolo (Code of Practice) da agência internacional (IAEA) específico para dosimetria em radiologia diagnóstica. Constitui-se num conjunto de recomendações bastante detalhado, abrangendo tanto medições em clínicas como em laboratórios de dosimetria com padrões secundários (SSDLs). De acordo com sua versão preliminar, a implantação de qualidades de feixes padrões deve estabelecer um compromisso entre os requisitos conflitantes de eliminar as ambigüidades, e evitar esforços excessivos em sua obtenção ${ }^{[30]}$. Suas recomendações incluem:

- $\quad$ Adotar as qualidades estabelecidas pela norma IEC $61267(2005)^{[52]}$;

- $\quad$ Determinar a filtração inerente de acordo com a norma ISO 4037-1 $(2006)^{[48]}$

- Seguir as recomendações do relatório ICRU 10b (1964) ${ }^{[53]}$ para determinar a primeira e a segunda camada semi-redutoras;

- Utilizar geometria de feixes estreitos ao determinar camadas semi-redutoras;

- Posicionar os filtros de alumínio numa posição eqüidistante entre as câmaras monitora e de referência, e que seja de, no mínimo, cinco vezes o diâmetro do feixe na posição da câmara de referência, para evitar espalhamento.

\section{Recomendações para a câmara monitora:}

- $\quad$ Deve ser posicionada à frente, mas próxima à abertura do colimador;

- $\quad$ Deve ser ampla e homogênea na região de passagem do feixe;

- $\quad$ Deve ser fina o suficiente para não ocasionar filtração adicional;

- $\quad$ Deve ter alta eficiência de coleta de íons, superior a 99\%;

- Sua corrente de fuga deve ser inferior a $2 \%$ da indicação máxima na escala mais sensível;

- $\quad$ Seus parâmetros de desempenho (e do eletrômetro associado) devem assemelhar-se aos do sistema de referência que the serve de padrão.

Acrescenta ainda: câmaras monitoras cuja estabilidade a longo termo seja melhor do que $0,3 \%(\mathrm{k}=1)$ podem ser utilizadas como instrumentos de referência, desde que devidamente calibradas. 


\subsubsection{Correções para o tempo de abertura do obturador}

Os geradores industriais de raios $X$ são frequentemente utilizados nos laboratórios de calibração em virtude de sua robustez e confiabilidade, sendo dimensionados para suportar regimes de potência elevada indefinidamente, em contraste com os equipamentos para radiodiagnóstico cujo funcionamento é necessariamente limitado a pulsos de duração pré-definida.

No projeto dos geradores de potencial constante recorre-se a circuitos controladores de tensão e corrente que privilegiam a precisão e estabilidade em detrimento do tempo de resposta, o que torna desaconselhável qualquer tentativa de se garantir o tempo de exposição diretamente através do painel de controle do gerador, particularmente para intervalos curtos onde 0 transitório de estabelecimento do feixe introduziria um erro considerável.

Quando se irradiam câmaras de ionização associadas a eletrômetros em que o tempo de integração pode ser precisamente estabelecido, é até aconselhável a aplicação do feixe antes da leitura, para maior estabilidade. Entretanto, há situações em que o tempo de exposição (ou o kerma resultante dessa exposição) precisa ser precisamente controlado, como por exemplo, quando se irradiam dosímetros termoluminescentes. A utilização de um obturador é praticamente obrigatória nesses casos.

A norma ISO 4037-2:1997 ${ }^{[54]}$ estabelece que um obturador deve ser espesso o suficiente para reduzir a taxa de kerma transmitido a 0,1\% para a maior energia de referência a ser utilizada, e que o seu tempo total de trânsito (atrasos inerentes aos mecanismos de abertura e fechamento) constitui uma fonte de incertezas que não pode ser ignorada, propondo inclusive uma correção através da fórmula:

$$
\Delta t=t_{1} \cdot \frac{K_{1}-K_{n}}{n \cdot K_{1}-K_{n}}
$$

onde: $\Delta t=$ tempo perdido a cada ciclo de abertura / fechamento

$t_{1}=$ tempo total de irradiação única

$K_{1}=$ leitura após irradiação única de duração nominal $t_{1}$

$n=$ número de irradiações fracionadas

$K_{n}=$ somatória de $n$ leituras de duração nominal $t / n$

Esse resultado pressupõe que toda operação de abertura e fechamento posterior do obturador cuja duração nominal seja $t$ será afetada por 
um erro sistemático igual a correspondente a $\Delta t$, de modo que o tempo efetivo de irradiação será igual a $(t-\Delta t)$. Caso a leitura $K_{1}$ corresponda a uma integração de duração precisamente igual a $t_{1}$ (como no caso em que o obturador é mantido aberto, e o eletrômetro efetua o controle de tempo), deve-se então utilizar esta equação:

$$
\Delta t=\frac{t_{1}}{n} \cdot\left(1-\frac{K_{n}}{K_{1}}\right)
$$

A fórmula acima também é aplicável nos casos em que $n$ é elevado, de modo que $\Delta t$ torna-se desprezível em relação a $t_{1}$ (mas não em relação a $t_{1} / n$ ).

A eficácia desse tipo de correção depende do comportamento repetitivo do obturador. $\mathrm{Na}$ prática, a rigor, quando se trabalha com feixes pulsados, há que se levar em conta atrasos de outras origens. Câmaras de ionização (particularmente as de maior volume) e os próprios eletrômetros apresentam um tempo de resposta, que pode ser definido como "o intervalo de tempo entre o instante em que um estímulo é submetido a uma variação abrupta especificada, e o instante em que a resposta alcança - e permanece dentro de limites especificados - seu valor final de regime" ${ }^{[42,54]}$. No caso em estudo, a variação abrupta é causada pela operação do obturador em dois momentos: abertura e fechamento. Seria uma suposição otimista admitir que atrasos similares ocorreriam em ambos os instantes, de modo a se cancelar, o que sugere um estudo mais minucioso nos casos em que a soma dos tempos de resposta do sistema composto por câmara de ionização / eletrômetro / obturador não for desprezível em relação ao tempo de exposição dentro da precisão desejada.

\subsection{Fonte de erros e incertezas na realização de ensaios e calibrações}

Como em qualquer outro ramo de atividade que envolva medições, a dosimetria das radiações é afetada por erros e incertezas. Embora não seja geralmente possível determinar precisamente o erro de uma medida, é possível e desejável - a quantificação da incerteza (dúvida envolvendo o resultado de uma medição), bem como da probabilidade de abrangência associada. A estimativa do erro envolve o estudo do valor médio de uma série de medições, enquanto a incerteza depende da dispersão, ou seja, do desvio padrão de um conjunto de 
valores que podem razoavelmente ser atribuídos ao mensurando ${ }^{[5]}$. Ao contrário do erro, a incerteza não possui um sinal (positivo ou negativo), é normalmente considerada simétrica, e seu estudo pressupõe que todas as fontes de erros ditos sistemáticos tenham sido previamente eliminadas através da aplicação de fatores de correção ${ }^{[41]}$.

Ao se avaliar incertezas, recomenda-se a divisão em dois tipos a partir de sua origem: tipo $A$, e tipo $B$, cada qual com seu método de avaliação. Para fins de memorização, é costume associá-las à contribuição de fatores aleatórios, e sistemáticos, respectivamente. Entretanto, essa não é uma definição rigorosa, muito menos oficial. A incerteza padrão do tipo $A$ pode ser estimada usando métodos estatísticos para avaliar a dispersão dos resultados de múltiplas medições de um mesmo mensurando, constituindo-se no desvio padrão da média. Já o conhecimento da incerteza do tipo B geralmente envolve a determinação de valores-limite dentro dos quais os resultados de uma medição se encontram, e a adoção de um modelo de distribuição para a probabilidade de ocorrência dentro desse intervalo, que pode ser uma gaussiana, mas também uma distribuição retangular ou triangular ${ }^{[56]}$. As duas podem ser combinadas conforme:

$$
u_{c}=\sqrt{u_{A}^{2}+u_{B}^{2}}
$$

Caso ambas as contribuições sejam gaussianas (distribuição normal), o intervalo de confiança da incerteza combinada também será cerca de $68 \%$. Através da aplicação do fator de abrangência $(k)$, obtém-se a partir da incerteza combinada $\left(u_{c}\right)$, o valor da incerteza expandida $\left(U_{p}\right)$ :

$$
U_{P}=k \cdot u_{c}
$$

Adotando-se o valor de $k=2$ (ou $k=3$ ) para o fator de abrangência, e admitindo-se distribuição normal, obtém-se um intervalo de confiança de 95\% (ou $99 \%)$.

Recomenda-se a tabulação em separado das diferentes contribuições para a incerteza final, inclusive classificando-as conforme o tipo (A ou $B)^{[41]}$. $O$ cálculo do termo referente à incerteza do tipo $A$ envolve necessariamente a realização de múltiplas medições do mesmo mensurando. Já a estimativa das parcelas do tipo $B$ requer a análise dos diferentes fatores de influência $e$ contribuição, que, no caso dos ensaios de calibração em raios $\mathrm{X}$ no $\mathrm{LCl}$, incluem: 
- Incerteza que consta do certificado de calibração do instrumento utilizado como referência (padrão);

- Incertezas associadas às medições de temperatura e pressão, utilizadas no cálculo dos fatores de correção ambiental;

- Incertezas no posicionamento da câmara de referência (quando da obtenção do fator de calibração da câmara monitora), e do instrumento sob calibração;

- Incertezas causadas por variações na corrente de fuga (leakage current) das câmaras de ionização;

- Incertezas causadas por diferenças entre o tempo de exposição desejado e obtido, quando da operação manual do obturador;

- Incertezas causadas por variações na taxa de kerma do feixe durante a irradiação;

- Incertezas causadas por diferenças de temperatura entre a câmara monitora e a câmara no ponto de irradiação, ou por flutuações de temperatura e pressão ao longo de ensaios envolvendo tempos de exposição mais prolongados.

Assim como em outros ensaios metrológicos, as fontes de incertezas distribuem-se em fatores associados ao padrão utilizado, ao sistema de medição, ao procedimento, ao ambiente, ao operador e ao instrumento propriamente dito. Cabe ao laboratório de calibração minimizar a contribuição em todos os aspectos que estiverem a seu alcance. A incorporação de novos equipamentos ao LCl (câmaras monitoras, termômetros e barômetro de precisão, cartão multi-funções) possibilitou vislumbrar sua integração num sistema automatizado que permitiu, com o advento do presente trabalho, considerável redução da incerteza associada a três dos fatores enumerados acima: comando do obturador, flutuação no feixe, e variações de temperatura e pressão.

\subsection{Comentários gerais sobre automação}

O termo automação derivou diretamente de automation (em inglês), proposto em 1946 pelo engenheiro Dale S. Harder, então vice-presidente da Ford Motor Company, numa referência aos equipamentos então utilizados em sua linha de montagem, capazes de realizar tarefas mecânicas com rapidez e precisão, sem a intervenção direta de seres humanos altamente treinados ${ }^{[57]}$. 
Nossa língua aceita automação na designação de "sistemas automáticos de controle cujos mecanismos verificam seu próprio funcionamento, efetuando medições e introduzindo correções, sem a interferência do homem" "[58]. Uma forma ligeiramente modificada é encontrada na língua espanhola (automatización); ambas são aceitas na língua francesa (automatization, e automation) ${ }^{[57]}$.

Embora já fossem popularmente encarados como "robôs", os aparelhos mecanizados tais como os utilizados desde os primórdios da Revolução Industrial careciam de uma flexibilidade e capacidade de adaptação que somente a tecnologia do pós Segunda Guerra viabilizaria.

Desde seus primórdios, a engenharia de controle dedicou-se à elaboração de modelos para o estudo de sistemas dinâmicos como ferramenta na obtenção de controladores que viabilizassem o funcionamento de sistemas naturalmente instáveis, ou que elevassem a rapidez e precisão de funcionamento de sistemas pré-existentes a patamares que seriam difíceis ou impossíveis de se atingir pela intervenção humana (operação manual).

Hoje considerada uma disciplina associada aos estudos da engenharia elétrica e da ciência da computação, a engenharia de controle já era praticada antes mesmo do advento em larga escala dos sistemas elétricos e eletromecânicos. Na indústria química, por exemplo, o controle de processos era tipicamente implantado por engenheiros mecânicos utilizando sensores e atuadores hidráulicos e pneumáticos.

Embora existam sistemas automáticos que trabalham em malha aberta (ou seja, sem colher informações que influenciem seus parâmetros durante a operação), uma das técnicas mais clássicas de controle envolve a aplicação de elos, ou malhas de realimentação (feedback loops) com o objetivo de atribuir capacidade de auto-correção ao sistema, permitindo que se comporte de maneira tão próxima quanto possível do desejado ${ }^{[59]}$. Um sistema operando desse modo é dito em malha fechada.

A partir da Segunda Guerra, a corrida armamentista levou à busca de novas técnicas de fabricação e operação de aeronaves e mísseis. Computadores digitais ainda eram incipientes, de modo que computadores analógicos dos mais diferentes tipos foram utilizados no período que se seguiu. Seu princípio de 
funcionamento era particularmente adequado ao estudo de sistemas de controle em tempo real, uma necessidade que os computadores digitais da época ainda não podiam atender.

$O$ advento do computador digital moderno desempenhou um papel fundamental nos sistemas de automação na forma em que conhecemos hoje. Pode-se grosseiramente dividi-los em duas categorias: manufatura automatizada, e sistemas automatizados de processamento e controle da informação. Pertence ao primeiro tipo a maior parte dos equipamentos utilizados nas mais diversas etapas das linhas de produção automatizada. Um exemplo típico são as máquinas-ferramenta de controle numérico, que podem, rápida e eficientemente, ser reprogramadas para executar diferentes trabalhos. Os demais sistemas envolvem a aquisição e processamento de dados com finalidades tais como: organização e classificação, armazenamento, transferência, e, naturalmente, tomadas de decisão em sistemas de supervisão e controle. Suas aplicações, por exemplo, vão desde o controle da temperatura de um forno, até a definição da trajetória de um veículo lançador de satélites.

De um modo geral, a implementação de um sistema de controle automático por realimentação requer a utilização de sensores e de atuadores para que um ponto de operação desejado (set point) possa ser obtido. A diferença entre o valor observado e o valor desejado de uma variável de controle estabelece um sinal de erro utilizado como parâmetro de entrada do sistema controlador. Este, por sua vez, influencia o sistema através de variáveis de processo que, no caso de controladores em tempo real, costumam ser entradas de atuadores. $O$ resultado passa a ser sentido através da malha de realimentação constituída por sensores que irão atualizar o valor observado para a variável de controle, desencadeando um processo que deve desejavelmente (para sistemas estáveis em malha fechada) ser de rápida convergência, minimizando o valor do erro presente na saída do elemento somador (FIG. 2.1). 


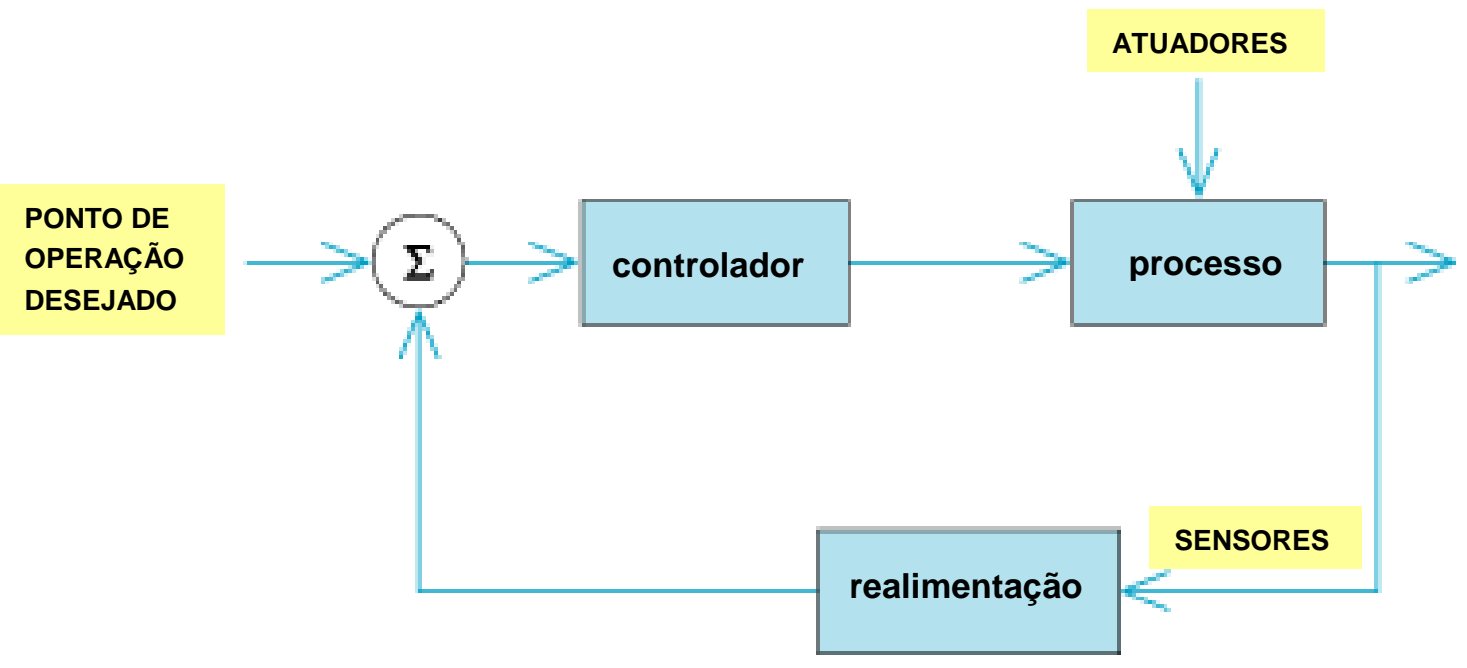

FIGURA 2.1- Diagrama básico de um sistema de controle realimentado.

Um dos grandes desafios na especificação e implantação de sistemas automatizados que continuarão dividindo tarefas com seres humanos é o estabelecimento adequado de fronteiras dividindo as responsabilidades entre cada lado - sistema e operador. De preferência, a interface com o usuário deve fornecer uma quantidade de informações apenas suficiente para que ele possa, a cada instante, certificar-se do correto funcionamento de todas as partes essenciais do sistema, dificultando, ou, se possível, impossibilitando, a tomada de ações que possam levar a resultados errôneos ou catastróficos, ou perda de registros; sem, com isso, tolher excessivamente sua iniciativa ou capacidade de análise e julgamento - um compromisso que pode ser bastante delicado. Salvo nos casos de sistemas redundantes de alta confiabilidade tais como os utilizados em aplicações críticas, costuma-se aceitar como indesejável adotar a postura de "confiança cega" nos resultados de um sistema automático, que deve, portanto, incorporar facilidades para a execução de rotinas de auto-verificação. 


\section{MATERIAIS E MÉTODOS}

Os principais recursos técnicos utilizados na realização deste trabalho foram provenientes da participação do LCl (Laboratório de Calibração de Instrumentos) num projeto de cooperação da Agência Internacional de Energia Atômica ${ }^{[60]}$. Os procedimentos descritos, tanto os previamente existentes, como os propostos por este trabalho, visam primariamente à aplicação no exercício das atividades - tanto de pesquisa quanto rotineiras - do laboratório de raios $\mathrm{X}$ do $\mathrm{LCl}$ do IPEN.

\subsection{Instalações}

O laboratório de raios $\mathrm{X}$ do $\mathrm{LCl}$ mantém em funcionamento um mínimo de dois equipamentos geradores de raios $X$ com seus respectivos sistemas de refrigeração e geradores de alta tensão, fixamente acoplados a bancos óticos de 2,5m de comprimento, dispostos em salas anexas a uma sala central de controle. Há provisões para o condicionamento e desumidificação do ar em todas as salas, bem como o armazenamento de câmaras de ionização e seus respectivos cabos em atmosfera de baixa umidade (recipientes com sílica gel).

Os acessórios utilizados durante as atividades de ensaios e calibrações incluem facilidades para o posicionamento e fixação de dosímetros e instrumentos, circuito fechado de monitoração, além de colimadores, conformadores de feixe, e filtros de alta pureza em diversos materiais e espessuras. Os sistemas de referência incluem câmaras de ionização com certificados de calibração rastreáveis a padrões primários, e desde 2001 o laboratório trabalha com um sistema da qualidade de acordo com as recomendações da norma NBR ISO/IEC $17025^{[5]}$.

Adicionalmente, o LCl possui um sistema invasivo de medição de alta tensão (Radcal Dynalyzer), e um espectrômetro portátil de germânio hiperpuro (Ortec Nomad Plus). As duas salas de irradiação possuem blindagens constituídas por folhas de chumbo para evitar o espalhamento de radiação para as salas vizinhas, e são supervisionadas pelo serviço de radioproteção do IPEN. 
Seus usuários utilizam dosímetros pessoais controlados e produzidos pelo próprio IPEN.

\subsection{Equipamentos}

Os seguintes instrumentos e equipamentos foram diretamente utilizados neste trabalho:

- $\quad$ Gerador de raios X industrial monopolar de potencial constante marca Agfa NDT Pantak Seifert GmbH modelo ISOVOLT HS com tubo gerador modelo 160 M2/0.4-3.0 (v. FIG. 3.1)

CARACTERÍSTICAS PRINCIPAIS:

○ Tensão máxima: $160 \mathrm{kV}$

○_Corrente máxima: 45mA@60kV; 19mA@160kV

○ Potência máxima de anodo (foco largo): $3 \mathrm{~kW}$

- Ângulo de feixe: $40^{\circ}$

- Filtração inerente: $1 \mathrm{~mm} \mathrm{Be}$

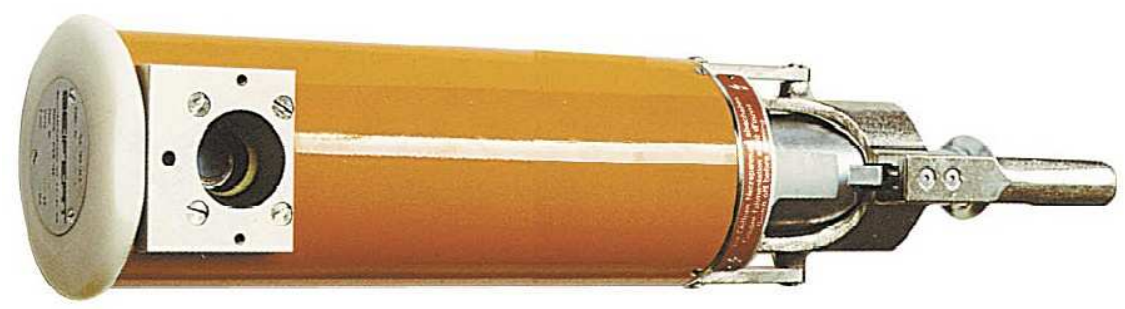

FIGURA 3.1 - Tubo unipolar de raios $X$ do tipo utilizado no gerador marca Pantak Seifert (Agfa NDT) modelo ISOVOLT HS 160.

- $\quad$ Eletrômetro marca PTW modelo UNIDOS, (v. FIG. 3.2, esq.)

○ número de série: 10476

○ normas: atende IEC 60731 (como dosímetro de referência) e IEC 61674 (como dosímetro diagnóstico)

CARACTERÍSTICAS ELÉTRICAS:

○ $\quad$ escalas de carga: 230pC (Low) e 23nC (High)

○ resolução: 0,01pC (Low) ou 0,5pC (High)

$\circ \quad$ escalas de corrente: 190pA (Low), 10nA (Med) e 1 $1 \mu \mathrm{A}$ (High)

○ resolução: $0,001 p A$ (Low), 0,05pA (Med) ou 5pA (High) 


$$
\begin{aligned}
& \text { - display: } 4 \text { dígitos } \\
& \circ \quad \text { precisão: } \leq \pm 0,5 \%
\end{aligned}
$$

- fonte de alta tensão: de 0 a $\pm 400 \mathrm{~V}$ em incrementos de $50 \mathrm{~V}$

- $\quad$ Eletrômetro marca PTW modelo UNIDOS E (v. FIG. 3.2, dir.)

- $\quad$ número de série: 000190

○ normas: atende IEC 60731 (como dosímetro de campo) e IEC 61674 (como dosímetro diagnóstico)

CARACTERÍSTICAS ELÉTRICAS:

$\begin{array}{ll}\circ & \text { escalas de corrente: } 117 \mathrm{pA}, 10 \mathrm{nA} \text { e } 1,2 \mu \mathrm{A} \\ \circ & \text { resolução: } 0,001 \mathrm{pC}(\mathrm{Low}), 0,1 \mathrm{pA}(\mathrm{Med}) \text { ou 10pA (High) } \\ \circ & \text { display: } 4 \text { dígitos } \\ \circ & \text { precisão: } \leq \pm(0,5 \%+1 \text { dígito) } \\ \circ & \text { fonte de alta tensão: de } 0 \mathrm{a} \pm 400 \mathrm{~V} \text { em incrementos de } 50 \mathrm{~V} \\ \circ & \text { precisão (alta tensão): } \leq \pm 2 \%\end{array}$

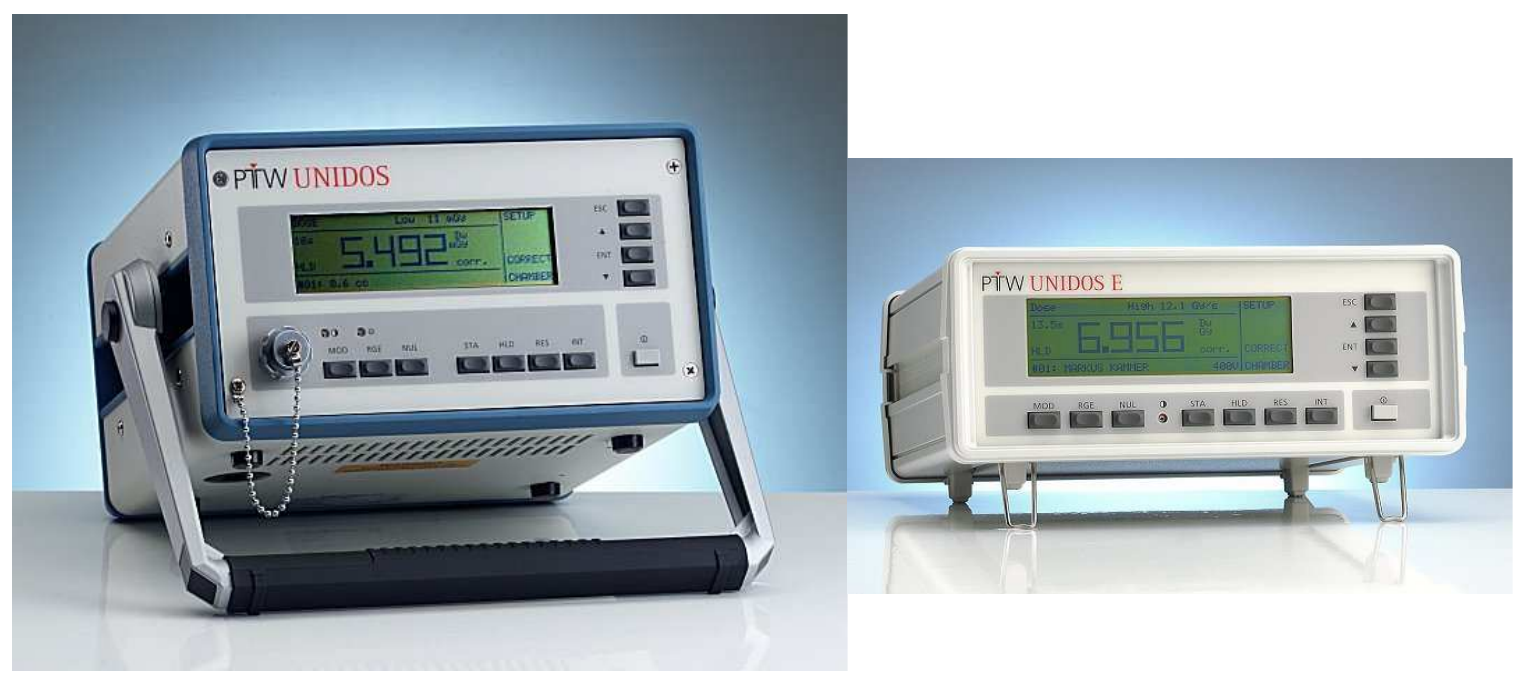

FIGURA 3.2 - Eletrômetros UNIDOS (esquerda), e UNIDOS E (direita), de fabricação alemã (PTW). O primeiro é indicado para uso como padrão secundário de referência.

- $\quad$ Câmara de ionização de referência marca PTW modelo 77334 com paredes e eletrodos de polimida grafitada de 50 $4 \mathrm{~m}$ de espessura; diâmetro externo de 55mm; sensibilidade nominal de 40pC/mGy (v. FIG. 3.3, dir.)

○ faixa nominal de energia: $14 \mathrm{keV} \sim 75 \mathrm{keV}$

CARACTERÍSTICAS DO VOLUME SENSÍVEL:

O

volume: $1 \mathrm{~cm}^{3}$ 


$$
\begin{array}{ll}
\circ & \text { diâmetro: } 34 \mathrm{~mm} \\
\circ & \text { comprimento: } 1,25 \mathrm{~mm}
\end{array}
$$

- $\quad$ Câmara de ionização de transmissão (monitora) marca PTW modelo 34014 com paredes e eletrodos de polimida grafitada de $25 \mu \mathrm{m}$ de espessura; diâmetro externo de 230mm (v. FIG. 3.3, esq.)

$\begin{array}{ll}\text { C faixa nominal de energia: } 7,5 \mathrm{kV} \sim 420 \mathrm{kV} \\ \text { CARACTERÍSTICAS DO VOLUME SENSÍVEL: } \\ 0 & \text { volume: } 86 \mathrm{~cm}^{3} \\ \circ & \text { diâmetro: } 148 \mathrm{~mm} \\ \circ & \text { comprimento: } 2 \times 2,5 \mathrm{~mm}\end{array}$

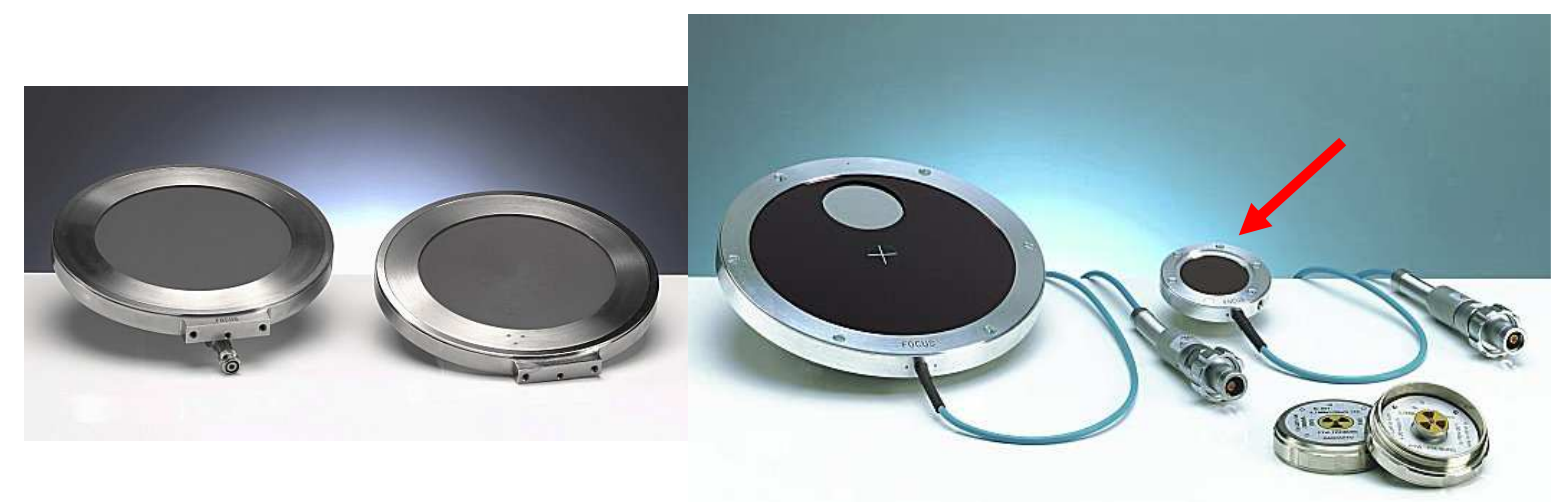

FIGURA 3.3 - $\quad$ Câmaras de ionização da PTW do tipo utilizado no LCI. Esquerda: câmaras de transmissão (monitoras), modelos 786 e 34014. Direita: câmara de referência para radiodiagnóstico, modelo 77334 (indicada pela seta).

- Unidade leitora de temperatura marca Hart Scientific modelo 1529-R Chub E-4 (v. FIG. 3.4, esq.)
○ número de série: $A 45645$
○ número de canais: 4
- $\quad$ tipo de entrada: 4 fios para PRT e termistores
- faixa de medição: $0 \sim 500 \mathrm{k} \Omega$
○ resolução: $0,0001^{\circ} \mathrm{C}$
○ precisão: $\pm 0,0025 \mathrm{C} @ 25^{\circ} \mathrm{C}$

- $\quad$ Barômetro digital de precisão marca Druck modelo DPI 142

(v. FIG. 3.4, dir.) número de série: 2295953 alcance (pressão absoluta): 750 a 1150 mbar 

- display: 7 dígitos
- resolução: 0,001mbar
○ precisão: melhor do que 0,01\% F.S.
○ estabilidade: melhor do que $\pm 0,01 \%$ F.S. / ano
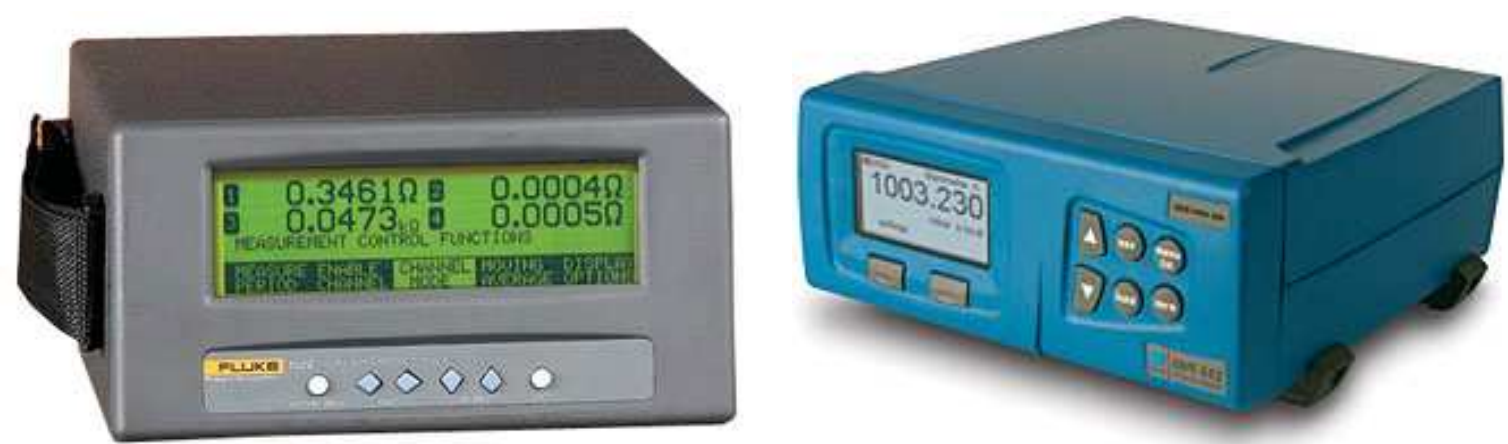

FIGURA 3.4 - Esquerda: termômetro de precisão marca Hart Scientific (atualmente sob controle da Fluke Corp.), modelo 1529 Chub E-4. Direita: barômetro absoluto de precisão marca Druck (atualmente sob controle da GE Sensing), modelo DPI 142 (direita).

- $\quad$ Termistor de referência padrão secundário marca Hart Scientific modelo 5611-X ("silicone-bead probe") - (v. FIG. 3.5)

$\begin{array}{ll}\circ & \text { números de série: } 0207-21 \text { e 0207-1112 } \\ \circ & \text { calibração: por conversão THERM-T } \\ \circ & \text { diâmetro nominal: } 1,8 \mathrm{~mm} \\ \circ & \text { resistência nominal: } 10 \mathrm{k} \Omega \\ \circ & \text { precisão: } \pm 0,015^{\circ} \mathrm{C} \\ \circ & \text { estabilidade: melhor do que } \pm 0,01 \% \text { / ano } \\ \circ & \text { repetibilidade: melhor do que } \pm 0,005 \%\end{array}$

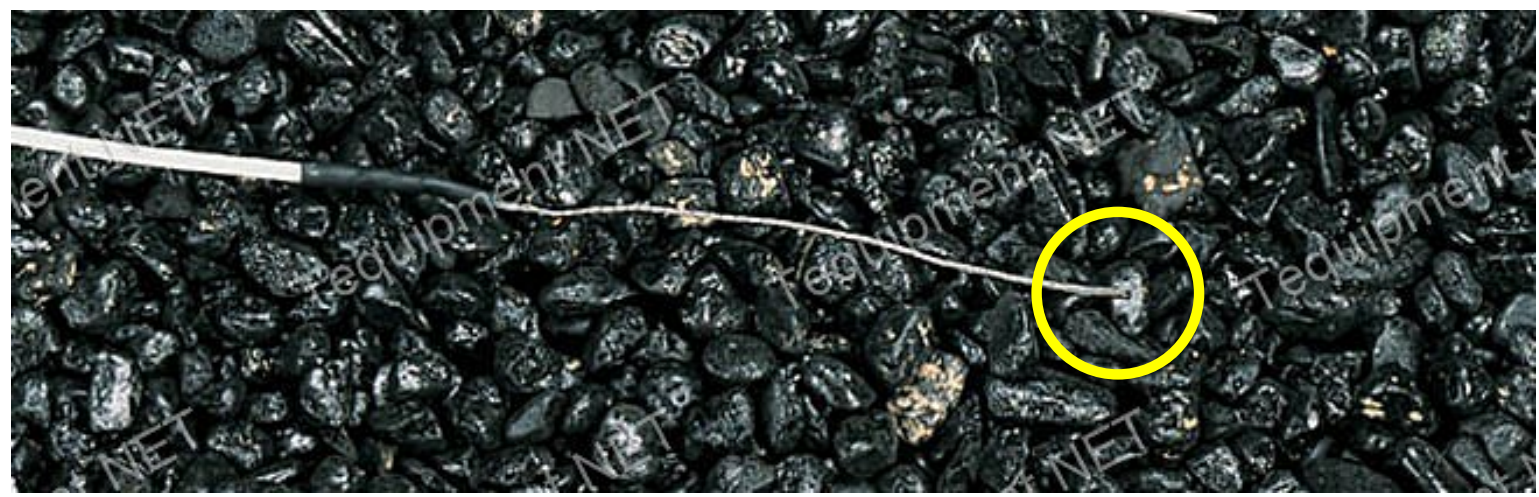

FIGURA 3.5 - $\quad$ Minúsculo termistor de referência (padrão secundário) Hart modelo 5611-X (no centro do destaque em amarelo). 


\subsection{Qualidades de feixes}

Os feixes padrões de radiação-X presentemente implantados no $\mathrm{LCl}$ a partir do gerador ISOVOLT HS 160 incluem três conjuntos de qualidades: para proteção radiológica ${ }^{[54]}$, para radiologia diagnóstica ${ }^{[52]}$, e para radioterapia ${ }^{[47]}$, tendo os dois primeiros sido utilizados neste trabalho.

Graças ao uso de um equipamento de potencial constante (segundo o fabricante, o valor de ripple é inferior a $2 \%$, graças à operação em $40 \mathrm{kHz}$ ), deixou de ser crítica a impossibilidade em se efetuar medições invasivas da tensão do tubo (por ser unipolar, sendo que o Dynalyzer aplica-se somente a unidades bipolares), bem como em determinar efetivamente o potencial de pico prático conforme recomendado pela norma IEC 61267:2005 ${ }^{[52]}$. Além disso, o draft do protocolo da IAEA $^{[30]}$ admite o uso alternativo de medição não-invasiva, de acordo com a definição dessa nova grandeza PPV (practical peak voltage, ou potencial de pico prático) recomendada pela norma IEC 61676:2002 ${ }^{\text {[61] }}$.

TABELA 3.1 - Características dos feixes diretos (emergentes do gerador): qualidades RQR de acordo com a norma IEC 61267, conforme implantados no LCl para calibração em radiologia diagnóstica.

\begin{tabular}{ccccccc}
\hline $\begin{array}{c}\text { Qualidade } \\
\text { da } \\
\text { radiação }\end{array}$ & $\begin{array}{c}\text { Tensão } \\
\text { nominal } \\
(\mathrm{kV})\end{array}$ & $\begin{array}{c}\text { Filtração } \\
\text { adicional } \\
(\mathrm{mm} \mathrm{Al})\end{array}$ & $\begin{array}{c}1^{\text {a }} \mathrm{CSR} \\
(\mathrm{mm} \mathrm{Al})\end{array}$ & $\begin{array}{c}\text { Coeficiente de } \\
\text { homogeneidade } \\
(h)\end{array}$ & $\begin{array}{c}\text { Energia } \\
\text { efetiva } \\
(\mathrm{keV})\end{array}$ & $\begin{array}{c}\text { Taxa de } \\
\text { kerma no } \\
\text { ar } \\
\left(\mathrm{mGy}^{-1}\right)\end{array}$ \\
\hline \hline RQR2 & 40 & 2,5 & 1,44 & 0,800 & 25,1 & 0,230 \\
\hline RQR3 & 50 & 2,5 & 1,79 & 0,752 & 27,2 & 0,401 \\
\hline RQR4 & 60 & 2,5 & 2,09 & 0,716 & 28,8 & 0,589 \\
\hline RQR5 & 70 & 2,5 & 2,35 & 0,687 & 30,2 & 0,786 \\
\hline RQR6 & 80 & 2,5 & 2,65 & 0,664 & 31,6 & 1,007 \\
\hline RQR7 & 90 & 2,5 & 2,95 & 0,639 & 33,0 & 1,242 \\
\hline RQR8 & 100 & 2,5 & 3,24 & 0,623 & 34,4 & 1,497 \\
\hline RQR9 & 120 & 2,5 & 3,84 & 0,609 & 37,0 & 2,030 \\
\hline RQR10 & 150 & 2,5 & 4,73 & 0,607 & 40,8 & 2,920 \\
\hline
\end{tabular}

NOTA: A distância utilizada entre a posição de irradiação e o ponto focal é de $1 \mathrm{~m}$. 
Os principais parâmetros obtidos e utilizados na obtenção das qualidades RQR e RQA, conforme implantados no $\mathrm{LCl}$; correspondem respectivamente aos feixes diretos (incidentes) e atenuados (saída do paciente) para utilização em radiodiagnóstico, conforme tabelas 1 e 2.

Para todas as qualidades $R Q R$ implantadas, a corrente de feixe utilizada é de $10 \mathrm{~mA}$. Para as qualidades RQA correspondentes, utiliza-se 20mA, o que leva o equipamento gerador ao limite de sua capacidade ( $3 \mathrm{~kW})$ quando em RQA-10. Embora não tenha sido observada nenhuma tendência a superaquecimento, o LCI limita os períodos de irradiação contínua a intervalos de 15 minutos, como medida de cautela.

TABELA 3.2 - Características dos feixes atenuados (emergentes do paciente): qualidades RQA de acordo com a norma IEC 61267, conforme implantados no LCI para calibração em radiologia diagnóstica.

\begin{tabular}{ccccccc}
\hline $\begin{array}{c}\text { Qualidade } \\
\text { da } \\
\text { radiação }\end{array}$ & $\begin{array}{c}\text { Tensão } \\
\text { nominal } \\
(\mathrm{kV})\end{array}$ & $\begin{array}{c}\text { Filtração } \\
\text { adicional } \\
(\mathrm{mm} \mathrm{Al})\end{array}$ & $\begin{array}{c}1 \text { a CSR } \\
(\mathrm{mm} \text { Al) }\end{array}$ & $\begin{array}{c}\text { Coeficiente de } \\
\text { homogeneidade } \\
(h)\end{array}$ & $\begin{array}{c}\text { Energia } \\
\text { efetiva } \\
(\mathrm{keV})\end{array}$ & $\begin{array}{c}\text { Taxa de } \\
\text { kerma no } \\
\text { ar } \\
\left(\mathrm{mGy}^{-1}\right)\end{array}$ \\
\hline \hline RQA2 & 40 & 6,5 & 2,22 & 0,888 & 29,5 & 0,0898 \\
\hline RQA3 & 50 & 12,5 & 3,91 & 0,942 & 37,3 & 0,0565 \\
\hline RQA4 & 60 & 18,5 & 5,34 & 0,916 & 43,2 & 0,0505 \\
\hline RQA5 & 70 & 23,5 & 6,86 & 0,937 & 49,4 & 0,0567 \\
\hline RQA6 & 80 & 28,5 & 8,13 & 0,952 & 54,8 & 0,0665 \\
\hline RQA7 & 90 & 32,5 & 9,22 & 0,951 & 59,7 & 0,0812 \\
\hline RQA8 & 100 & 36,5 & 10,09 & 0,940 & 64,0 & 0,0960 \\
\hline RQA9 & 120 & 42,5 & 11,39 & 0,937 & 71,2 & 0,1322 \\
\hline RQA10 & 150 & 47,5 & 13,02 & 0,944 & 82,1 & 0,2213 \\
\hline
\end{tabular}

NOTA: A distância utilizada entre a posição de irradiação e o ponto focal é de $1 \mathrm{~m}$. 
TABELA 3.3 - Características dos feixes para calibração de instrumentos de radioproteção no LCI: qualidades "narrow", conforme a norma ISO 4037-1.

\begin{tabular}{ccccccc}
\hline $\begin{array}{c}\text { Qualidade } \\
\text { da } \\
\text { radiação }\end{array}$ & $\begin{array}{c}\text { Tensão } \\
\text { nominal } \\
(\mathrm{kV})\end{array}$ & $\begin{array}{c}\text { Filtração } \\
\text { adicional } \\
(\mathrm{mm} \mathrm{Cu})\end{array}$ & $\begin{array}{c}1^{\text {a }} \mathrm{CSR} \\
(\mathrm{mm} \mathrm{Cu})\end{array}$ & $\begin{array}{c}\text { Coeficiente de } \\
\text { homogeneidade } \\
(h)\end{array}$ & $\begin{array}{c}\text { Energia } \\
\text { efetiva } \\
(\mathrm{keV})\end{array}$ & $\begin{array}{c}\text { Taxa de } \\
\text { kerma no } \\
\text { ar } \\
\left(\mathrm{mGy}^{-1}\right)\end{array}$ \\
\hline \hline $\mathrm{N}-60$ & 60 & 0,6 & 0,24 & 0,923 & 48 & 0,00539 \\
\hline $\mathrm{N}-80$ & 80 & 2,0 & 0,58 & 0,935 & 65 & 0,00286 \\
\hline $\mathrm{N}-100$ & 100 & 5,0 & 1,11 & 0,949 & 83 & 0,00136 \\
\hline $\mathrm{N}-150$ & 150 & $\left(^{* \star}\right)$ & 2,36 & 0,955 & 118 & 0,01147 \\
\hline
\end{tabular}

NOTAS: A distância utilizada entre a posição de irradiação e o ponto focal é de $2,5 \mathrm{~m}$.

$\left(^{\star *}\right)$ No caso de N-150: 2,5 mm Sn

\subsection{Recursos computacionais}

Todos os instrumentos apresentados na seção anterior possuem interface RS-232, sendo que o termômetro Hart e o barômetro Druck também dispõem de interface IEEE-488, conhecida ainda como GP-IB. Embora o LCI também tenha conseguido, por intermédio do projeto de cooperação ${ }^{[60]}$, um adaptador GPIB-USB-B de fabricação da National Instruments, visando principalmente sua conexão com dois eletrômetros marca Keithley modelo 6517A recebidos pelo mesmo projeto, estes não puderam ser postos em uso imediato, devido à indisponibilidade de cabos ou adaptadores compatíveis com seu conector triaxial de entrada.

O computador utilizado neste trabalho (descrito a seguir) dispunha originalmente de apenas uma porta serial. Consultando-se o manual, foi possível confeccionar um adaptador para conseguir acesso à segunda porta serial (COM2) onboard. Adquirindo-se um cartão PCl com uma porta paralela e duas portas seriais adicionais, foi possível implementar as portas COM3 e COM4 nesse computador, conforme a FIG. 3.6.

Outro importante recurso conseguido foi um cartão analógico-digital multi-funções modelo PCI-MIO-16E-4 (equivalente ao atual modelo PCI-6040E) fabricado pela National Instruments, com 16 entradas analógicas single-ended (ou oito entradas diferenciais), conversão $A / D$ de 12-bits com taxa de amostragem de $500 \mathrm{kHz}$ (single channel), duas saídas analógicas de 12-bits, além de oito entradas e saídas digitais padrão TTL. Incorpora ainda dois timers contadores 
independentes de 24-bits. Em modo multiplexado de aquisição não simultânea, a taxa de amostragem cai para $250 \mathrm{kHz}$, dividida pelo número de entradas analógicas ativas. Para os casos em que se requer aquisição simultânea com taxas elevadas de amostragem (tais como medição de fase relativa entre sinais de alta freqüência), existem placas com múltiplos conversores A/D (modelo 6133, por exemplo), a um custo consideravelmente mais elevado.

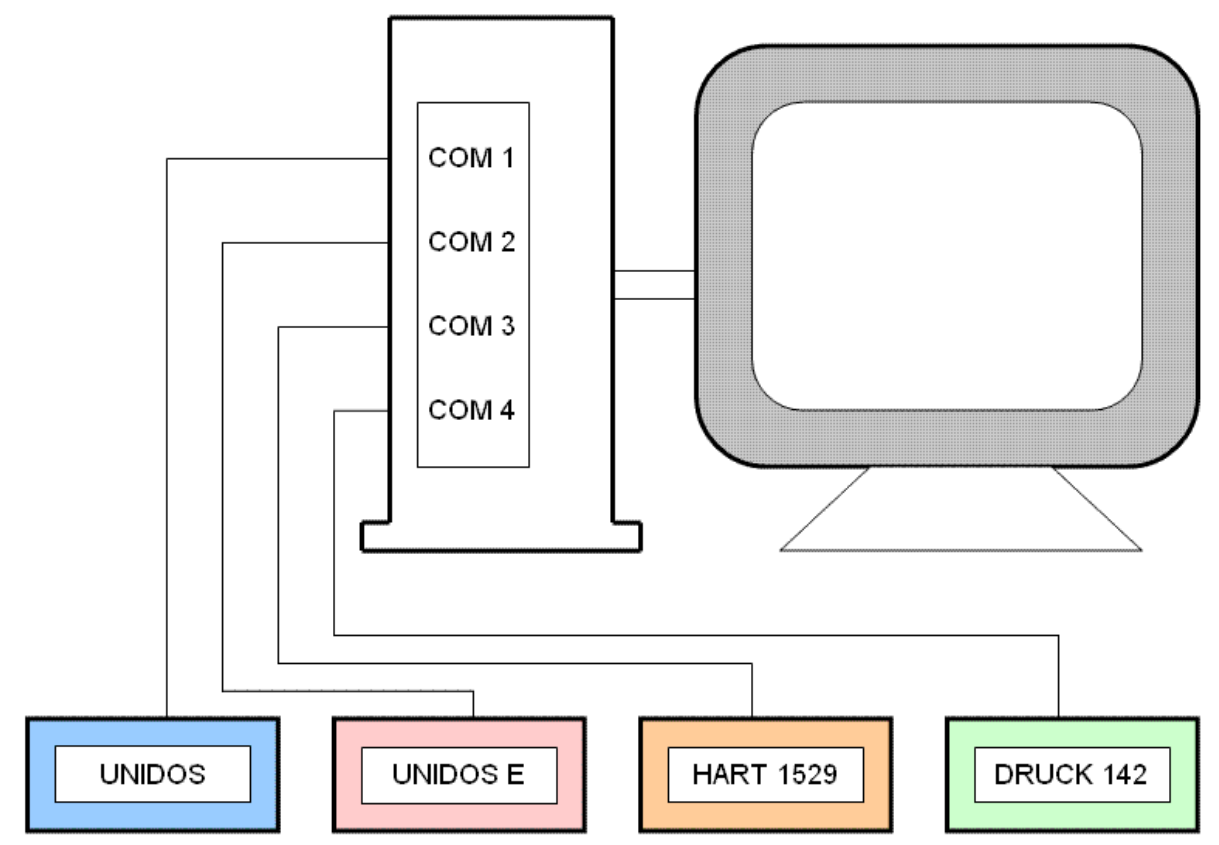

FIGURA 3.6 - Diagrama de conexão entre o microcomputador e os instrumentos

Em que pese seu baixo custo segundo os padrões atuais, o modelo de placa utilizado atendeu com ampla margem as necessidades do $\mathrm{LCl}$, considerando-se inclusive as perspectivas de desenvolvimento futuro (v. seção 4.6). Na realização deste trabalho, seu uso restringiu-se à utilização de uma única saída digital, para comando do obturador através de uma interface dedicada especialmente projetada e construída, consistindo num circuito conversor de nível e driver de relé. Esta solução foi adotada pela sua simplicidade, permitindo aproveitar grande parte do sistema de comando manual pré-existente, que recebeu uma modificação que pode ser considerada como "minimamente invasiva" para viabilizar seu comando remoto. É evidente que essa placa da National reserva ainda um grande potencial de expansão para aplicações futuras no âmbito do próprio LCI. 
Deve-se ainda mencionar que foi utilizado em conjunto com a placa da National um acessório de grande conveniência e praticidade: um bloco adaptador para conectores BNC (National Instruments, modelo BNC-2110), acompanha um cabo especial blindado com conector de 68 pinos compatível com a placa. A FIG. 3.7 ilustra este arranjo.

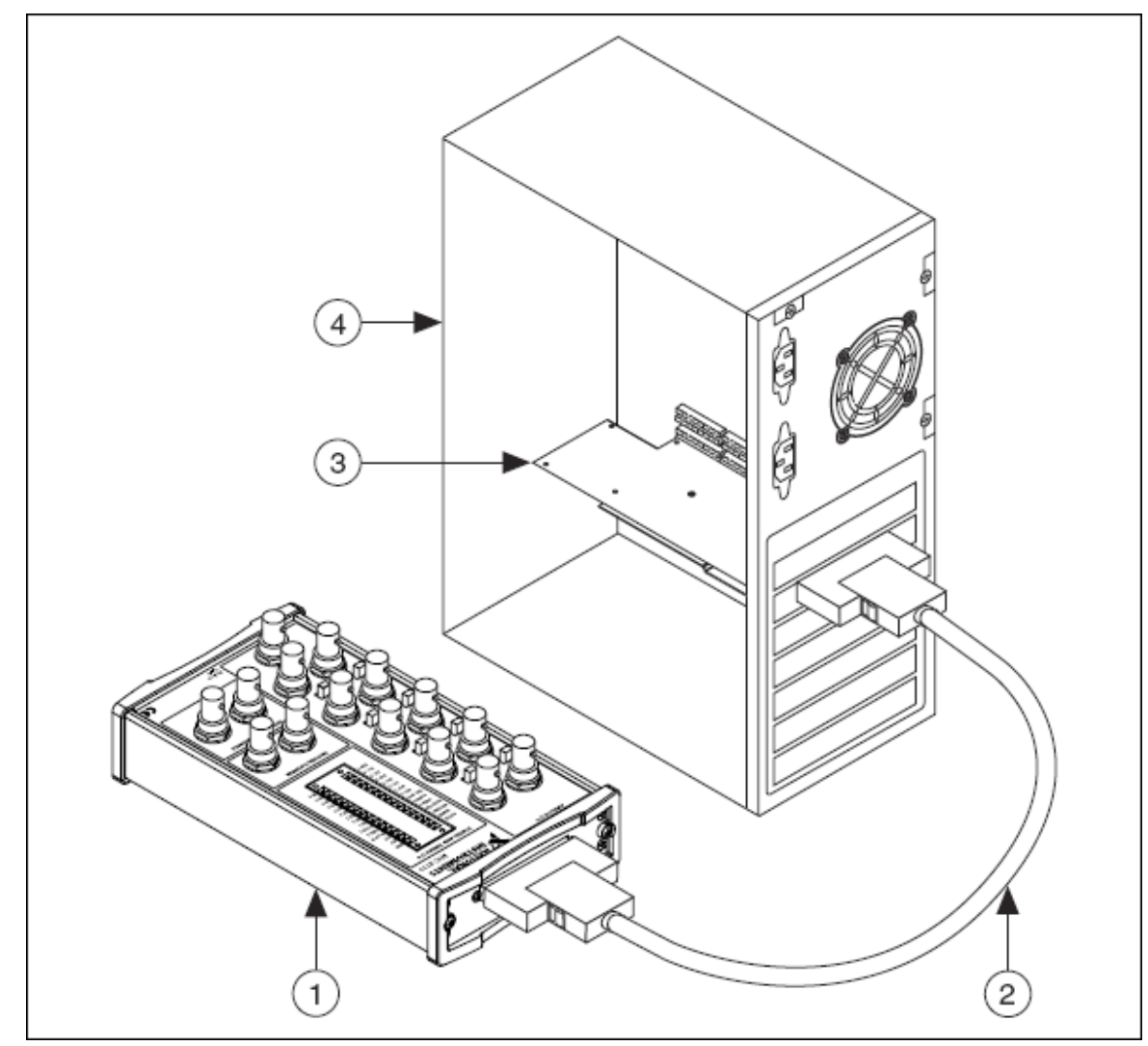

FIGURA 3.7 - Diagrama ilustrativo mostrando: (1) caixa de conexões National BNC-2110; (2) cabo blindado com conectores de 68 vias; cartão National PCI MIO 16E-4 (equivalente a PCI-6040E); (4) microcomputador Pentium IV ou equivalente com slot PCI.

O computador utilizado foi um Pentium IV de 3.0GHz com $1 \mathrm{~GB}$ de RAM e HD de 80GB que, aparte dos cartões PCl previamente mencionados (placa da National, e cartão de comunicação serial), pode ser considerado absolutamente convencional.

\subsubsection{Programas utilizados}

Conforme apresentado na parte introdutória deste trabalho, o principal pacote de programação utilizado ao longo deste trabalho foi 0 LabVIEW $^{\text {MR }} 7$ Express, comercializado pela própria National Instruments ${ }^{[20]}$, fornecedor de alguns dos itens de hardware descritos acima. A garantia de 
compatibilidade mútua é apenas mais um dos apelos para a conveniência dessa combinação.

Para facilitar a integração com os diferentes recursos que podem vir a ser comandados pelo LabVIEW $^{\mathrm{MR}}$, são oferecidas bibliotecas identificadas por siglas conforme sua categoria: DAQ (para comunicação com módulos dedicados de aquisição digital de dados tais como os produzidos pela National Instruments); VISA (de "Virtual Instrument Software Architecture"), uma API ("Application Programming Interface') dedicada primariamente à comunicação com instrumentos de teste e medição; IVI ("Interchangeable Virtual Instruments"), uma biblioteca de drivers para oito categorias pré-determinadas de instrumentos que vão desde multímetros digitais até analisadores de espectro; FieldPoint ${ }^{\mathrm{MR}}$ para leitura e comando de controladores programáveis distribuídos como os utilizados na automação de processos industriais; IMAQ no caso de aquisição e processamento de imagens; e ainda NI-Motion, um conjunto de rotinas para facilitar o comando de posicionadores e atuadores na indústria. A possibilidade de inclusão de programas originalmente escritos em LabWindows/CVI (um software de comunicação multi-plataforma), Visual Basic e $\mathrm{C} / \mathrm{C}_{++}$aumenta a versatilidade do LabVIEW ${ }^{\text {MR }}$ como ambiente primário de desenvolvimento.

Algumas rotinas da biblioteca VISA acima mencionada puderem ser facilmente utilizadas neste trabalho; elas permitem a pré-definição tanto da categoria como da classe do evento. A categoria define o recurso a se utilizar (tal como: GPIB, serial; USB ou TCP/IP); e a classe especifica o tipo de evento esperado (trigger, interrupt, talk ou listen, por exemplo).

Os primeiros testes bem sucedidos de comunicação foram feitos com os eletrômetros modelo UNIDOS E, tendo-se utilizado uma versão estudantil do LabVIEW ${ }^{M R} 6 \mathrm{i}$. Ao longo de todo o trabalho, foi frequentemente utilizado um programa gratuito disponível na Internet para o envio e recebimento de dados isolados para as portas seriais, chamado RComSerial, que a despeito de sua simplicidade, revelou-se extremamente útil para pequenos testes (v. FIG. 3.8) [ $\left.{ }^{62}\right]$.

As versões finais dos programas foram desenvolvidas utilizando-se 0 LabVIEW $^{\mathrm{MR}} 7$ Express. Entre as principais novidades, o advento da biblioteca expandida DAQmx, e de um conjunto de sub-rotinas expressas desenvolvidas com o objetivo de encurtar o tempo de desenvolvimento de um programa a partir 
do zero. Como as rotinas da biblioteca VISA tradicional já estavam funcionando perfeitamente com as portas seriais, optou-se por mantê-las em uso.

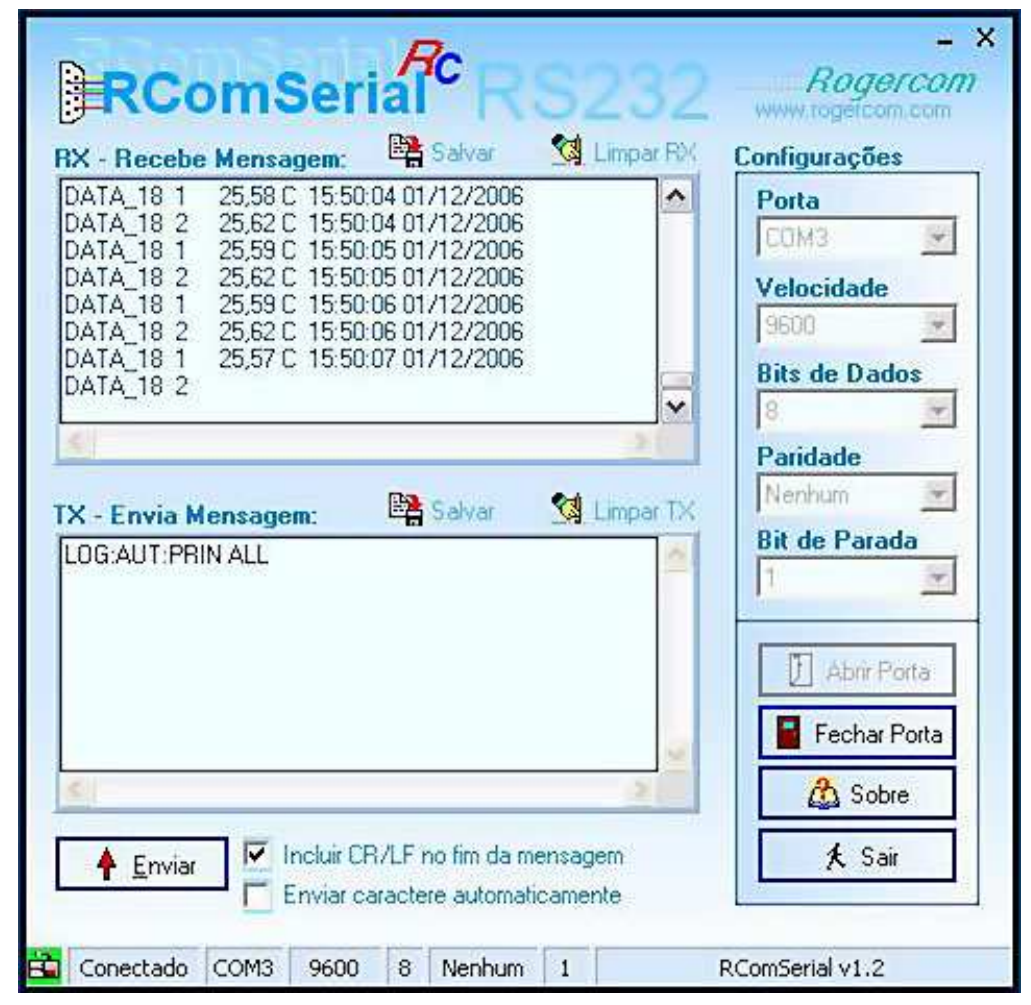

FIGURA 3.8 - Tela do programa freeware utilizado em testes durante as etapas preliminares de desenvolvimento deste trabalho, mostrando a descarga parcial do buffer de armazenamento do termômetro Hart 1529, que havia sido programado para a coleta offline da temperatura de dois sensores a cada segundo. 


\section{Resultados}

Os programas desenvolvidos no decorrer deste trabalho são resultantes do esforço do $\mathrm{LCl}$ no sentido de se utilizar todos os recursos técnicos presentemente disponíveis da melhor maneira possível e em consonância com o anseio em se elevar a qualidade de ensaios e calibrações. Através da interface padrão RS-232, os seguintes instrumentos foram conectados ao microcomputador:

- $\quad$ Câmara de ionização de referência acoplada a eletrômetro UNIDOS;

- $\quad$ Câmara monitora acoplada a eletrômetro UNIDOS E;

- $\quad$ Termômetro Hart 1529 acoplado a dois termistores;

- $\quad$ Barômetro Druck 142.

Adicionalmente foi necessário projetar, montar e instalar um circuito acionador de relé que permitisse o comando remoto do obturador através de uma entrada lógica padrão TTL, viabilizando sua conexão direta a uma das saídas digitais da placa da National Instruments.

O objetivo de implementar um painel de controle unificado na tela do computador foi ao encontro dos anseios dos técnicos do $\mathrm{LCl}$, antes encarregados de operar sois ou mais equipamentos simultaneamente.

Como um dos principais problemas relatados pelos responsáveis e técnicos do LCl foi a dificuldade na realização de ensaios que exigissem o comando simultâneo de dois ou mais equipamentos, o objetivo inicial foi o de implementar uma central unificada de controle e monitoramento dos vários sistemas na tela do computador.

Em virtude da disponibilidade imediata de leituras precisas e confiáveis de pressão e temperatura (esta última em dois pontos distintos), foi natural a opção em se aplicar os fatores de correção (conforme a equação 14 do item 2.2) concomitantemente às leituras, permitindo assim a conversão instantânea de carga (expressa em $\mathrm{nC}$ ) para kerma (expresso em mGy). A trilogia de programas descritos a partir da seção 4.2 relata como isso foi feito.

Um grande diferencial em relação aos métodos de calibração anteriormente empregados no $\mathrm{LCl}$ consistiu na implementação de um sistema através do qual a câmara monitora passou a ser efetivamente utilizada como padrão 
de referência, durante os intervalos entre comparações diretas com a câmara de referência propriamente dita.

\subsection{Controle digital do obturador}

Conforme fornecido pelo fabricante, o painel de controle do obturador oferecia apenas a opção de operação manual por intermédio de uma chave rotativa de duas posições. Um breve estudo revelou que essa chave comandava dois contatos do tipo NA (normalmente abertos). A colocação de um relé cujos contatos NA fossem dispostos em série com os referidos contatos da chave atribuiria uma lógica do tipo "E" $(A N D)$, de modo que continuasse sendo possível fechar o obturador através da operação da chave. Para a abertura, seria necessário que tanto a chave quanto o comando lógico assim o determinassem.

Para viabilizar a utilização de um relé com bobina de 12VDC, foi projetado e montado um pequeno circuito para abaixar e regular a tensão disponível no painel (cerca de 38VDC), além de dispor de uma entrada inversora compatível com os níveis da lógica TTL. Aplicando-se 5VDC (ou deixando-se em aberto) tal entrada, os contatos do relé não se fecham, impedindo a abertura do obturador, mesmo que a chave manual esteja acionada. Para liberar a exposição, deixa-se essa chave na posição ligada, e aplica-se um nível lógico baixo à entrada do circuito através de um conector BNC. Na eventual necessidade de se comandar diretamente o obturador por intermédio de intervenção manual nessa chave, deve-se aplicar uma baixa

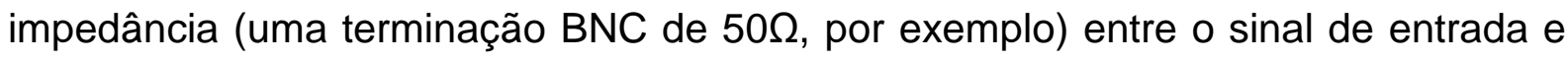
seu terra de referência.

\subsection{Programa de controle do obturador e da câmara monitora}

Durante a fase de estudos preliminares, verificou-se que alguns problemas poderiam surgir, e algumas decisões teriam que ser tomadas, conforme sintetizado abaixo:

\footnotetext{
- $\quad$ O conjunto de comandos (instruções) é peculiar a cada instrumento, bem como o formato do strings de retorno e o tempo de resposta;

- $\quad$ O controle do exato tempo decorrido (em tempo de execução do programa) teria que ser delegado a um dos instrumentos, para evitar o risco de perda de sincronismo causada por pequenas diferenças;
} 
- $\quad$ A versatilidade de utilização via interface é consideravelmente superior em alguns instrumentos (Hart 1529, UNIDOS E);

- A utilização dos recursos básicos do LabVIEW ${ }^{M R}$ pressupõe como resultado um programa a ser executado dentro do Windows ${ }^{\mathrm{MR}}$, sem o uso de definições especiais de prioridades de processos;

- $\quad$ Fontes conhecidas de erros sistemáticos (tais como o tempo de trânsito do obturador) deveriam ser levadas em conta e corrigidas (v. seção 2.5.2);

- $\quad$ Não deveriam se efetuar suposições otimistas a respeito da estabilidade ao longo do tempo de irradiação nem para a taxa de kerma, nem para os valores de temperatura e pressão, o que implica no cálculo e aplicação concomitante dos fatores de correção aplicáveis (v. equação 14).

Além disso, evidentemente, havia o compromisso de se proporcionar ao usuário uma interface gráfica que fosse tão esclarecedora quanto fácil de utilizar, não se poupando esforços em se evitar indicações que pudessem levar a erros de interpretação ou de operação, e, dentro do possível, prevendo as situações de exceção. Nesse sentido, pode-se dizer que o LabVIEW ${ }^{\mathrm{MR}}$ oferece amplos recursos, ficando a qualidade do resultado final limitada praticamente apenas pela habilidade do programador.

Os três programas que são descritos nas subseções seguintes são, na verdade, originários de uma mesma concepção, podendo cada um deles ser considerado uma versão modificada do outro. Os três deflagram um processo que se inicia com a abertura do obturador e que em seguida passa a ser comandado pelo eletrômetro UNIDOSE. Esse instrumento oferece um modo peculiar de operação denominado streaming mode, que só pode ser iniciado (e interrompido) através de comandos específicos via interface RS-232, pela qual o instrumento passa automaticamente a enviar - sem necessidade de qualquer requisição posterior - informações em sua taxa nominal de operação (duas leituras por segundo), até que receba um comando de término. O teclado de seu painel frontal permanece travado durante esse tipo de operação, assim evitando ações inadvertidas. A disponibilidade de tal recurso desempenhou um papel fundamental 
no desenvolvimento destes programas, tendo talhado alguns de seus aspectos mais fundamentais.

\subsubsection{Controle pelo tempo de exposição}

Conforme abordado na seção 2.5.2, para assegurar máxima precisão no tempo de exposição, é necessário aplicar correções para os atrasos inerentes aos subsistemas, traduzindo-se:

- $\quad$ Tempo de deslocamento mecânico do obturador;

- $\quad$ Constantes de tempo do circuito de acionamento do obturador;

- $\quad$ Tempos de resposta do eletrômetro e da câmara de ionização.

Geralmente não é trivial distinguir os atrasos causados pelo obturador e pelo sistema de medição. De acordo com os manuais dos equipamentos utilizados, pelo menos para câmaras de pequeno volume (da ordem de $1 \mathrm{~cm}^{3}$ ), o tempo de coleta de íons é da ordem de $0,1 \mathrm{~ms}$, de modo que pode ser considerado desprezível em relação aos demais atrasos e suas respectivas incertezas. Já o tempo de resposta de um eletrômetro é um pouco mais expressivo, dependendo inclusive do fundo de escala. No caso do UNIDOS E utilizado em conjunto com a câmara monitora, o valor nominal declarado pelo fabricante no manual é de $200 \mathrm{~ms}$ para as escalas High e Med, e 350 ms para a escala Low.

A partir do momento em que os primeiros protótipos do programa de controle simultâneo do obturador e do eletrômetro tornaram-se funcionais, passou a ser possível realizar medidas práticas para quantificar os intervalos de tempo associados às correções pretendidas. O relógio de tempo real do microcomputador foi utilizado para fornecer os instantes exatos de início e término do envio dos comandos de abertura e fechamento do obturador, uma vez que a resolução do temporizador do eletrômetro é de apenas $0,5 \mathrm{~s}$, ou seja, grosseira demais para os objetivos a se alcançar.

O menor intervalo de integração pré-programada para o UNIDOS E é de 6 segundos. Contribuir com menos de 0,5\% para a incerteza no tempo significa garantir o tempo de exposição efetiva com uma precisão melhor do que $30 \mathrm{~ms}$. O primeiro teste efetuado foi exclusivamente para avaliar se uma sub-rotina de temporização escrita em LabVIEW ${ }^{M R}$ (rodando, portanto, como um processo supervisionado pelo Windows $^{\mathrm{MR}}$ ) teria condições de atender a tal pré-requisito. 
A FIG. 4.1 mostra que, para um período pré-definido (tempo de espera desejado) de $100 \mathrm{~ms}$, o intervalo real proporcionado pelo LabVIEW ${ }^{\mathrm{MR}}$ situa-se entre $93 \mathrm{~ms}$ e $110 \mathrm{~ms}$, ou seja, no pior caso, pode-se esperar uma precisão de $10 \mathrm{~ms}$. Dessa forma, durante o projeto passou-se a admitir como limite de resolução o valor de $10 \mathrm{~ms}$ (ou 0,01s) para um sistema temporizado pelo LabVIEW ${ }^{\mathrm{MR}}$. Tal avaliação foi efetuada em ambiente normal do Windows ${ }^{\mathrm{MR}}$, rodando outros aplicativos que não requerem uso intensivo de CPU ou manuseio de tráfego de rede.

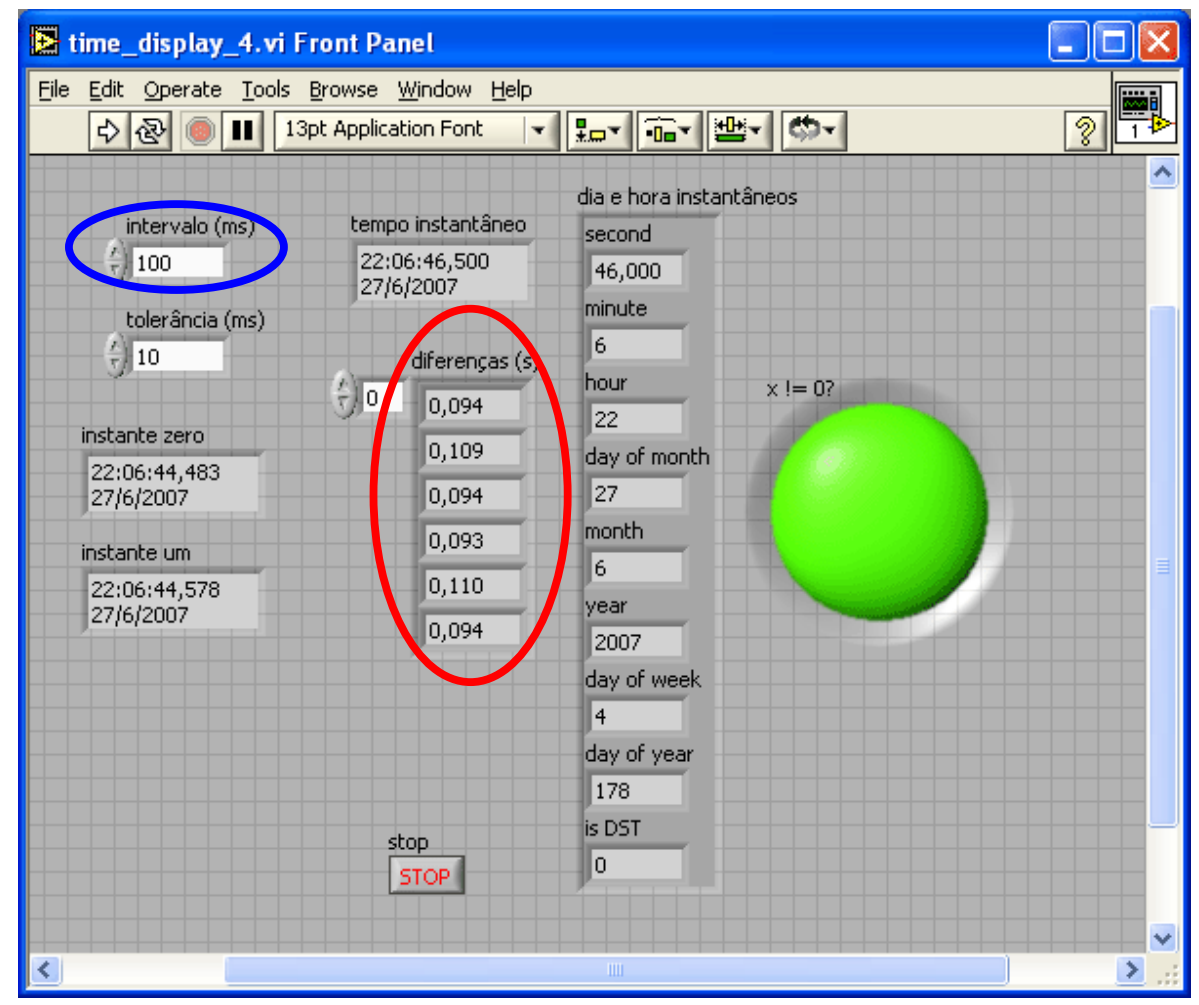

FIGURA 4.1 -

Painel do programa utilizado para avaliar a resolução da rotina de temporização do LabVIEW ${ }^{\mathrm{MR}}$ pela comparação entre o intervalo de tempo solicitado (azul), e .os efetivamente obtidos (vermelho).

O próximo passo foi o de avaliar o atraso efetivo introduzido pelo obturador e subsistemas correlatos. Ao invés de tentar-se estimar o erro global resultante da sobreposição dos erros nos instantes de abertura e fechamento, decidiu-se lançar mão de recursos distintos para avaliar os tempos de correção (de abertura e de fechamento) separadamente.

Uma característica marcante do algoritmo desenvolvido para o controle de carga (que na realidade foi escrito antes dos outros dois) foi o uso de uma sub-rotina da biblioteca interna do LabVIEW ${ }^{M R}$, capaz de ajustar velozmente um conjunto de pontos para uma reta pelo método dos mínimos quadrados. Os parâmetros de saída 
são: o coeficiente angular e a intersecção com o eixo $x$. Como o primeiro ponto fornecido pelo eletrômetro é invariavelmente $(0,0)$, ele deve ser desprezado para não interferir com o ajuste dos pontos subseqüentes. O programa trabalha com um conjunto inicial de onze pontos (esse número pode ser facilmente reconfigurado). Aliás, durante a execução do programa, os onze últimos pontos adquiridos são mantidos como buffer para fins de estimativa do instante de término da irradiação, conforme será explicado posteriormente. Mantendo-se o obturador artificialmente aberto, o tempo inicial de correção é aproximadamente zero (v. FIG. 4.2).

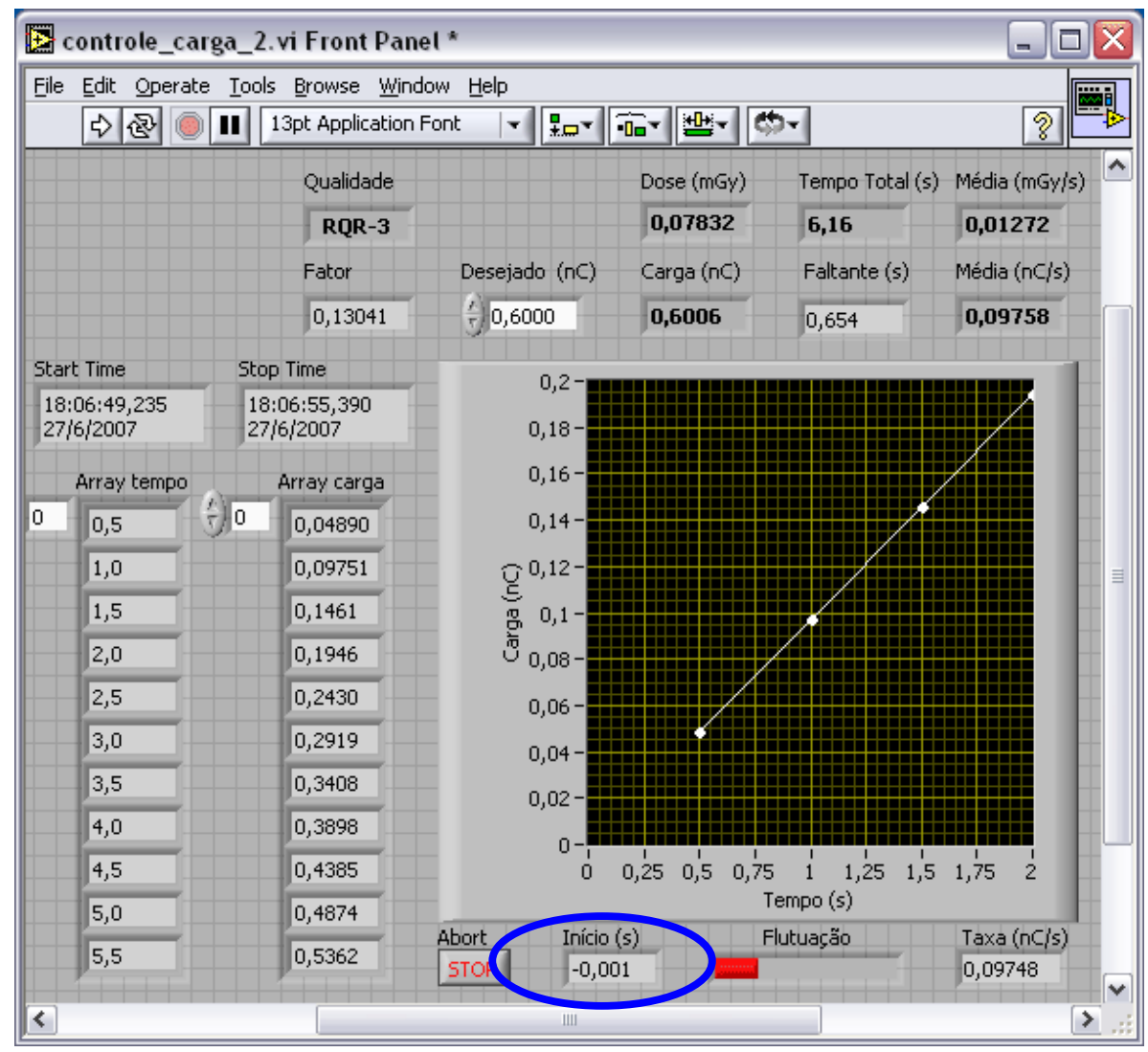

FIGURA 4.2 - $\quad$ Obturador é mantido artificialmente aberto antes do início da leitura; pode-se notar que o prolongamento da reta passa pela origem. Observa-se que o valor resultante para a correção é próximo de zero.

A FIG. 4.3 mostra a situação em que o comando de abertura é enviado quase simultaneamente com o de início das leituras. Observa-se que ocorre um deslocamento de $85 \mathrm{~ms}{ }^{(\dagger)}$. Nesse caso, o programa considera o início da irradiação como tendo ocorrido $85 \mathrm{~ms}$ depois do instante inicial. A grande vantagem desse

\footnotetext{
† Visando evitar o aquecimento excessivo do obturador durante longos períodos de exposição, posteriormente reduziu-se a tensão de alimentação de seu painel de controle de 220VAC para cerca de 190VAC, o que elevou o tempo estimado de abertura em cerca de $25 \mathrm{~ms}$.
} 
método reside no fato da reprodutibilidade não ser afetada por flutuações no comportamento do sistema de obturador, posto a correção ser recalculada toda vez que uma medida é iniciada.

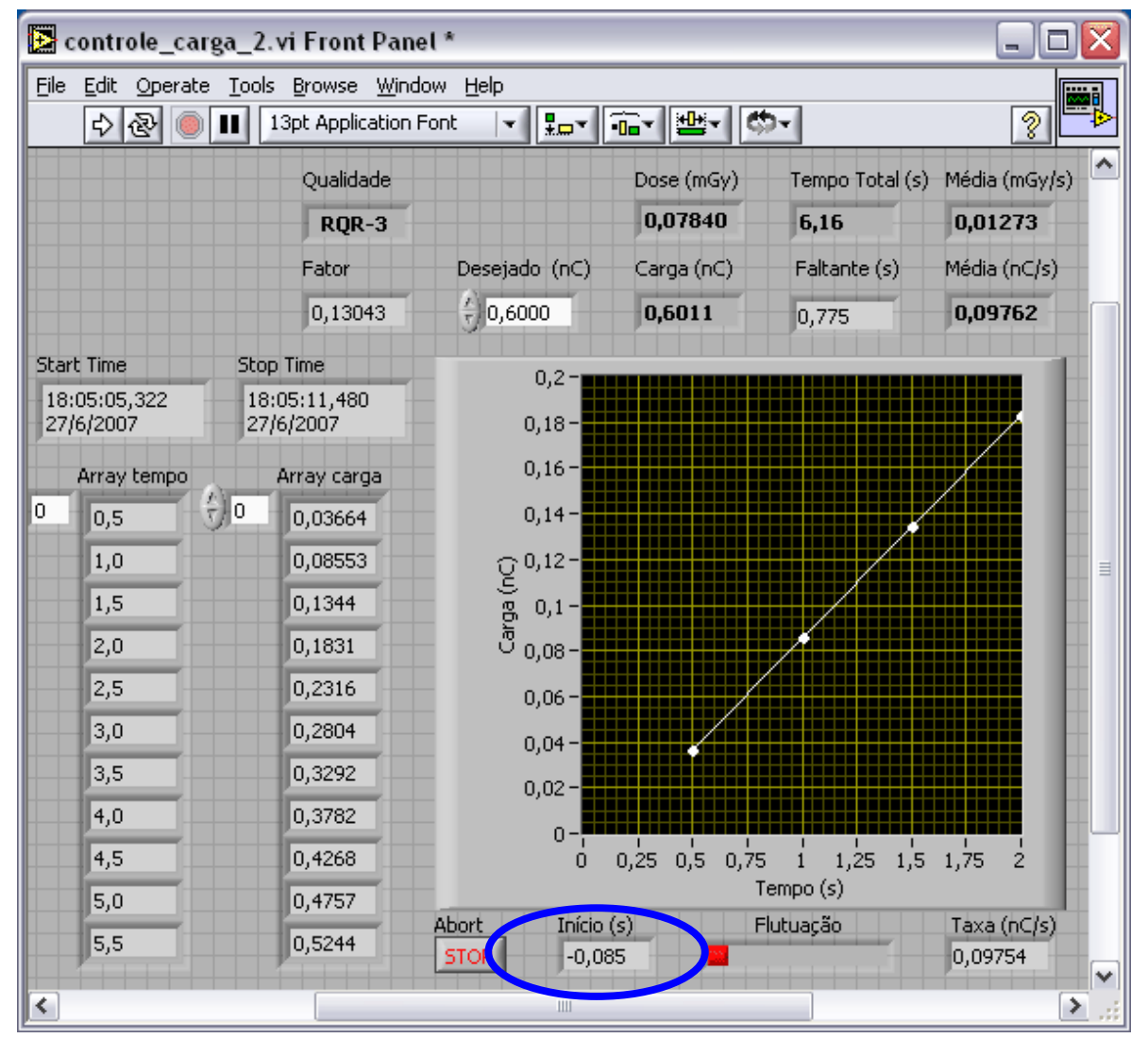

FIGURA 4.3 - $\quad$ Operação normal: o obturador se abre somente sob o comando remoto de início de leitura; o prolongamento da reta intercepta o eixo horizontal em $85 \mathrm{~ms}$. O programa estima esse valor a partir do conjunto inicial de pontos.

O próximo passo foi o de estimar e corrigir o erro associado ao atraso entre o envio do comando de fechamento do obturador, e o término da irradiação (fechamento efetivo do obturador e estabilização da leitura do eletrômetro).

Conforme dito anteriormente, os eletrômetros da PTW fornecem leituras em períodos de $0,5 \mathrm{~s}$. Um pequeno programa em LabVIEW ${ }^{\mathrm{MR}}$ foi rapidamente escrito com a finalidade específica de se avaliar qualitativamente o efeito do fechamento em diversos instantes intermediários. A FIG. 4.4 mostra seus resultados gráficos. 

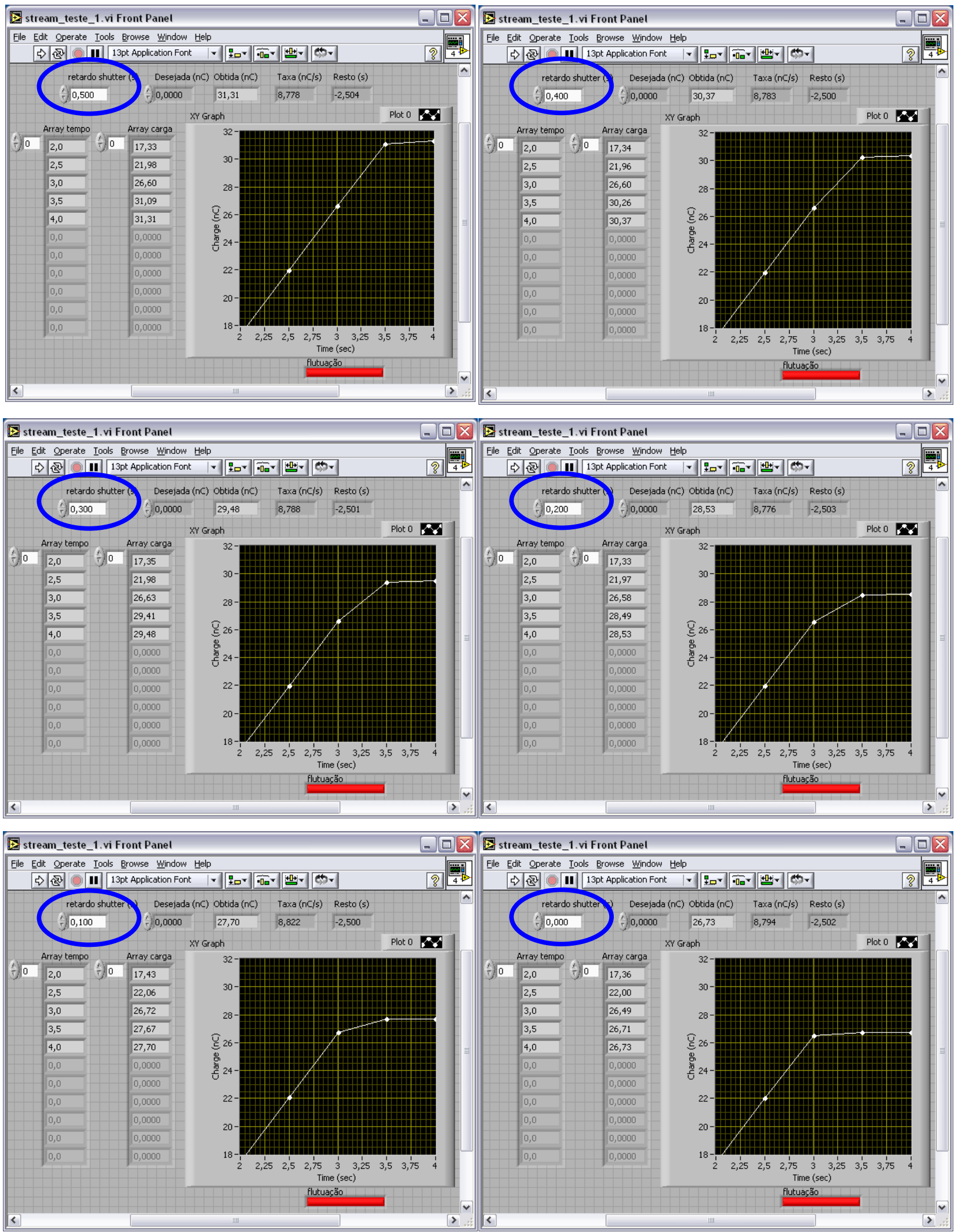

FIGURA 4.4 - $\quad$ Efeito da variação do instante de fechamento do obturador nas leituras finais de carga. O momento exato do envio do comando de fechamento é o instante $t=2,5 s$ acrescido do retardo (variável entre 0 e $0,5 \mathrm{~s}$ ). 
Nessa etapa, já havia sido determinado que o atraso entre o envio do comando, e o fechamento efetivo do obturador era de aproximadamente $0,5 \mathrm{~s}$ (essa estimativa foi feita a partir da extrapolação da reta cuja inclinação representa a taxa de kerma). A principal conclusão tirada da análise dessas figuras foi a necessidade de se aguardar mais um mínimo de 0,5 s (ou seja, colher-se ao menos mais um ponto de leitura) após o fechamento efetivo do obturador, possivelmente decorrente do tempo de resposta do conjunto eletrômetro / câmara de ionização.

O método prático utilizado para o acerto final do tempo de correção para o fechamento (na forma da antecedência com a qual o comando de fechamento deveria ser enviado para que o resultado desejado fosse obtido) foi:

- $\quad$ Estabelecer um feixe escolhendo um ponto de operação em que o gerador apresente boa estabilidade de curto prazo (no caso do HS 160, isso significa não utilizar tensões ou principalmente correntes muito baixas);

- $\quad$ Efetuar uma leitura de curta duração (para maximizar a influência do erro relativo na contagem do tempo), acompanhando pelo painel do programa o valor instantâneo da taxa de kerma;

- Ao término da leitura, confrontar esse valor com o da taxa média de kerma, que é o quociente entre a carga integrada e o tempo total estimado. Para confirmação de tendência, repetir o procedimento algumas vezes.

Caso a diferença sistemática entre os dois valores não seja desprezível, significa que a estimativa do atraso no tempo de fechamento do obturador precisa ser refeita. Esse método pressupõe que uma correção satisfatória para o atraso na abertura do obturador já está sendo aplicada. Se houver dúvidas quanto a isso, deve-se repetir o ensaio mantendo o obturador artificialmente aberto antes do início, e comparar-se os valores ${ }^{(\ddagger)}$. A FIG. 4.5 salienta em vermelho os valores a se comparar. Em azul, a comprovação da boa concordância entre os valores de tempo (esperado e obtido).

\footnotetext{
‡ Embora não tenha sido mencionado antes, o tempo efetivo de correção é $40 \%$ maior do que o atraso de abertura conforme estimado pelo método do ajuste de reta. Tal fato também foi atribuído ao tempo de resposta do eletrômetro e da câmara, tendo sido considerado na versão final do programa.
} 


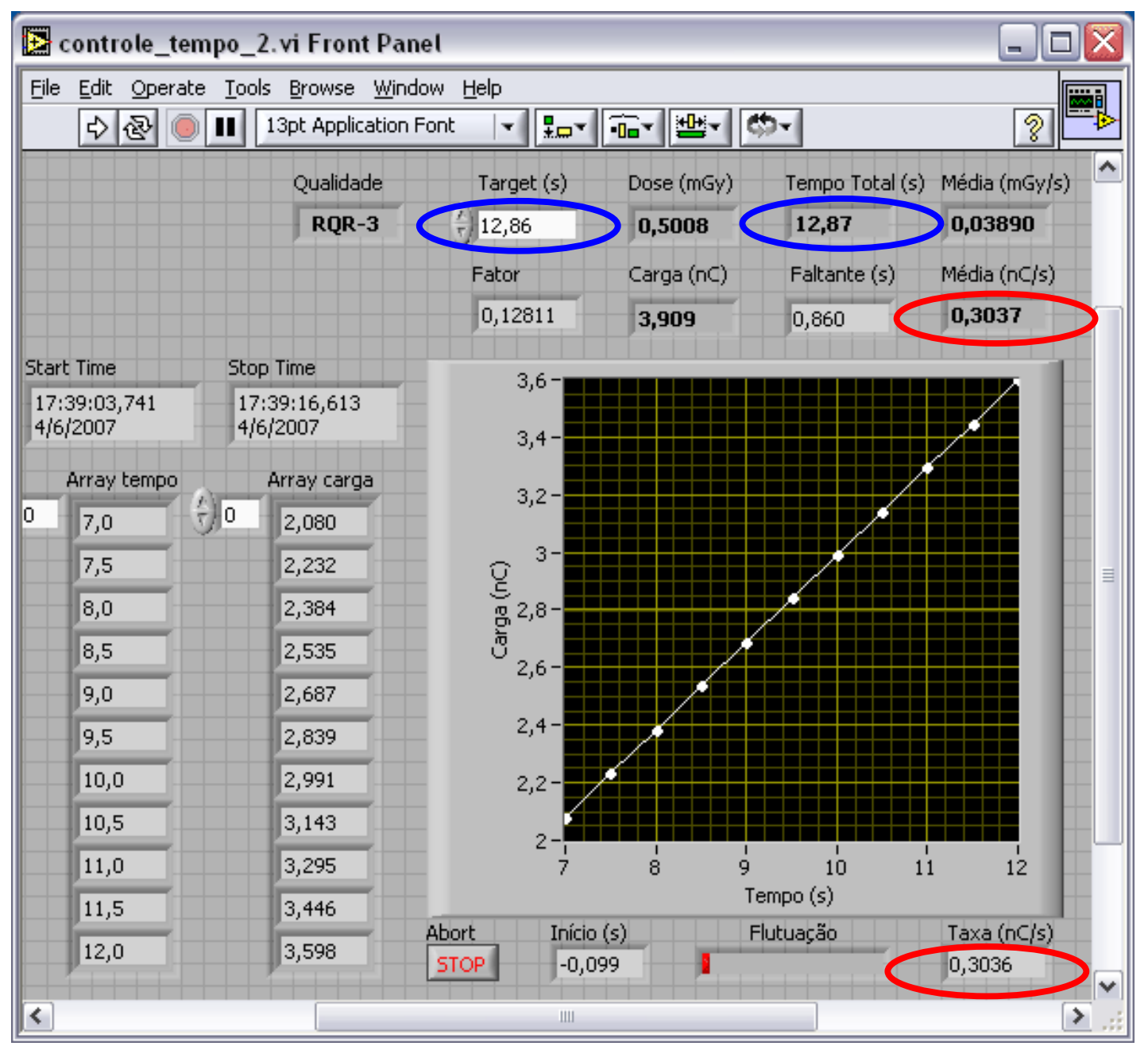

FIGURA 4.5 - $\quad$ Painel do módulo de programa de controle pelo tempo de exposição. Em azul: tempo desejado, e tempo obtido. Em vermelho: taxa de kerma (média global) em negrito, e taxa de kerma para o conjunto de 11 pontos mais recentes.

\subsubsection{Controle pela carga na câmara monitora}

Embora seja um recurso disponibilizado pelo fabricante (PTW, no caso), a metodologia vigente de aplicação dos eletrômetros do $\mathrm{LCl}$ não prevê nunca sua utilização em modo de unidades radiológicas - apenas em unidades elétricas. Todos os cálculos de conversão de carga para kerma, e de corrente para taxa de kerma, são efetuados em planilhas próprias para essa finalidade. Sem o conhecimento a priori do valor exato da taxa de kerma, os ensaios e calibrações dependem da determinação de valores desejados de tempo (ou de carga) associados ao kerma resultante, devidamente corrigido para as condições ambientais do laboratório durante a irradiação. Em outras palavras, pode-se assim dizer que o caminho para obter o controle do valor de kerma passa necessariamente pelo controle da carga na onipresente câmara monitora. Conceitualmente falando, essa é a essência da 
primeira parte deste trabalho; a segunda parte (irradiação simultânea das câmaras monitora e de referência) tem por objetivo apenas dar respaldo ao uso da câmara monitora como um padrão de trabalho através de sua calibração periódica.

Este foi o primeiro dos três programas desenvolvidos, tendo sido testado antes mesmo da implementação da sub-rotina de cálculo online do fator de correção para pressão e temperatura (descrita na seção seguinte). Sua parte principal é constituída por um loop temporizado pelo eletrômetro UNIDOS E operando em modo streaming, conforme comentado na seção 4.2. Durante sua execução, o programa utiliza o método da extrapolação a partir dos coeficientes de uma reta ajustada aos 11 pontos mais recentes para estimar o tempo faltante para que o valor desejado de carga seja atingido. Quando esse tempo for inferior a 1,5 segundos, a execução do loop é interrompida, e o valor de tempo faltante é entregue a uma seqüência de comandos de finalização, consistindo sucessivamente em:

- $\quad$ Coletar o tempo real a partir do relógio interno do microcomputador, e subtrair um valor empiricamente pré-determinado (cerca de $170 \mathrm{~ms}$ ) que propicia a desejada coincidência entre os valores médio e instantâneo da taxa de kerma (o instante inicial já havia sido determinado pela técnica descrita na seçao 4.2.1);

- $\quad$ Aguardar o tempo necessário (igual ao valor estimado pelo loop, subtraído de cerca de $500 \mathrm{~ms}$ para compensar os atrasos elétricos e mecânicos), e enviar o comando digital para o fechamento do obturador;

- $\quad$ Dar tempo suficiente, incluindo uma pequena folga (cerca de 1,3s) para que o eletrômetro estabilize sua leitura, e interromper o modo streaming, enviando um comando para destravar o teclado de painel (devolver o controle manual ao operador);

- $\quad$ Obter a última leitura de carga (após estabilizada), e fechar a porta serial.

Embora o relógio do computador seja consultado em dois instantes - no início, e no final da aquisição dos dados, quem efetivamente controla o programa em tempo de execução é o eletrômetro em modo streaming, funcionando com se fosse o "metrônomo" do loop. Felizmente, sua cadência de 0,5s é lenta o bastante para que haja tempo mais do que suficiente para o loop executar uma série de outras atividades, tais como calcular os fatores de correção ambiental, atualizar o gráfico na tela, e estimar o tempo faltante. 


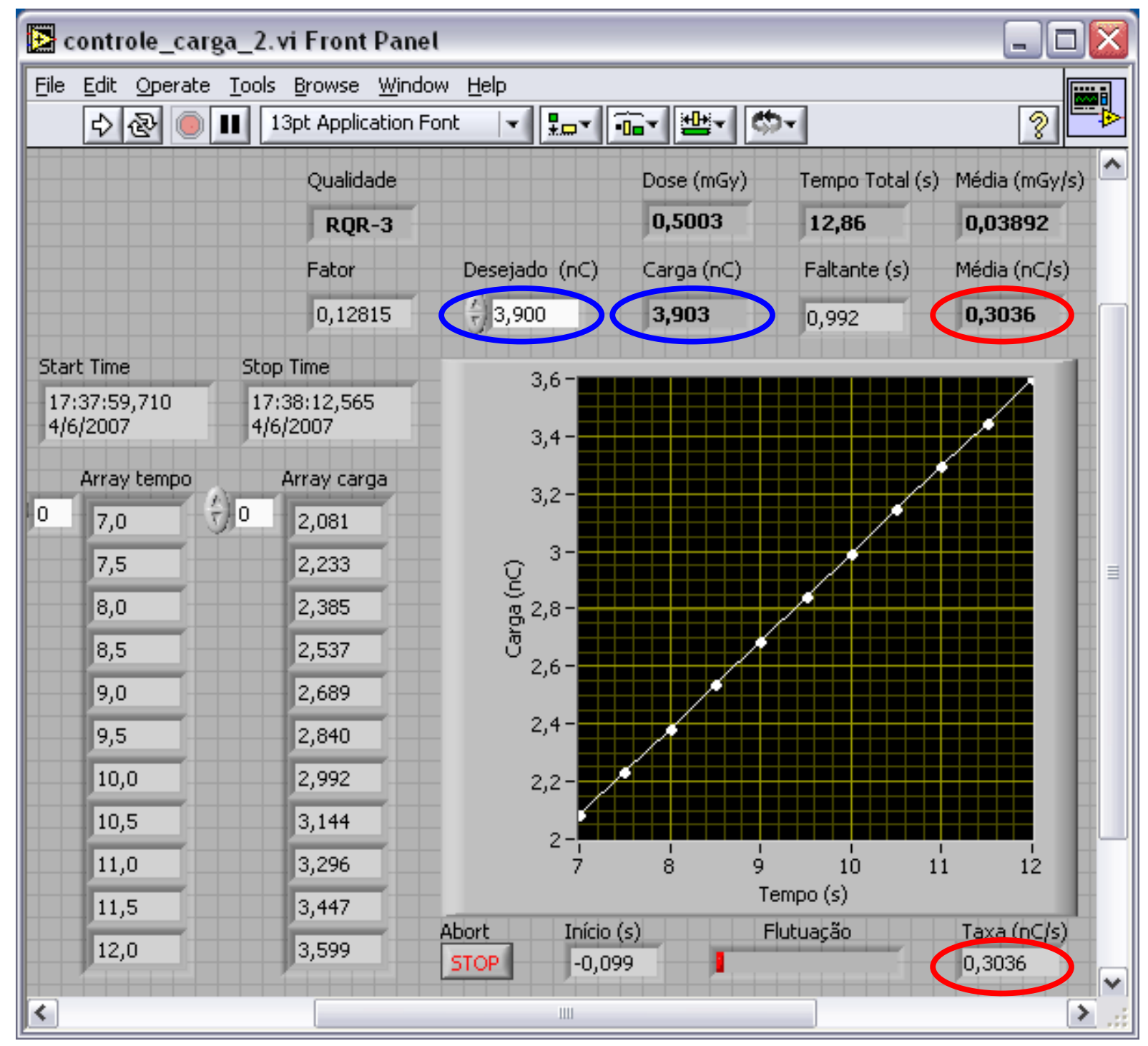

FIGURA 4.6 - Painel do módulo de programa de controle pela carga na câmara monitora. Em azul: carga desejada, e carga obtida. Em vermelho: taxa de kerma (média global) em negrito, e taxa de kerma para o conjunto de 11 pontos mais recentes.

O sucesso da técnica utilizada baseia-se no fato que o gerador de raios $X$ estabelece uma taxa de kerma com boa estabilidade de curto prazo, exceto para correntes extremamente baixas. Para a deteção e sinalização de eventuais flutuações questionáveis, foi adicionado ao painel um bargraph vermelho cuja indicação é proporcional ao desvio padrão associado à regressão linear dos 11 últimos pontos (visíveis no gráfico). Sua sensibilidade foi ajustada de tal modo que, em operação normal, não se aproximará da metade da escala. Em caso de flutuação repentina na taxa de kerma, a barra ilumina-se toda em vermelho, chamando a atenção do operador para uma provável anomalia. 
Caso surjam diferenças entre os valores desejado e obtido de carga (salientados em azul na FIG. 4.6), deve-se proceder a uma verificação do tempo de correção para fechamento do obturador, uma vez que, ao contrário do atraso de abertura, este não é recalculado a cada execução. Para uma melhor reprodutibilidade, adicionou-se deliberadamente uma constante de tempo elétrica ao circuito de comando remoto, com o intuito de diluir a contribuição de eventuais variações no tempo de fechamento do obturador propriamente dito à incerteza global.

\subsubsection{Controle pelo kerma na câmara monitora}

Ao contrário de alguns laboratórios de referência, o $\mathrm{LCl}$ não possui um sistema de condicionamento de ar capaz de garantir uma alta estabilidade ou homogeneidade de temperatura na sala de irradiação. $O$ trocador de calor do tubo de raios $\mathrm{X}$, bem como seu gerador de alta tensão contribui para o estabelecimento de um gradiente de temperatura que afeta principalmente a câmara monitora, em decorrência de sua posição física dentro do arranjo. Além disso, embora seja menos usual, podem ocorrer variações de pressão não desprezíveis ao longo de ensaios mais prolongados.

Com a disponibilidade de instrumentos aptos a efetuar medições altamente precisas de temperatura e pressão (Hart 1529 e Druck 142, respectivamente, conforme mencionado no capítulo 3) e enviar prontamente os resultados a um microcomputador através da interface serial, efetuar correções ambientais em tempo real tornou-se uma tarefa simples. A sub-rotina "le_fator" foi escrita em LabVIEW MR para desempenhar as seguintes tarefas:

- $\quad$ Consultar a temperatura do sensor (termistor) conectado ao Hart 1529 (canal correspondente à câmara monitora), o qual foi previamente configurado para fornecer o valor médio das 10 últimas leituras, efetuadas a uma taxa de uma leitura a cada segundo;

- $\quad$ Solicitar leitura da pressão absoluta ao barômetro Druck 142, o qual foi previamente configurado para fornecer as leituras expressas na unidade $\mathrm{kPa}$ (kilopascal);

- Consultar a sub-rotina "selecao" de armazenamento dos valores de $N_{k}$ (fator de calibração da câmara monitora para os valores padrão de 
pressão e temperatura) e de $K_{q}$ (fator de dependência energética da câmara monitora) para uma qualidade de feixe previamente caracterizada;

- $\quad$ Determinar o coeficiente de calibração resultante do produto de $\mathrm{Nk}, \mathrm{Kq}$ e ktp (calculado conforme a equação 14 da seção 2.2).

Essa sub-rotina ("le_fator") é chamada no início da execução do programa, e depois ciclicamente a cada execução do loop.

A chave do sucesso da técnica utilizada está no fato de se aplicar o fator de calibração (corrigido online para pressão e temperatura) somente aos incrementos de carga, e não a seu valor acumulado. Em seguida, o loop reintegra os valores de dose incremental por intermédio de uma somatória (a implementação deste conceito viu-se extremamente simplificada pela aplicação de um recurso característico do controle de loops dentro do LabVIEW ${ }^{\mathrm{MR}}$ - o uso de shift registers). Dessa maneira, eventuais variações de pressão e temperatura ao longo da irradiação produzirão um efeito apenas prospectivo - e não retrospectivo - sobre o valor-alvo (target) de carga. Conforme se pode observar pela similaridade do painel frontal (v. FIG. 4.7) em relação ao anteriormente apresentado, este módulo é totalmente similar ao de controle pela carga, uma vez que quem define o momento exato de término da irradiação continua sendo a carga, com a diferença que seu valor é dinamicamente atualizado ao longo do tempo, de modo a assegurar que o valor desejado de kerma (e por conseguinte de dose) seja obtido. Aliás, tanto o programa de controle pela carga, como o de controle pelo tempo, também incorporam esta metodologia, só que apenas para fins de cálculo e display do kerma. 


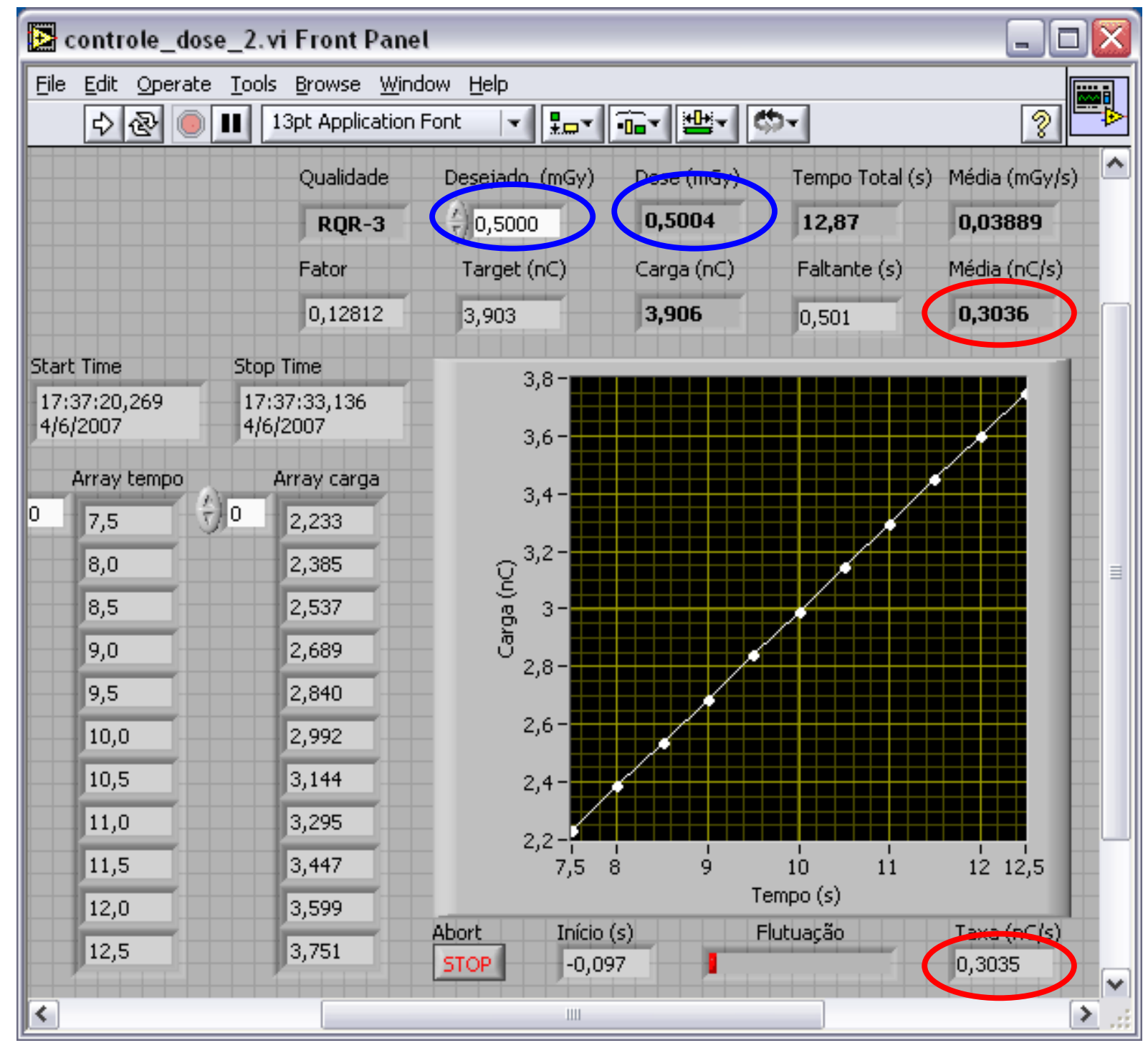

FIGURA 4.7 - $\quad$ Painel do módulo de programa de controle pelo kerma na câmara monitora. Em azul: kerma desejado, e kerma obtido. Em vermelho: taxa de kerma (média global) em negrito, e taxa de kerma para o conjunto de 11 pontos mais recentes.

\subsection{Programa de calibração da câmara monitora pela câmara de referência}

A validação do método de se utilizar a câmara monitora como padrão de trabalho, ou seja, como elo legítimo e rastreável da cadeia de calibração, e não apenas para meras checagens de rotina da taxa de kerma, como era feito antes, requer que seja estabelecido um rígido procedimento de calibração dessa câmara em relação ao sistema de referência do laboratório. Embora a periodicidade ideal de realização desse procedimento ainda não tenha sido totalmente estabelecida, é esperado que inicialmente tenha que ser repetido pelo menos numa base mensal, 
até haver um maior conhecimento do comportamento da câmara de transmissão, principalmente no que diz respeito a sua estabilidade de longo prazo.

O método padrão consiste em irradiar simultaneamente as duas câmaras em condições de referência, ou seja, para as qualidades de feixes já estabelecidas, e aplicando-se os fatores de correção para pressão e temperatura. A tarefa parecia simples diante das dificuldades encontradas durante 0 desenvolvimento dos programas anteriores; bastaria incluir os comandos de comunicação com o eletrômetro UNIDOS utilizado em conjunto com a câmara de referência. Na prática, este revelou uma série de peculiaridades na forma de diferenças funcionais em relação ao UNIDOSE que passamos a descrever. O conjunto de comandos via interface RS-232 é muito limitado, especialmente quando comparado a instrumentos de projeto mais moderno; o tempo de resposta aos comandos da interface é lento, quando comparado ao UNIDOS E; além disso, inexiste o modo streaming que havia se revelado tão útil no desenvolvimento dos programas anteriores. Por outro lado, embora o display assim não sugerisse (por marcar apenas segundos inteiros), a taxa de amostragem é a mesma do UNIDOS E (duas leituras por segundo), tornando-o a princípio funcionalmente equivalente do ponto de vista do programador.

A abordagem inicialmente adotada de enviar comandos simultâneos de início e término de leitura a ambos os eletrômetros revelou imediatamente um problema: o UNIDOS mostrou-se quase um segundo mais lento do que o UNIDOS E para iniciar a integração. Com isso, tornava-se impossível garantir a igualdade de tempos caso os comandos de término fossem enviados simultaneamente. A tentativa de contornar esse problema buscando um valor de "antecedência" (avanço de tempo) para o início do UNIDOS resultou infrutífera, pois invariavelmente ocorria uma incerteza de $0,5 \mathrm{~s}$ no final do período. Esse problema foi atribuído à combinação de dois fatores: a lentidão de resposta do UNIDOS, e a falta de sincronismo entre os clocks internos dos dois eletrômetros.

Embora uma normalização tenha sido adotada para corrigir a leitura do UNIDOS sempre que o tempo final de integração for diferente do UNIDOS E, evitando assim que o usuário tire conclusões acidentalmente errôneas a partir dos resultados na tela (aliás, essa situação só ocorre no caso do operador pressionar o botão Abort no painel frontal do programa), a solução encontrada para garantir incondicionalmente a igualdade de tempos foi a seguinte: enquanto o UNIDOS E 
trabalha mais uma vez em modo streaming, o período de cada execução do loop principal fica a ele vinculado, ou seja, é de precisamente meio segundo. Iniciando-se ligeiramente na frente (dois terços de segundo, no caso) a contagem pelo UNIDOS E, ele passa a ser o primeiro a terminar. Depois, o loop passa a rodar numa velocidade maior (inferior a $200 \mathrm{~ms}$ ), limitada apenas pelo tempo de resposta do UNIDOS aos comandos de leitura. Isso garante que o comando de interrupção $(H O L D)$ seja enviado com a antecedência necessária para que seja sempre respeitado no próximo ciclo de leitura.

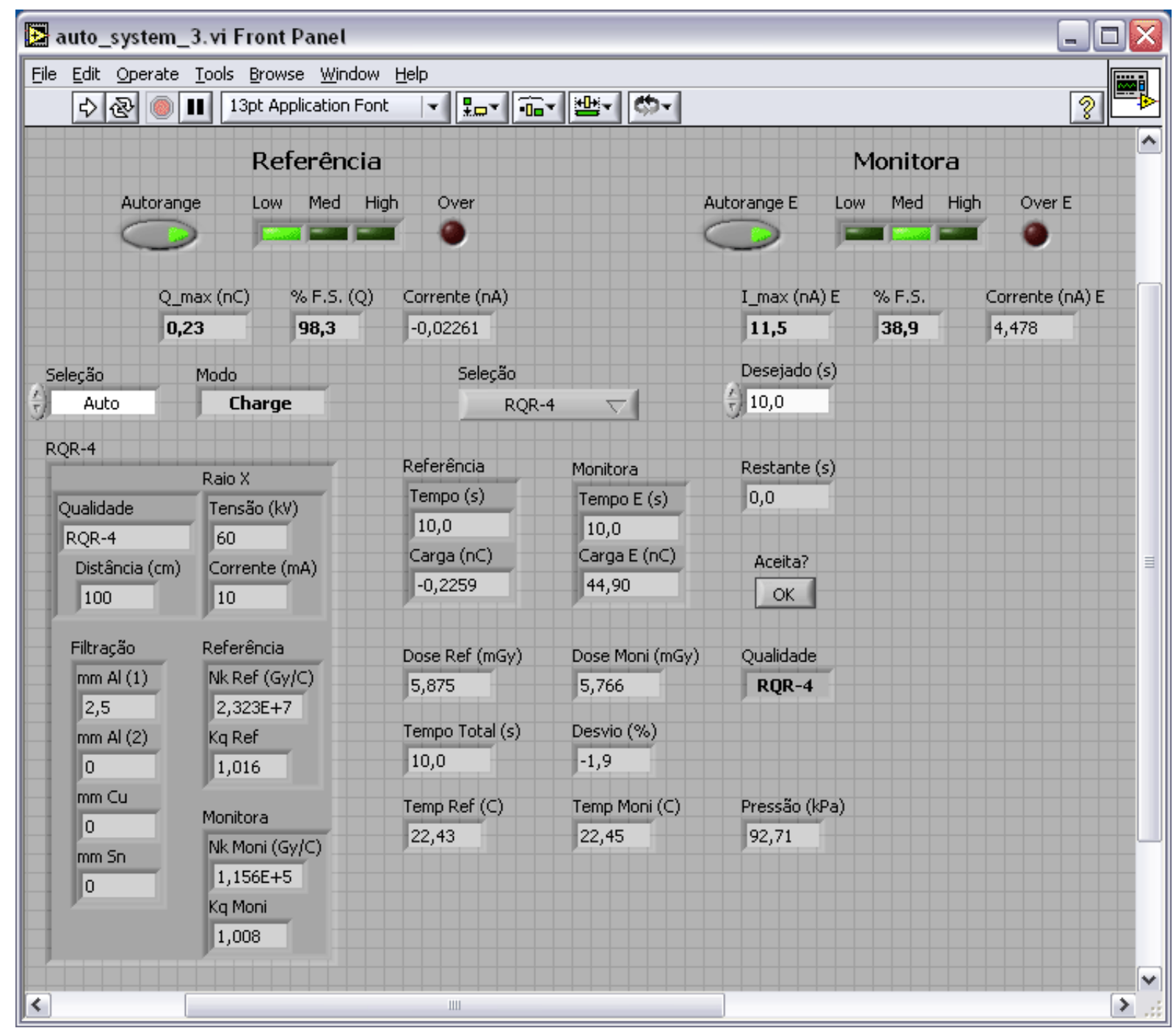

FIGURA 4.8 - $\quad$ Painel frontal do programa de calibração da câmara monitora. As informações adicionais referentes à qualidade de feixe (tensão, corrente, filtração) são apenas para fins de orientação do técnico de laboratório.

Embora possa parecer estranho à primeira vista o fato de não ter sido feita a opção de acionar os eletrômetros em modo "INT" (atribuindo-Ihes um intervalo 
pré-fixado de integração), o fato é que não foi encontrada uma maneira simples de alterar o tempo de integração do UNIDOS através da interface RS-232, por falta de um comando específico para tal finalidade (apenas comandos de incremento e decremento em passo fixo de 1 segundo). O mesmo não ocorre com o UNIDOS E, porém, do ponto de vista do programa conforme desenvolvido, a conveniência de utilizá-lo em modo streaming acabou sendo determinante.

Ao ser inicializado (e finalizado), o programa envia comandos de abertura (e de fechamento) do obturador apenas para poupar o operador da execução manual dessa tarefa. Diferentemente dos casos discutidos na seção anterior, não se realiza qualquer tipo de temporização do obturador; apenas o tempo de integração dos eletrômetros será levado em conta durante as medições. As câmaras são irradiadas antes do início dos intervalos de integração (a partir do momento em que aparece a tela de prompt para a escolha da qualidade dos feixes), e o fechamento ocorre somente após o término das leituras e coleta dos resultados. Essa situação tornou não apenas possível, como desejável a implementação de uma característica de autorange não originalmente disponível nesses eletrômetros.

Conforme já citado em outra parte deste trabalho, tanto o UNIDOS quanto - UNIDOS E possuem três escalas de corrente: Low, Med, e High, varrendo cada uma cerca de duas ordens de grandeza, ou seja, o final de cada escala corresponde a aproximadamente $1 \%$ do fundo da escala seguinte. Os fundos das escalas Med e High passam ligeiramente de $10 \mathrm{nA}$, e de $1 \mu \mathrm{A}$, respectivamente; no caso da escala Low, situa-se entre 100pA e 200pA. Curiosamente, existem pequenas variações no valor de fundo da escala Low de um instrumento para outro, conforme seu número de série.

Para evitar comutações oscilatórias na transição de uma escala para outra, utilizou-se a técnica tradicional de se incluir pequenas faixas de histerese. $O$ método de deteção do estado de overange foi distinto para os dois instrumentos, pois somente o UNIDOS envia um string específico para identificar esse status. No caso do UNIDOS E, foi necessário comparar o valor fornecido da leitura com o do fundo de escala (que pode ser obtido a partir de um comando específico através da interface). Adicionalmente, foram feitas provisões para a escolha manual de escalas via computador, caso o operador necessite. Em todas as situações, o programa 
fornece indicações de fundo de escala, porcentagem sendo utilizada, além da corrente propriamente dita (v. FIG. 4.8).

Considerando-se que as medidas a se efetuar durante o procedimento de calibração são de carga, e não de corrente, pode inicialmente causar estranheza o fato de se haver implantado rotinas para o controle das escalas de corrente dos eletrômetros. O fato é que existe uma diferença fundamental entre os modelos UNIDOS, e UNIDOSE, quando em modo carga. A realidade é que o modelo UNIDOS não possui um modo carga verdadeiro; suas leituras de carga são sempre decorrentes da integração digital das leituras de corrente. Diga-se de passagem, para quem o utiliza pela interface RS-232, é indiferente o modo em que ele estiver, por se tratar apenas de uma opção de display; ambas as grandezas (carga e corrente) são sempre acessíveis através da interface.

Contrariamente ao que ocorre com o UNIDOS E, no caso do UNIDOS é necessário que esteja no modo desejado para que, quando consultado pela interface, envie a informação esperada. Mas não é necessário que o operador se preocupe com isso, pois o programa se encarrega de fazê-lo.

O eletrômetro UNIDOS também pode trabalhar dessa maneira; ele oferece um modo chamado "Integral Current $d t$ " que equivale ao modo Charge do UNIDOSE. A principal utilidade desse recurso é contornar os problemas de overrange que podem ocorrer com certa facilidade quando utilizado em modo Charge (que neste caso corresponde ao modo carga verdadeiro, em que um capacitor interno de referência acumula a carga proveniente da câmara de ionização).

O UNIDOS utilizado possui apenas duas escalas de carga (verdadeira): $230 \mathrm{pC}$, e $23 \mathrm{nC}$. Para que o programa pudesse fazer a melhor escolha da escala a ser utilizada, é absolutamente necessário conhecer a priori: a corrente, e o tempo pretendido de exposição. Como a taxa de kerma do ISOVOLT HS 160 (e portanto a corrente na câmara de referência) pode ser considerada razoavelmente constante (pelo menos dentro de $2 \%$ ), pode-se estimar o valor final de carga simplesmente multiplicando-se esses valores. Caso seja previsto o overrange da segunda escala $(23 n C)$, o programa comutará automaticamente para o modo integral de corrente quando do início da integração. 
Há também provisões para a seleção manual (forçada) tanto do modo integral, como do modo carga. Nesse último caso, se for previsto o "estouro" da escala maior de carga, o programa passa a emitir um aviso sonoro intermitente. No caso de mesmo assim o operador autorizar o início da leitura, o programa limitará o tempo de exposição ao maior valor possível sem que ocorra overrange, além de gerar uma notificação visual em vermelho para esse valor. Tais medidas visam não apenas evitar que se percam leituras, como também induzir o operador a fazer o melhor uso possível do equipamento, através da escolha judiciosa de escalas. $\mathrm{Na}$ prática, o melhor a se fazer será sempre deixar os modos automáticos ligados, apenas observando as decisões do programa. No caso de alguma medição resultar no uso de uma porcentagem muito baixa do fundo de escala (tipicamente ao redor de $1 \%$, o que tende a causar uma dilatação da incerteza associada à leitura), devese, quando possível, considerar a possibilidade de alterar algum parâmetro de irradiação, como o tempo de exposição, ou a taxa de kerma, por exemplo. Nesse sentido, as informações visuais do painel do programa revelam-se sumamente úteis, auxiliando o técnico a tomar decisões, quando necessário.

A próxima etapa consistiu em avaliar o kerma a partir dos coeficientes de calibração das duas câmaras (monitora e de referência) conforme armazenados numa sub-rotina que serve como pequena biblioteca de consulta para todas as qualidades de feixes implantados no LCl. Essa biblioteca contém um array de clusters compostos por:

\footnotetext{
- $\quad$ Strings de identificação da qualidade;

- $\quad$ Tensão de feixe (em kV);

- $\quad$ Corrente de feixe (em mA);

- $\quad$ Distância entre o foco e o ponto de irradiação (em cm);

- $\quad$ Espessura do filtro de alumínio (em mm);

- $\quad$ Espessura (e material) da filtração adicional (em mm);

- $\quad$ Valores de $N_{k}(\mathrm{em} \mathrm{Gy} / \mathrm{C})$ e de $K_{q}$ para cada uma das câmaras.

$\mathrm{Na}$ prática, somente estes últimos valores são utilizados para fins de cálculo; os demais são para fins de display somente.

As principais saídas do programa são:

- $\quad$ os valores de kerma avaliados segundo cada uma das câmaras;
} 
- $\quad$ o desvio porcentual da estimativa de kerma pela câmara monitora em relação ao mesmo valor pela câmara de referência;

- $\quad$ os tempos de integração em cada um dos eletrômetros, normalmente iguais entre si ${ }^{(\$)}$;

- $\quad$ o valor de pressão, e os valores de temperatura em cada uma das câmaras, lidas ao término do tempo de integração;

- $\quad$ aquele que deveria ser o novo valor do coeficiente de calibração (correspondente ao produto $N_{k} \cdot K_{q}$, devidamente corrigido para os valores padrão de pressão e temperatura) para que a câmara monitora passasse a fornecer um resultado coincidente com o da câmara de referência.

Neste tipo de ensaio, como os tempos de exposição são geralmente curtos, é razoável admitir-se que as variações de pressão e temperatura durante a exposição sejam pequenas. O que se faz normalmente é colher um certo número de leituras, para que se possa depois determinar um valor médio, e um desvio padrão associado às incertezas do tipo A. Ao final de cada rodada, novos valores de pressão e temperatura serão sempre colhidos, de modo que eventuais variações entre leituras sucessivas serão efetivamente consideradas e corrigidas.

Não foi previsto nenhum recurso de transcrição automática destes resultados de calibração para as pequenas bibliotecas de armazenamento das qualidades de feixes (escritas em LabVIEW ${ }^{M R}$ ). Entendeu-se que a atualização desses valores deverá ser antecedida por uma judiciosa análise prévia dos resultados. Conforme será exposto na seção de discussões, nesta fase de implantação, tende a ser mais conveniente trabalhar no sentido de facilitar a exportação de resultados para algum tipo de planilha.

Com a finalidade de se avaliar o desempenho do sistema resultante, partiu-se inicialmente para um ensaio prático de utilização do programa de calibração descrito neste item. Optou-se por varrer todas as qualidades RQR disponíveis no LCl (ou seja, RQR-3 a RQR-10). A TAB. 4.1 sintetiza os principais resultados obtidos. Seguiu-se um achado inesperado.

\footnotetext{
$\S$ Exceto no caso de se haver pressionado o botão Abort". Ainda assim, a leitura do UNIDOS é normalizada para o tempo do UNIDOS E, de modo a permitir que os valores indicados para o kerma sempre possam ser diretamente comparados. Há ainda uma segunda causa, associada a um comportamento anômalo do UNIDOS, conforme discutido em seguida.
} 
TABELA 4.1 - Resultados de um ensaio de avaliação do erro porcentual do valor de kerma estimado pela câmara monitora, quando comparado à câmara de referência, para diferentes escalas do eletrômetro UNIDOS.

\begin{tabular}{c|cc||ccc|c}
\hline Qualidade & \multicolumn{9}{c}{$\begin{array}{c}\text { Escala } \\
230 \mathrm{pC}\end{array}$} & \multicolumn{3}{c}{$\begin{array}{c}\text { Escala } \\
23 \mathrm{nC}\end{array}$} & \multicolumn{2}{c}{$\begin{array}{c}\text { Escala } \\
\text { Integral I dt }\end{array}$} \\
\hline & $\begin{array}{c}\text { Tempo de } \\
\text { exposição (s) }\end{array}$ & $\begin{array}{c}\text { Erro relativo } \\
(\%)\end{array}$ & $\begin{array}{c}\text { Tempo de } \\
\text { exposição (s) }\end{array}$ & $\begin{array}{c}\text { Erro relativo } \\
(\%)\end{array}$ & $\begin{array}{c}\text { Fundo de } \\
\text { Escala } \\
(\% \text { aprox.) }\end{array}$ & $\begin{array}{c}\text { Erro relativo } \\
\text { (\%) }\end{array}$ \\
RQR-3 & 15 & $-1,9$ & 16 & $-1,9$ & $<1$ & $-2,1$ \\
RQR-4 & 10 & $-1,7$ & 11 & $-1,8$ & $<1$ & $-2,1$ \\
RQR-5 & 7 & $-1,7$ & 75 & $-1,6$ & $\sim 10$ & $-1,9$ \\
RQR-6 & $N A$ & $N A$ & 60 & $-1,5$ & $\sim 10$ & $-1,7$ \\
RQR-7 & $N A$ & $N A$ & 45 & $-1,5$ & $\sim 10$ & $-1,7$ \\
RQR-8 & $N A$ & $N A$ & 40 & $-1,4$ & $\sim 10$ & $-1,6$ \\
RQR-9 & $N A$ & $N A$ & 30 & $-1,5$ & $\sim 10$ & $-1,8$ \\
RQR-10 & $N A$ & $N A$ & 20 & $-1,2$ & $\sim 10$ & $\left({ }^{*}\right)$ \\
\hline
\end{tabular}

NA - fora do alcance da escala; o tempo mínimo de integração foi limitado em 6,5s.

$\left(^{*}\right)$ - O valor inicialmente obtido foi de cerca de $-4,3 \%$.

A biblioteca de fatores de calibração continha valores resultantes de um levantamento efetuado em meados de fevereiro de 2007, ou seja, cerca de 4 meses antes deste ensaio. Diante do bom resultado quando em modo carga, a diferença encontrada para RQR-10 quando da utilização do modo integral de corrente foi considerada inaceitável. Uma investigação posterior revelou um fato inesperado: para uma determinada faixa de porcentagem do fundo da escala baixa de corrente (entre 56\% e 69\%), ao se iniciar uma leitura por corrente integrada através de comando via interface, o instrumento assume um valor inicial errôneo (inesperadamente positivo, sendo que neste caso a corrente era negativa) para a primeira leitura propriamente dita, desconsiderando-o ponto inicial $(0,0)$. Esse estranho fato que se observou sob tais condições específicas pôde também ser visualizado no display (LCD) do instrumento, e ocorreu de maneira sistematicamente consistente, tendo sido atribuído a um comportamento anômalo do aparelho possivelmente um bug do firmware, cuja versão foi identificada como sendo 2.20i. Através da FIG. 4.9 pode-se ilustrar esquematicamente o que se observou. 


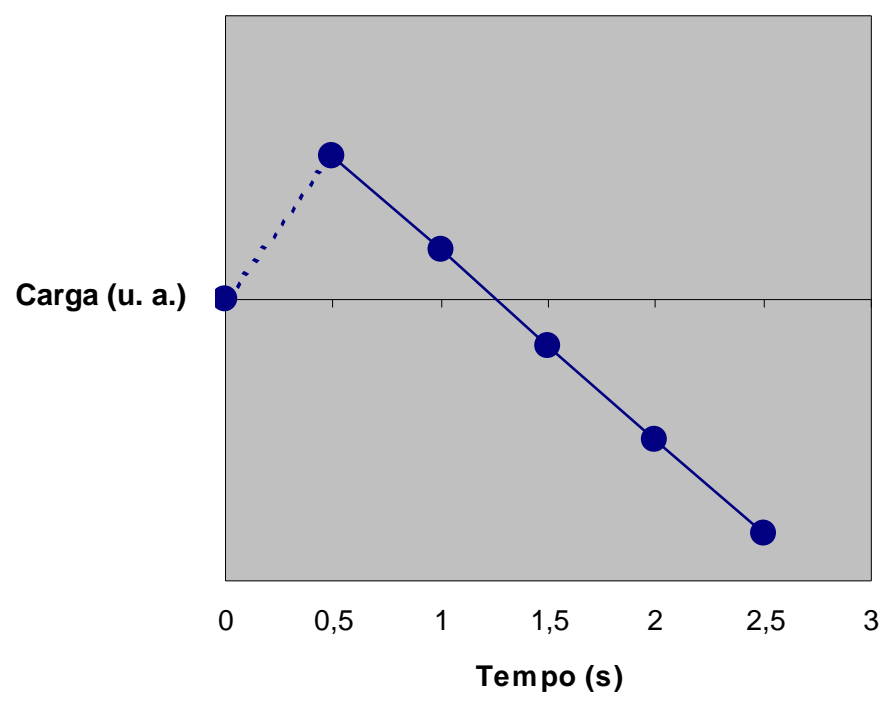

FIGURA 4.9 - Representação da anomalia de operação encontrada durante a utilização via interface do modo "integral de corrente" do eletrômetro UNIDOS. A câmara estava sendo polarizada com uma tensão negativa, e irradiada com uma taxa de kerma constante, correspondente a cerca de $60 \%$ do fundo da escala baixa de corrente. $\mathrm{O}$ valor de cruzamento da reta ajustada aos pontos (desconsiderandose $o$ inicial, coincidente com a origem) com o eixo $X$ foi sistematicamente igual a $1,25 \mathrm{~s}$.

Uma vez descartada a possibilidade de ocorrência de erro causado pelo programa em LabVIEW ${ }^{M R}$ (pois até mesmo enviando-se o comando de início de leitura por intermédio do freeware "RComSerial", o indesejável fenômeno se repetia), passou-se a tentar utilizá-lo na solução do problema. Descartando-se o primeiro ponto (origem), e executando mais uma vez a rotina de regressão linear da biblioteca interna do LabVIEW ${ }^{\mathrm{MR}}$ para os 11 pontos subseqüentes, determina-se precisamente o ponto de intersecção da reta ajustada com o eixo X. Esse valor é subtraído do tempo final de integração para o UNIDOS. É como se a integração houvesse iniciado em $t=1,25 \mathrm{~s}$, e não em $t=0$. Embora tenha sido sempre $1,25 \mathrm{~s} o$ valor observado nas situações de ocorrência da anomalia, ele não é de maneira alguma pressuposto; fica sempre a cargo da rotina de ajuste linear a determinação desse valor.

A ocorrência de um problema inesperado, seguido da rápida implementação de uma solução via software, serviu inclusive para atestar a flexibilidade e versatilidade do LabVIEW ${ }^{M R}$ na situação de uso. Feita a correção, o valor estimado para o desvio da câmara monitora em RQR-10 passou a ser de $-1,9 \%$ - bastante coerente com o conjunto de dados da TAB. 2. Para o usuário, o 
único indício de que o problema ocorreu - e foi corrigido - será através da consulta ao campo "Referência - Tempo (s)" (v. FIG.. 4.8), que acusará uma diferença de 1,25 s (para menos) em relação ao valor correspondente ("Monitora - Tempo E (s)") para o UNIDOS E.

\subsection{Discussão dos resultados}

Durante todo o desenvolvimento, procurou-se testar nas mais variadas condições, cada funcionalidade dos programas desenvolvidos, ora agregando alguma não inicialmente prevista, ora removendo outra admitida como supérflua além, é claro, das correções dos inevitáveis erros, e da necessidade da superação dos obstáculos não inicialmente previstos, frequentemente associados às características peculiares de cada instrumento ou componente do sistema.

Um dos trabalhos mais delicados foi o de encontrar os precisos valores de correção para os atrasos de abertura e de fechamento do obturador, os quais acabam se confundindo, e de uma maneira virtualmente impossível de diferenciar, com os tempos de resposta do eletrômetro e da câmara de ionização. Devido à interação entre os diferentes parâmetros de correção, foi preciso adotar uma seqüência lógica para que os resultados pudessem convergir de maneira satisfatória:

1. Solicitando-se valores de carga que acarretem tempos de exposição bastante curtos (inferiores a 10s) para maior sensibilidade, efetuaram-se comparações dos valores sucessivamente indicados de carga média, nas situações com e sem o artifício de se manter o obturador inicialmente aberto; escolheu-se (por tentativa e erro) um valor para o multiplicador do atraso inicial que tornou esses valores tão próximos quanto possível (valor encontrado: 1,4).

2. Solicitando-se valores de carga que acarretassem tempos de exposição da ordem de 10 s, efetuaram-se sucessivas comparações entre os valores indicados para a carga média global, e para a taxa média de variação de carga dos últimos 11 pontos; escolheu-se (por tentativa e erro) um valor para adicionar ao tempo final de modo a tornar tais valores tão próximos quanto possível (valor encontrado: $0,17 \mathrm{~s}$ ). 
3. Finalmente, efetuaram-se sucessivos ensaios de irradiação para cargas cujo tempo de exposição fosse da ordem de $10 \mathrm{~s}$ a $15 \mathrm{~s}$, buscando (por tentativa e erro) um valor para subtrair do tempo restante, de modo a tornar tão próximos quanto possíveis os valores desejado e obtido de carga (valor encontrado: 0,5s).

Atenção: Estes passos foram aplicados ao programa de controle de carga; os resultados obtidos foram em seguida transpostos para os programas de controle de kerma, e de tempo.

Embora o LabVIEW ${ }^{\text {MR }}$ teoricamente permita o ajuste das sub-rotinas de espera com uma precisão de até $1 \mathrm{~ms}$, foi evidenciado na seção 4.2.1 que essa seria uma expectativa demasiado otimista para um processo rodando sob a supervisão do sistema operacional Windows ${ }^{\mathrm{MR}}$, sendo muito mais realista pensar em termos de $10 \mathrm{~ms}$ para cima. Felizmente, essa resolução mostrou-se satisfatória para a aplicação. Aliás, pode-se inclusive dizer que no princípio foi até surpreendente perceber que diferenças de 2 a 3 centésimos de segundo ocasionavam erros sutis, mas claramente perceptíveis (no sentido de serem repetitivos) no valor final da carga na câmara monitora.

Quanto ao método de correção online das condições ambientais: em situações normais, pode-se dizer até dizer que não costumam se prever diferenças ou flutuações acentuadas de temperatura (e menos ainda de pressão) entre câmaras dentro de uma mesma sala, ou no decorrer de um ensaio. Entretanto, efetuar medições com intuitos metrológicos envolve buscar uma proximidade cada vez maior da perfeição, através da redução de incertezas onde for possível, por menor que sejam. Se por um lado pode parecer exagero solicitar leituras de pressão e temperatura a cada $0,5 \mathrm{~s}$ ao longo de quase todo o ensaio, há que se considerar que esse acaba sendo inclusive um método indireto de efetuar médias, uma vez que o programa avalia o kerma acumulado a partir de uma somatória de incrementos individualmente corrigidos para as condições ambientais instantâneas. A realidade é que não haveria outro método mais eficiente de se garantir a precisão do valor final de kerma na eventualidade de uma situação em que as condições variam ao longo do ensaio, uma vez que o valor alvo de carga é dinamicamente atualizado ao longo de todo o ensaio. 
Diante do exposto, chega-se à conclusão que o sistema conforme implementado é capaz de proporcionar um bom desempenho no que diz respeito à facilidade, rapidez e comodidade de uso, bem como quanto à repetibilidade e redução de incertezas, notadamente nas situações mais adversas, a saber:

- Tempos de exposição muito curtos, inclusive nos casos em que a operação manual do obturador conduziria a erros inaceitavelmente elevados;

- $\quad$ Tempos de exposição longos o suficiente para que as variações ambientais introduzam componentes adicionais à incerteza global.

Embora esses sejam casos extremos, acredita-se que, mesmo para situações mais rotineiras, outras conveniências decorrentes da adoção das técnicas de automação irão se tornar evidentes com o passar do tempo, inclusive com o estreitamento do controle de qualidade dos sistemas do laboratório, por estarem permanentemente monitorados, e de uma forma abrangente.

Outra contribuição esperada deste trabalho diz respeito à melhoria da compreensão, por parte do usuário, dos critérios de escolha das escalas e (no caso do UNIDOS) dos modos de integração. O programa de calibração oferece a escolha tanto automática quanto manual de modos e escalas, efetuando uma estimativa da porcentagem do fundo da escala utilizada, mesmo quando em modo carga, e assim evitando que uma medição resulte em overrange ou aumento de incertezas por subutilização da escala. São recursos previamente indisponíveis que no mínimo facilitarão o trabalho do usuário.

Quanto às dificuldades encontradas durante 0 desenvolvimento do programa de calibração, pode-se dizer que estiveram mais associadas a peculiaridades dos instrumentos, do que com os aspectos da calibração propriamente dita. Na maioria das vezes, foi possível ratificar a adequação do LabVIEW $^{\mathrm{MR}}$ às tarefas para as quais foi designado.

\subsection{Perspectivas futuras}

Quando consideradas as necessidades de expansões futuras do sistema, ficam mais evidentes as vantagens inerentes a soluções baseadas em LabVIEW ${ }^{M R}$. Graças à automatização do obturador, da adoção da câmara monitora como padrão de referência, e da comunicação digital do microcomputador com os principais instrumentos do laboratório de calibração (possibilitando o envio e recebimento de 
dados e parâmetros de configuração do sistema dosimétrico), os ensaios de calibração passaram a se realizar de forma mais simples e confiável, com menores incertezas, e menos sujeitos a erros humanos.

Embora alguns dos componentes essenciais do laboratório ainda não estejam prontos para conexão com as interfaces disponíveis, seria indubitavelmente desejável que fossem inclusos na próxima etapa de expansão - notadamente:

- $\quad$ o painel de controle do gerador de raios-X;
- $\quad$ sistema de substituição (roda) de filtros;
sistema motorizado de posicionamento ao longo do banco ótico.

O painel de controle do equipamento da marca Pantak-Seifert aparentemente dispõe de uma interface serial com protocolo proprietário que poderia potencialmente ser utilizada caso o fabricante disponibilize a informação necessária para que o acionamento e a comutação entre as diferentes qualidades de feixes possam ser feitos remotamente.

Os outros dois sistemas dependem de investimentos adicionais. Como o banco ótico já recebeu uma série de marcadores a laser, pode-se cogitar em instalar sensores óticos que se utilizem de tais marcas de referência para confirmar o correto posicionamento do carrinho que eventualmente evoluirá para um sistema motorizado de posicionamento, com vantagens evidentes para a rapidez e precisão (sob a forma de reprodutibilidade de posição) em ensaios que requeiram diferentes distâncias ao gerador.

Analogamente, caso venha a se adicionar uma roda de filtros mecanizada, ficará evidente a conveniência de se comandá-la a partir dos programas desenvolvidos.

Algumas das possibilidades viabilizadas a partir dos recursos para a coleta e tratamento dos dados de leituras são:

- $\quad$ elevação o número de medições efetuadas durante cada ensaio de modo a fornecer dados para uma melhor análise estatística, com a conseqüente redução dos intervalos de confiança, ou das incertezas propriamente ditas;

- $\quad$ proposição de um padrão para os arquivos de importação e exportação de dados entre esta plataforma e outros programas que fazem parte do processo, tais como MS-Excel ${ }^{\mathrm{MR}}$, MS-Word ${ }^{\text {MR }}$ ou mesmo AUTOLAB ${ }^{\circledR}$ (embora a solução mais provável seja a construção de um banco de dados); 
- $\quad$ diversificação da biblioteca de protocolos de comunicação com diferentes modelos de eletrômetros, visando coletar digitalmente os dados de instrumentos de clientes, e não apenas dos equipamentos do laboratório.

A tendência natural será a de estabelecer vínculos de importação e exportação de dados entre os programas em LabVIEW ${ }^{M R}$ e bancos de dados pré-existentes ou que venham a ser criados especialmente com a finalidade de se manter registros das calibrações e dos instrumentos (eletrômetros e câmaras de ionização).

Há entretanto funções que dificilmente deixarão de depender de operação manual. É o caso da inversão da polaridade da tensão enviada às câmaras de ionização, que nos eletrômetros de fabricação PTW, depende da comutação de uma chave eletro-mecânica. Ainda assim, é possível consultar a situação dessa polaridade através da interface.

Exemplos recentes da aplicação de técnicas similares em outros países mostram como correto o caminho trilhado pelo LCl. Uma aplicação particularmente bem sucedida do LabView ${ }^{M R}$ foi registrada no laboratório de calibração do ENEA IRP ${ }^{[63]}$.

A FIG. 4.10 mostra o painel frontal do programa desenvolvido que revela a preocupação em montar uma central de controle e monitoração do laboratório reunindo um bom número de informações, incluindo indicações relevantes (avisos) para fins de radioproteção. 


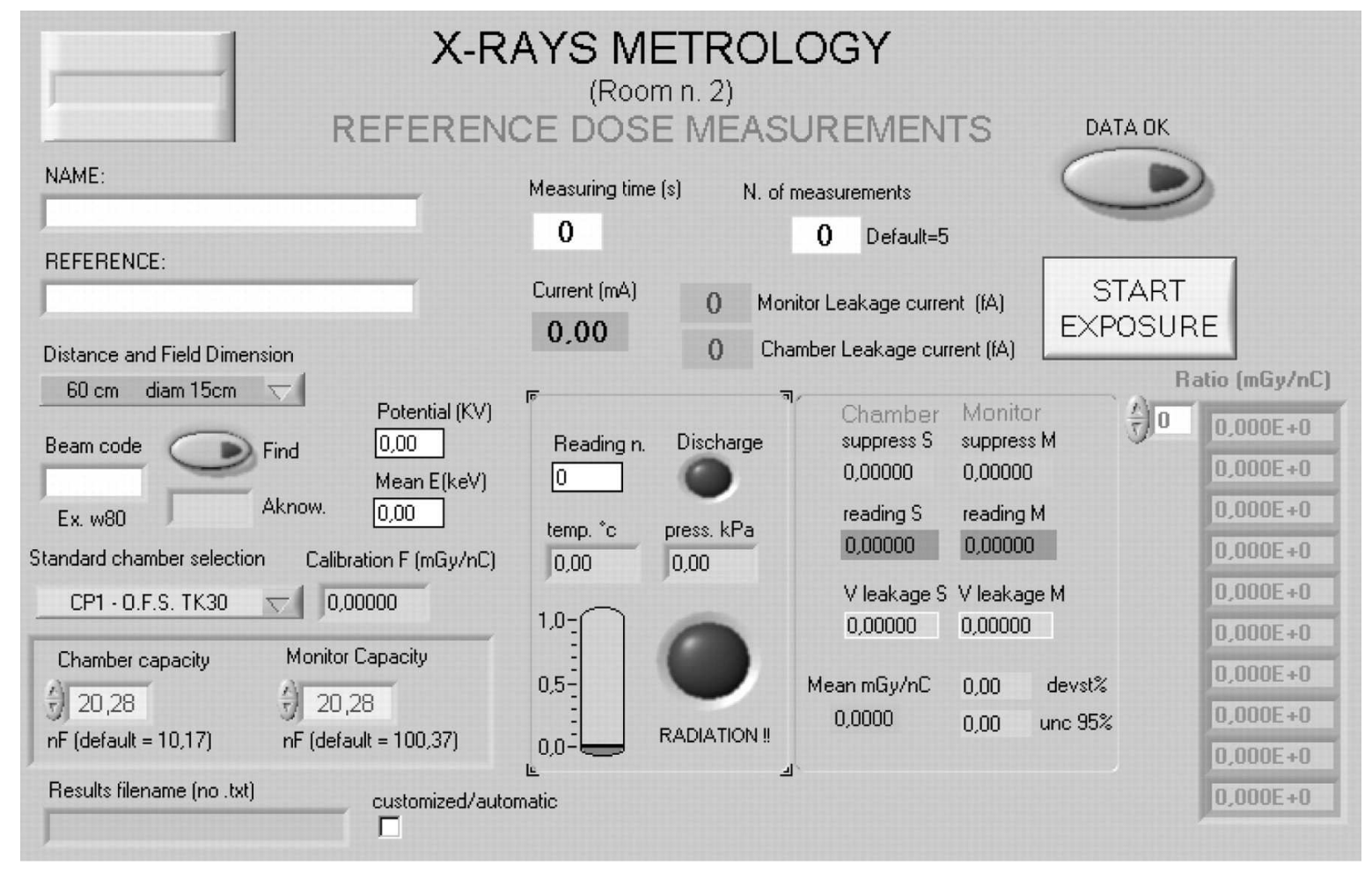

FIGURA 4.10 - painel frontal do controle em LabView ${ }^{M R}$ implantado em 2005 no laboratório de calibração do ENEA IRP (Bolonha, Itália).

Dentre o conjunto de características implantadas, pode-se destacar a facilidade proporcionada para:

- $\quad$ consulta a uma biblioteca de qualidades de feixes;

- $\quad$ escrita de resultados num arquivo do tipo texto;

- $\quad$ realização de medições sucessivas;

- $\quad$ monitoração das correntes de fuga;

- $\quad$ controle dos parâmetros (tensão e corrente) do gerador;

- $\quad$ seleção de filtros a partir de uma roda servocontrolada (v. FIG. 4.11). 


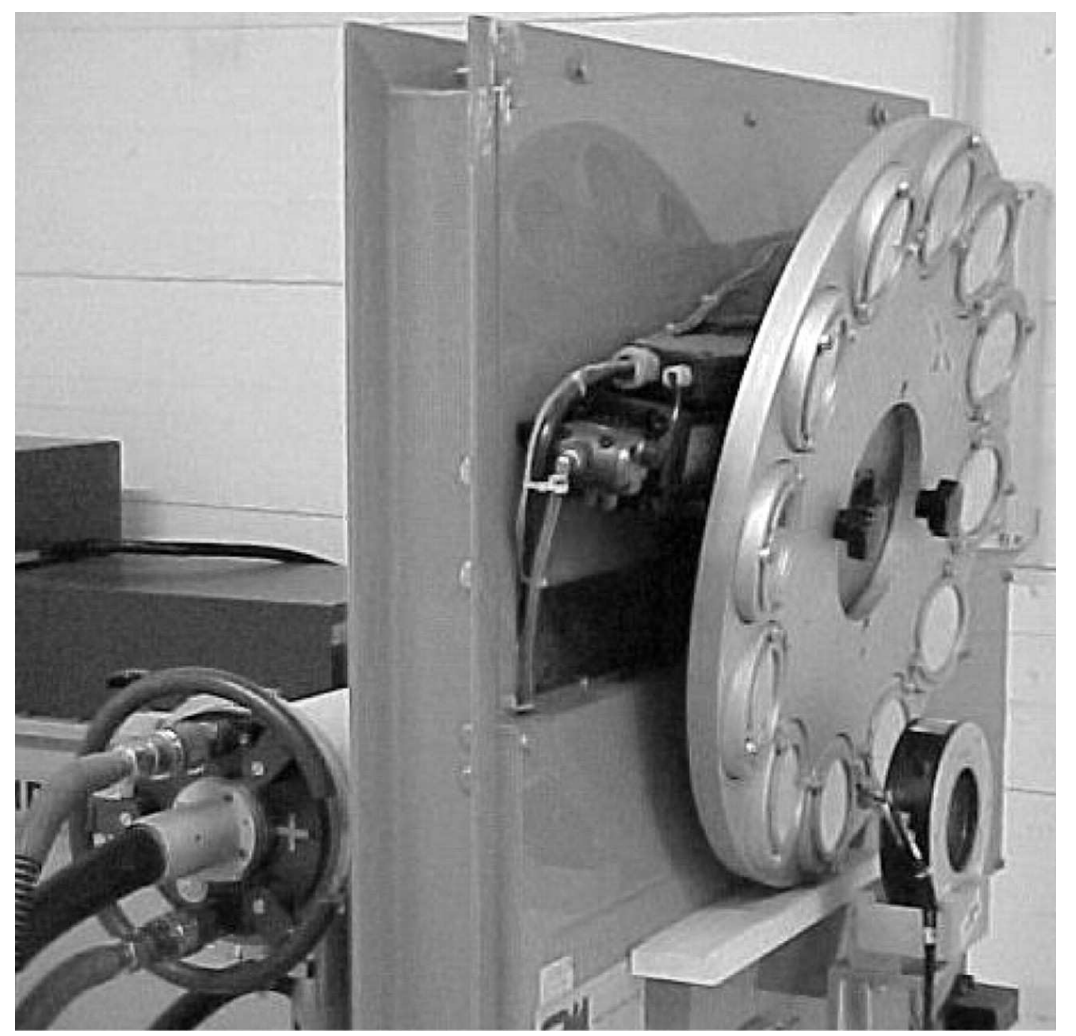

FIGURA 4.11 - Roda de filtros automática (motorizada) utilizada pelo ENEA IRP (Bolonha, Itália). Nota-se o posicionamento antes da câmara monitora posterior aos filtros, diferentemente do LCI do IPEN.

Todas são ferramentas bastante adequadas à utilização por parte de programas de controle e garantia da qualidade, inclusive pela diminuição da probabilidade de ocorrência de erros humanos tais como a transcrição incorreta de dados.

Última mas não menos importante é a menção ao sistema de espectrometria para baixas energias disponível no LCl (marca ORTEC ${ }^{\circledR}$, modelo Nomad Plus ${ }^{\mathrm{MR}}$ ) que correntemente opera em conjunto com um programa analisador multicanais (Maestro), e que poderá vir a ser alvo de estudos futuros de integração com os sistemas controlados pelos programas em LabVIEW ${ }^{\mathrm{MR}}$. 
Embora o esforço de programação que constituiu o cerne deste trabalho admita, inclusive por uma questão de simplicidade, a divisão em duas grandes partes, a saber: automatização do comando do obturador, e incorporação dos recursos para a correção online dos fatores ambientais, o verdadeiro impacto causado pelo advento dessas técnicas só pode ser devidamente descortinado se levadas em conta as fragilidades da metodologia anterior. Utilizada até então apenas como um mero coadjuvante no controle de qualidade do laboratório, a câmara monitora pode agora assumir um papel pleno no sentido de evidenciar e corrigir eventuais variações na taxa de kerma do aparelho gerador de raios $X$ no mesmo instante em que elas ocorrem. $O$ mesmo se pode dizer para as flutuações das condições ambientais, sem se falar na suposta diferença de temperatura entre os pontos de irradiação e a câmara monitora.

Foi significativo perceber que, particularmente para tempos curtos de exposição, a instrumentação do laboratório foi sensível o suficiente para evidenciar claramente diferenças relacionadas a ajustes da ordem de poucos centésimos de segundo no instante de fechamento do obturador. Somente a partir de uma análise comparativa dos procedimentos práticos antes e depois da adoção dos programas de automação será possível avaliar o grau dos benefícios trazidos pela possibilidade de se garantir, dentro dos limites das incertezas dos equipamentos propriamente ditos, e não mais dos operadores, um valor esperado de kerma.

Ao mesmo tempo em que puseram à prova a eficácia da linguagem de programação escolhida, as dificuldades encontradas ao longo deste desenvolvimento demonstraram que, independente da ferramenta computacional, os melhores resultados nunca poderão ser alcançados se não forem cuidadosamente levadas em conta as peculiaridades de cada instrumento componente do sistema.

O que se espera daqui para frente é aumentar cada vez mais o grau de conhecimento sobre as eventuais limitações das técnicas de calibração baseadas na leitura simultânea da câmara monitora, para que o pessoal do LCl possa, sem qualquer tipo de receio, desfrutar da rapidez, comodidade e precisão proporcionada por esta pequena suíte de programas. 


\section{APÊNDICE}

\section{Apresentação das sub-rotinas desenvolvidas}

Embora o LabVIEW ${ }^{\text {MR }}$ ofereça uma extensa biblioteca de sub-rotinas prontas para utilização, o usuário também pode anexar bibliotecas desenvolvidas por terceiros, ou escritas por ele mesmo. Mesmo para a versão 7 (hoje já existe a versão 8), a lista de compatibilidade inclui: $\mathrm{C} / \mathrm{C}++, \mathrm{C}$, Visual Studio .NET, e Visual Basic, além, naturalmente, do próprio LabVIEW ${ }^{M R}$.

Muitas das sub-rotinas utilizadas nos programas expostos nas seções anteriores foram desenvolvidas especialmente para este trabalho, utilizando-se o próprio LabVIEW ${ }^{M R}$. Segue-se a descrição de suas características e funcionalidades:

\footnotetext{
"escreve_le": uma sub-rotina de uso geral para os casos que envolvem o envio de um comando para a interface serial para o qual se espera uma resposta imediata na forma do envio de um string; inclui os comandos de abertura e fechamento da porta, o que pode tornar desaconselhável sua utilização dentro de loops onde a máxima velocidade possível de execução for desejada;

"fator_novo": foi escrita especialmente para uso dentro do programa de calibração da câmara monitora a partir da câmara de referência; apenas efetua as operações matemáticas necessárias para gerar um novo fator de calibração para a câmara monitora a partir dos dados de entrada, que devem necessariamente incluir o valor do kerma (devidamente corrigido) medido pela câmara de referência, bem como os valores de pressão e temperatura para a câmara monitora no momento do ensaio;
} 


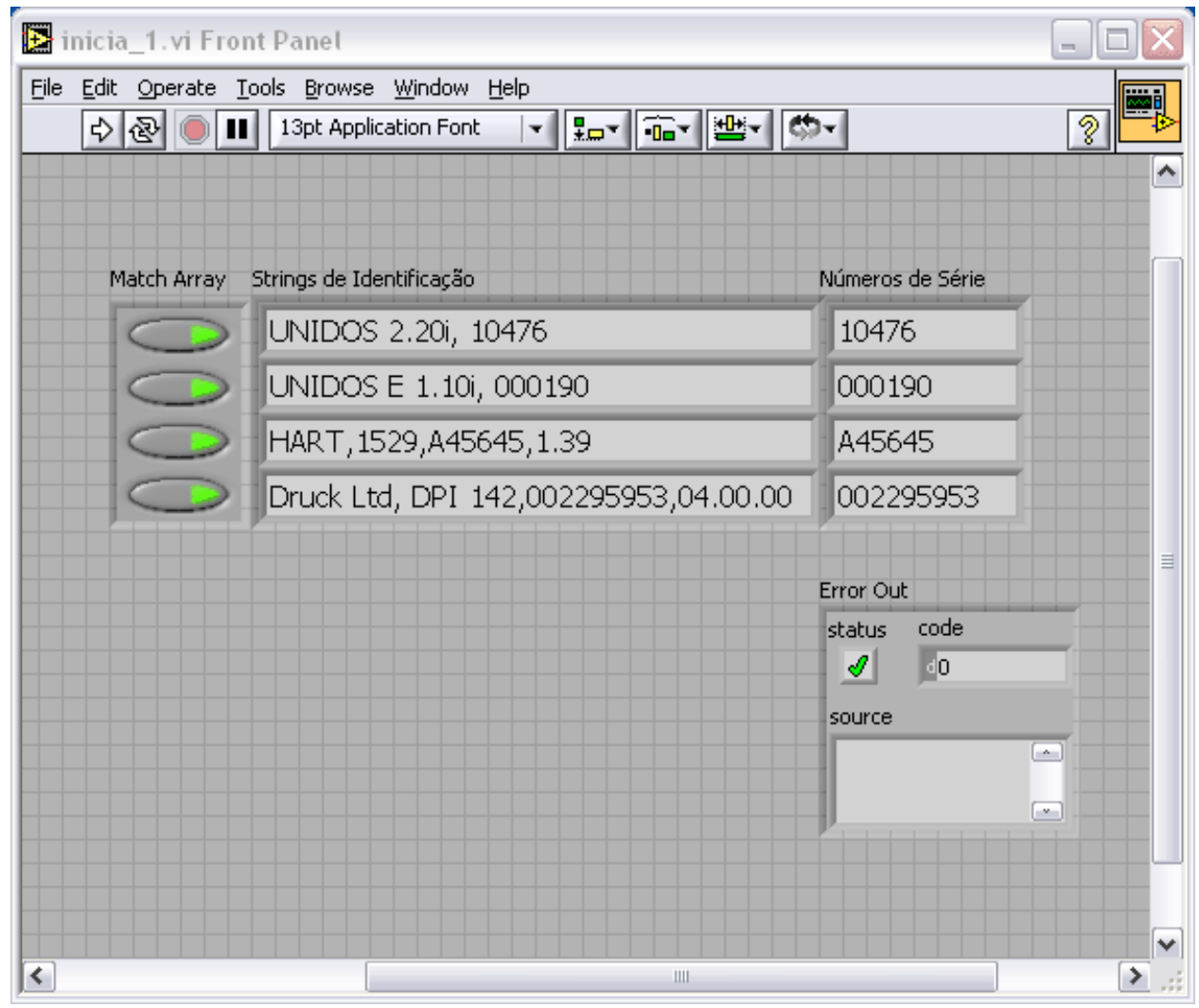

FIGURA A.1 - Painel frontal da sub-rotina de inicialização e checagem através da identificação via interface RS-232 dos quatro instrumentos que constituíram, juntamente com a implementação do comando digital remoto do obturador, a base deste projeto de automação do $\mathrm{LCl}$, conectados respectivamente às portas COM1, COM2, COM3 e COM4 de um microcomputador padrão PC. Há previsão de expansões futuras com o uso da interface GP-IB (protocolo IEE-488).

- "inicia": esta sub-rotina é bastante peculiar ao arranjo adotado para os equipamentos no laboratório; ela envia comandos de solicitação de identificação a cada um deles, através das quatro portas seriais onde espera encontrá-los; ao receber as respostas, ainda verifica se seus números de série correspondem ao esperado de acordo com uma pequena tabela internamente armazenada; somente no caso de sucesso em todas as checagens, gera um sinal de OK como saída (a FIG. A.1 mostra seu painel frontal);

- “fim_azul”: escrita apenas para finalizar a utilização do UNIDOS pela interface, destravando o teclado do painel do aparelho para que o usuário possa voltar a utilizá-lo sem precisar desligar e religar o aparelho - um procedimento a ser evitado sempre que desnecessário, em prol da estabilidade; inclui comandos para fechamento da porta serial, e de 
atribuição de status verdadeiro ao sinal de erro, caso o instrumento não envie a resposta esperada ao comando;

sub-rotinas "RQR", "RQA", e "ISO": são conjuntamente utilizadas para compor um array de clusters utilizado diretamente pelo programa de calibração da câmara monitora, e indiretamente pelos três programas de controle do obturador, através da sub-rotina "selecao"; são instâncias onde se deseja consultar o conteúdo da biblioteca de fatores de calibração de ambas as câmaras para cada uma das qualidades de feixe implantadas, além de fornecerem os dados essenciais para a obtenção dos feixes (tensão, corrente e filtração) para fins de informação do usuário; podem ser prontamente revistas e ampliadas em tempo de edição, mas não de execução;

- "selecao": conforme mencionado no parágrafo anterior, é utilizada pelos três programas de controle do obturador para oferecer a opção da escolha de qualidade de feixe ao usuário a partir das sub-rotinas de armazenamento das qualidades; esta sub-rotina é peculiar em relação às demais, no sentido que ela abre um sub-painel, quando chamada pelo programa principal;

- $\quad$ "le_azul": envia um comando específico para o UNIDOS, que lhe retorna com o valor da leitura atual, no modo em que estiver; o string de retorno é manipulado, de modo que a saída é numérica; não envia comandos nem de abertura, nem de fechamento da porta serial, o que a torna particularmente indicada para a execução dentro de loops; seu nome advém da cor do gabinete do eletrômetro UNIDOS;

- "le_druck": como o próprio nome já diz, foi especificamente criada para colher um valor de leitura da pressão atmosférica a partir do barômetro Druck, na unidade em que ele estiver; a versão atual do programa ainda não prevê checagem, nem correção de unidade imprópria, de modo que o mesmo deve ser sempre mantido na unidade $\mathrm{kPa}$ para que suas informações sejam corretamente utilizadas;

- "le_fator": esta é uma sub-rotina intensivamente utilizada pelos programas de controle do obturador, que constantemente recalculam o fator de correção ambiental a partir de novos valores colhidos para 
pressão e temperatura da câmara monitora; "le_hart", bem como "le_druck" são sucessivamente executadas dentro desta sub-rotina; não efetua abertura, nem fechamento de portas;

"le_hart": analogamente à sub-rotina "le_druck", também utiliza a sub-rotina "escreve_le" para enviar um pedido de leitura ao termômetro Hart e convertê-la numa saída numérica através da manipulação de strings; por se tratar de um instrumento para até quatro sensores, o número do canal deve ser cuidadosamente especificado de modo a corresponder à câmara desejada, que pode ser a monitora, ou então a que estiver no ponto de irradiação, que pode - ou não - ser a câmara de referência;

"le_ponto": esta é uma sub-rotina escrita especificamente para o eletrômetro UNIDOS E; envia uma solicitação, e logo em seguida recebe a leitura atual de carga, independente do modo em que seu display estiver, fornecendo saídas numéricas para o tempo de integração (em segundos) e para o valor de carga (em nanocoulombs) correspondente a esse mesmo instante; para não perder tempo, não efetua abertura, nem fechamento de portas seriais;

- $\quad$ "le_serial": trata-se de uma sub-rotina simples, diretamente adaptada (simplificada) a partir de uma das rotinas de exemplo de aplicação da biblioteca VISA do LabVIEW ${ }^{\text {MR }}$ (a mesma que aloca os recursos do computador para o programa principal); diferentemente das demais aqui descritas, esta limita-se a receber os dados que forem transmitidos pelo instrumento conectado à porta serial especificada, convertendo-os num string; foi utilizada internamente em outra sub-rotina de aplicação específica chamada "stream_ponto" (mais abaixo);

"ponto_final": abre a porta serial, solicita uma leitura de tempo e de carga ao UNIDOS E (estando o mesmo previamente em modo carga), e fecha a porta novamente; sua utilização foi um artifício para garantir que a leitura final (e não a penúltima) pudesse ser recebida pelo programa de calibração, ao término do intervalo de integração; enviar a penúltima leitura, mesmo após seu display já revelar a última, foi um outro 
comportamento inesperado do UNIDOS E, talvez associado a algum tipo de buffer interno;

- "stream_inicio": trata-se da rotina que inicializa o processo principal executado dentro dos programas de controle do obturador; promove a abertura da porta serial, envio do comando que deflagra o modo streaming do UNIDOS E, e a coleta de um conjunto ("array") de 11 pontos - tanto o tempo (em s), quanto a carga (em nC), independente do modo de display; é necessário que o loop principal recebe esses 11 pontos para que possa efetuar corretamente a regressão linear que permite estimar o instante exato de encerrar o processo; depende internamente de uma outra sub-rotina, a "stream_ponto" (abaixo);

"stream_ponto": aplica a sub-rotina "le_serial" para colher os strings enviados pelo UNIDOS E durante seu modo streaming, e em seguida os converte em dados numéricos - tempo (s), e carga $(\mathrm{nC})$; é intensivamente utilizada em todas as instâncias em que o modo "streaming" é determinante da taxa de execução dos loops principais, tanto nos programas de controle do obturador, quanto no de calibração;

"corrige_atraso": esta foi a última rotina escrita; efetua a regressão linear dos 11 primeiros pontos (excluindo-se o primeiro) para calcular o tempo a ser abatido do intervalo de integração quando da ocorrência da anomalia descrita na seção 4.3 para o eletrômetro UNIDOS em modo "integral da corrente". 


\section{REFERÊNCIAS BIBLIOGRÁFICAS}

1 PORTARIA 453 DO MINISTÉRIO DA SAÚDE - "Diretrizes de proteção radiológica em radiodiagnóstico médico e odontológico" - Diário Oficial da União 02 de junho de 1998 - Brasília, DF.

POTIENS, M.P.A. - "Metodologia dosimétrica e sistema de referência para radiação X nível diagnóstico" - Tese (doutoramento) - IPEN/USP - São Paulo, 1999.

3 POTIENS, M.P.A.; CALDAS, L.V.E. - "Calibration of kVp meters used in quality control tests in diagnostic radiology by spectrometry" - Radiat. Prot. Dosim. 98(3), 343-346, 2002.

MAIA, A. F. - "Padronização de feixes e metodologia dosimétrica em tomografia computadorizada" - Tese (doutoramento) - IPEN/USP - São Paulo, 2005.

NORMA BRASILEIRA ABNT NBR ISO/IEC 17025:2005 - "Requisitos gerais para competência de laboratórios de ensaio e calibração" - publicada em 25 de setembro de 2006.

SILVA, P.A.; LELIS, E. S.; SANTOS, E. P.; SOARES, F. M.; CARVALHO, J. C. D.; GUEDES, L. A.; SILVA, M. S.; COSTA, M. M.; OLIVEIRA, R. M. S.; ROMEIRO, S. M. C. - "Resultados da Implantação de Calibrações Automáticas no Laboratório Central da Eletronorte" - METROLOGIA 2003 - Metrologia para a Vida Sociedade Brasileira de Metrologia (SBM) - 01 a 05 de setembro de 2003 Recife, Pernambuco.

$7 \quad$ LI, X.; HENKELMANN, R.; BAUMGÄRTNER, F. - "An automated fast transfer system at the research reactor Munich" - Nuclear Instruments \& Methods in Physics Research A 522, 470-476, 2004.

D. BARR, J. D. GILPATRICK, D. MARTINEZ, AND R. B. SHURTER, "Automated System Calibration and Verification of the Position Measurements for the Los Alamos Isotope Production Facility and the Switchyard Kicker Facilities" - AIP Conference Proceedings, November 10, 2004, Volume 732, Issue 1, pp. 213-220.

GRIMONI, J. A. B.; LOPES, VINICIUS JOSÉ SANTOS - "A Utilização do Software LABVIEW no Ensino Experimental de Sistemas de Energia Elétrica" - Ibero American Summit on Engineering Education, 2003 - São José dos Campos, BRASIL.

10 KREHBIEL, D.; ZERGER, R.; PIPER, J.K. - "A remote-access LabVIEW-based laboratory for enviromental and ecological science" - International Journal of Engineering Education 19(3), 495-502, 2003.

11 PERES, MARCOS A. L.; BECKER, PAULO H. B.; CORREA , SAMANDA C.A. "Automação da calibração de divisores de alta tensão utilizados em raios- $X$ diagnóstico" - METROLOGIA 2003 - Metrologia para a Vida - Sociedade Brasileira de Metrologia (SBM) - 01 a 05 de setembro de 2003 - Recife, Pernambuco - BRASIL.

12 YEUNG, K.; HUANG, J. - "Development of a remote-access laboratory: a DC motor control experiment" - Computer in Industry 52, 305-311, 2003. 
13 WU, X.Q.; CHEN, J.F.; JIANG, Z.M.; ZHONG, Q.H., XIONG, Y.Y.; WU, K,H. "Computer-controlled system for plasma ion energy auto-analyzer" - Plasma Science \& Technology 5(1), 1619-1624, 2003.

14 MALKI, H. A.; MATARRITA, A. - "Web-based control systems laboratories using LabVIEW" - Journal of Engineering Technology, V. 20, N. 1, pp. 22-25 - Spring, 2003.

15 Automa Consultoria \& Informática Ltda. - "AUTOLAB - Sistemas Integrados para Metrologia e Qualidade" - página de apresentação: acesso http://www.automa.com.br/principal.html em 21/11/2006.

16 STEMPNIAK , CHARLES R.; LANDGRAF, WAGNER R. - "Automação de laboratórios de metrologia e ensaios" - METROLOGIA 2003 - Metrologia para a Vida - Sociedade Brasileira de Metrologia (SBM) - 1 a 5 de setembro de 2003 Recife, Pernambuco - BRASIL.

17 INMETRO - "Guia para Expressão da Incerteza de Medição" (ISO-GUM) - terceira edição brasileira - agosto de 2003.

18 STEMPNIAK, C. R.; DE PAULA, LEONARDO COSTA; LANDGRAF, W. R. "Reduzindo a incerteza de medição com ajuda de software" - ENQUALAB 2005 Encontro para Qualidade de Laboratórios - São Paulo, 2005.

19 DO NASCIMENTO, GEORGIO RAPHAELLI; CÂMARA, ANA PAULA - "Retorno de investimento em automação de laboratórios" - ENQUALAB 2005 - Encontro para a qualidade de laboratórios - REMESP - Rede Metrológica do Estado de São Paulo - 07 a 09 de junho de 2005 - São Paulo, Brasil.

20 EE-Evaluation Engineering - "National Instruments LabVIEW 7 Express" - Acesso http://www.evaluationengineering.com/archive/articles/0603soft.htm em 21/11/2006.

21 YE, LIN; MAJOROS, M.; CAMPBELL, A. M.; COOMBS, T.; HARRISON, S.; SARGENT, P.; HASLETT, M.; HUSBAND, M. - "Investigations of current limiting properties of the $\mathrm{MgB}_{2}$ wires subjected to pulse overcurrents in the benchtop tester" - Superconductor Science and Technology 20 (2007) 320-326

22 ESPOSITO, B.; RIVA, M.; MAROCCO, D.; KASCHUCK, Y. - "A digital acquisition and elaboration system for nuclear fast pulse detection" - Nuclear Instruments and Methods in Physics Research A 572 (2007) 355-357

23 POSTOLACHE, O.; GIRÃO, P. M. B. SILVA; PEREIRA, J. M. DIAS; RAMOS, H. G. - "Dew Point and Relative-Humidity Smart Measuring System" - IEEE Transactions on Instrumentation and Measurement, V. 55, No. 6, pp. 2259-2264, December 2006.

24 ROTHENBERG, L. N. - "Quality Control in Diagnostic Radiology" - Medical Physics 6 (1), 22-26 (1992).

25 LYKAWKA, R.; BOTELHO, M. Z.; TORUNSKY, C. G.; BEMVENUTI, M. S.; WUNDERLICH, R. C.; FELDMAN, C. J.; ALMEIDA, W. M. - "Comparação da dose absorvida na entrada da pele entre exames de mamografia digital e mamografia convencional" - IX Congresso Brasileiro de Física Médica - Salvador, Bahia 2005. 
26 OLIVEIRA, M. L.; KHOURY, H. J. - "Influência do procedimento radiográfico na dose de entrada na pele de pacientes em raios-X pediátricos" - Radiol. Bras. 2003, 36:105 9 .

27 BONGARTZ, G.; GOLDING, S.J.; JURIK, A.G.; LEONARDI, M.; VAN MEERTEN, E.V.P.; GELEIJNS, J.; JESSEN, K.A.; PANZER, W.; SHRIMPTON, P.C.; TOSI, G.; MENZEL, H.G.; SCHIBILLA, H.; TEUNEN, D. - "European guidelines on quality criteria for computed tomography" (EUR 16262 EN) - European Commission, Luxembourg - May, 1999.

MARCONATO, J. A.; MAZZOLA, A. A.; SANVITTO, P. C.; CARVALHO, A. C. P.; VASQUES, M. V. - "Redução de dose e aumento na vida útil do tubo de raios-X em tomografia computadorizada" - Radiol. Bras. 2004; 37(5): 351-356.

INTERNATIONAL COMMISSION ON RADIATION UNITS AND

MEASUREMENTS. Fundamental quantities and units for ionizing radiation. Bethesda, MD, 1998 (Publication 60).

INTERNATIONAL ATOMIC ENERGY AGENCY. "Dosimetry in diagnostic radiology. An international code of practice", Vienna: IAEA, 2005 (Draft).

31 INTERNATIONAL COMMISSION ON RADIATION UNITS AND

MEASUREMENTS - "Measurement of Dose Equivalents from External Photon and Electron Radiations" - ICRU Report 47, 1992.

32 BARBIN, E. L.; SPANÓ, J. C. E.; PÉCORA, J. D. - "Unidades de Eletricidade e Grandezas Correlatas no Sistema Internacional de Unidades (SI)" - FORP (acesso http://www.forp.usp.br/restauradora/pg/metrologia/metrologia eletric/elet correlat. html em 29/07/2007)

33 INSTITUTO DE PESOS E MEDIDAS DO ESTADO DE SÃO PAULO - Sistema Internacional de Unidades - SI - "Unidades Elétricas e Magnéticas" - extraído do "Quadro Geral de Unidades" aprovado pela Resolução do CONMETRO no 12/88 (acesso http://www.ipem.sp.gov.br/5mt/unidade.asp?vpro=eletrica em 29/07/2007)

34 ATTIX, F. H. - "Introduction to radiological physics and radiation dosimetry" - John Wiley \& Sons - USA, 1986.

35 KNOLL, G. F.- "Radiation Detection and Measurement", 2nd ed., New York, N. Y.: John Wiley \& Sons, 1989.

36 BERGHÖFER, TH., ENGLER J., MILKE J. M.; HÖRANDEL J. R. - "A Liquid Ionization Chamber as Monitor in Radiotherapy" - Proceedings at the University and Forschungszentrum Karlsruhe, Institut für Kernphysik, Karlsruhe, Germany October 15, 2005

37 KEITHLEY - "Low Level Measurements Handbook: Precision DC Current, Voltage, and Resistance Measurements" - 6th edition - acesso: http://www.ntb.ch/Pubs/sensordemo/wtm/m op/LLHB 6 Keithley.pdf em 29/06/2007.

38 LOEVINGER, R. - "Precision Measurement with the Total-Feedback Electrometer" - Phys. Med. Biol., Vol. 11, No. 2, pp. 267-279 - 1966. 
39 RAKO, P. (Technical Editor) - "Measuring nanoamperes" - EDN, 4/26/2007 (acesso http://www.edn.com/article/CA6434367.html em 29/07/2007)

40 PTW (Physikalisch-Technische Werkstätten) - "Universal dosemeter PTW UNIDOS E instruction manual" - PTW-Freiburg - July, 1999.

41 INTERNATIONAL ATOMIC ENERGY AGENCY. - "Calibration of radiation protection monitoring instruments", IAEA, Vienna, 2000, (Safety Reports Series No. 16).

INSTITUTO NACIONAL DE METROLOGIA, NORMALIZAÇÃO E QUALIDADE INDUSTRIAL. Vocabulário Internacional de Termos Fundamentais e Gerais de Metrologia $-3^{\underline{a}}$ ed., Rio de Janeiro, 2003.

43 PIANEZZOLA, C. H.; MOL, A. W.;FAUSTO, A. M. F.; LISBOA, E.A. "Intercomparação dos testes de controle de qualidade entre equipamentos de diagnóstico por imagem em uma instituição de saúde na cidade de Itabuna e uma na cidade de Ilhéus" - XII Seminário de Iniciação Científica da UESC - Ciências Exatas, da Terra e Engenharias (acesso http://www.seminarioicuesc.com.br/sistema/resumos/12 pag312.pdf em 20/07/2007)

44 MiRAPAlHeTA, T. E.; PINHEIRO, W.; DYTZ, A.G.; MAEKAWA, C.M. "Intercomparação ao uso de monitores individuais para radiação ionizante entre setores de radiologia e medicina nuclear" - III Mostra da Produção Universitária Fundação Universidade Federal do Rio Grande (acesso http://www.propesp.furg.br/mpu/cd2004/resumos.html em 29/07/2006)

45 AMERICAN ASSOCIATION OF PHYSICISTS IN MEDICINE - "A protocol for the determination of absorbed dose from high-energy photon and electron beams" Task Group No. 21. Med Phys 1983;10: 741-771.

46 INTERNATIONAL COMMISSION ON RADIOLOGICAL PROTECTION "Recommendations of the International Commission on Radiological Protection" ICRP 60, 1990, Pergamon Press, Oxford, 1991.

47 BESSA, A. C. M. B. - "Intercomparação de câmaras de ionização em feixes padrões de raios $\mathrm{X}$, níveis radioterapia, radiodiagnóstico e radioproteção" dissertação de mestrado - IPEN, 2007.

48 INTERNATIONAL ORGANIZATION OF STANDARDIZATION (ISO) - "X and gamma reference radiation for calibrating dosemeters and doserate meters and for determining their response as a function of photon energy - Part 1: Radiation characteristics and production methods" - ISO Standard 4037-1:2006.

49 INTERNATIONAL ATOMIC ENERGY AGENCY. Absorbed Dose Determination in External Beam Radiotherapy: An International Code of Practice for Dosimetry based on Standards of Absorbed Dose to Water, IAEA, Vienna, 2000, (Technical Reports Series No. 398).

50 JOHNS, H. E.; CUNNINGHAM, J. R.; - "The Physics of Radiology" - $4^{\text {th }}$ ed., Springfield: Charles C. Thomas Publisher, 1983. 
51 GREEN, S.; PALETHORPE, J. E.; PEACH, D. E.; BRADLEY, D. A. "Development of a calibration facility for test instrumentation in diagnostic radiology" - Radiation Protection \& Dosimetry, V. 67, N.1, pp.41-46 (1996).

52 INTERNATIONAL ELECTROTECHNICAL COMMISSION (IEC) - "Instruments as used in the non-invasive measurement of $X$-ray tube potential in diagnostic radiology" - IEC 61627, 2005.

53 INTERNATIONAL COMMISSION ON RADIATION UNITS AND

MEASUREMENTS - "Physical Aspects of Irradiation" (NBS 85) - ICRU 10b (1964).

54 INTERNATIONAL ORGANIZATION OF STANDARDIZATION (ISO) - "X and gamma reference radiation for calibrating dosemeters and doserate meters and for determining their response as a function of photon energy" - Part 2: "Dosimetry for radiation protection over the energy ranges from $8 \mathrm{keV}$ to $1,3 \mathrm{MeV}$ and $4 \mathrm{MeV}$ to 9 MeV" - ISO Standard 4037-2:1997.

55 ABNT/INMETRO - "Guia para Expressão da Incerteza de Medição" ("Guide to the Expression of Uncertainty in Measurement" - ISO GUM) - 3. ed. Rio de Janeiro, 2003.

56 FIDÉLIS, G. F. (ministrante) - "Garantia da Qualidade de Resultados e Incerteza de Medição" - Fundação Centros de Referência em Tecnologias Inovadoras (CERTI) - apostila de curso - São Paulo, agosto de 2004.

57 Acesso http://www.answers.com/topic/automation?cat=biz-fin em 29/07/2007.

58 FERREIRA, AURELIO BUARQUE DE HOLANDA - "Novo Aurelio Século XXI: o dicionario da lingua portuguesa" - 3르 ed. Rio de Janeiro: Nova Fronteira, 1989.

59 D'AZZO, J.; HOUPIS, C. - "Feedback Control System Analysis and Synthesis" McGraw Hill, 1966.

60 IAEA Technical Co-Operation Project: BRA/1/034 - "Calibration Network for Dosimeter and Quality Control Equipment Used in Radiodiagnostics"

61 INTERNATIONAL ELECTROTECHNICAL COMMISSION (IEC) - "Dosimetric instruments used for non-invasive measurement of X-ray tube potential in diagnostic radiology" - IEC61676, 2002.

62 MESSIAS, ANTÔNIO ROGÉRIO - RComSerial v1.2 - "Comunicação com a Porta Serial" (acesso http://rogercom.com/PortaSerial/PortaSerial.htm em 29/07/2007)

63 BEDOGNI, R. AND MONTEVENTI, F. - "Development of automatic systems for the ionising radiation metrology at the ENEA-IRP secondary standard laboratory" Radiation Protection Dosimetry 2005115 (1-4):612-615. 